Portland State University

PDXScholar

Fall 10-4-2013

\title{
Disjointed Cosmopolitanism: Climate Change and Lived Experience in Portland, Oregon
}

Stephen Wayne Flinn

Portland State University

Follow this and additional works at: https://pdxscholar.library.pdx.edu/open_access_etds

Part of the Social and Behavioral Sciences Commons

Let us know how access to this document benefits you.

\section{Recommended Citation}

Flinn, Stephen Wayne, "Disjointed Cosmopolitanism: Climate Change and Lived Experience in Portland, Oregon" (2013). Dissertations and Theses. Paper 1435.

https://doi.org/10.15760/etd.1434

This Thesis is brought to you for free and open access. It has been accepted for inclusion in Dissertations and Theses by an authorized administrator of PDXScholar. Please contact us if we can make this document more accessible: pdxscholar@pdx.edu. 


\title{
Disjointed Cosmopolitanism: Climate Change and
}

Lived Experience in Portland, Oregon

\section{by}

Stephen Wayne Flinn

A thesis submitted in partial fulfillment of the requirements for the degree of

\author{
Master of Science \\ in \\ Communication
}

\section{Thesis Committee:}

Priya Kapoor, Chair

Sue Poulsen

Chris Carey

Portland State University

2013 


\begin{abstract}
Climate change has emerged as one of the most significant issues facing the world. This research endeavored to uncover and describe the lived experience of Portland, Oregon residents in relation to the substantive issue of climate change. The specific purpose of this research was to gain a better understanding of the ways that Portland residents conceive of and communicate about climate change. Utilizing semistructured phenomenological interviews, particular attention was paid to the culture of Portland residents, their lived experience and how the issue of climate change manifests itself in their everyday experiences. In addition, this particular phenomenological inquiry incorporated elements of auto ethnography by positioning the researcher's experiences, imagination and intellect at the center of the research endeavor. Multiple themes emerged from the in-depth, descriptive interviews that helped to reveal the structure or essence of the participant's experience(s). A single meta-theme was identified and informed by contemporary theories such as Cosmopolitanism and the Environmental Justice Paradigm.
\end{abstract}




\section{Table of Contents}

Abstract......................................................................

Chapter One: Background...................................................1

Chapter Two: Research Question(s).........................................4

Chapter Three: Conceptual Framework............................................5

Chapter Four: Methodology..................................................12

Chapter Five: Theoretical Influence.........................................43

Chapter Six: Thematic Descriptions.........................................69

Chapter Seven: Discussion................................................143

Works Cited ............................................................158

Appendix A Participant Chart..................................................162

Appendix B Theme: Freedom..............................................164

Appendix C Theme: Green Pressure..........................................167

Appendix D Meta-Theme: Disjointed Cosmopolitanism..........................172

Appendix E HSRRC Application............................................182

Appendix F Participant Informed Consent and Release Agreement...................188

Appendix G Interview Questions and Prompts...................................189 


\section{CHAPTER ONE: BACKGROUND}

The environment has emerged as one of the most important issues in modern society. While development and consumption patterns increase around the globe, so do calls for reform in both government policy and individual consumption. Consensus exists in the scientific community that climate change is happening as a result of human consumption of fossil fuels. This consensus on climate change and its causes erodes beyond the scientific community or when the general public is polled. Past studies have shown that the issue of climate change remains largely abstract and intangible to the general public because they do not feel the immediate impacts of climate change. As a result, the media becomes integral to their conceptions of climate change (Antilla, 2008, p. 2). Additional research has demonstrated that even though the U.S. public has access to high quality information on climate change, concern remains low and the public remains disengaged on the issue (Nisbet and Kotcher, 2009, p. 329). Environmental Sociologist Dr. Kari Norgaard (2006) has conducted interdisciplinary investigations of climate change consensus and the public's response. She has documented this lack of public response to the issue of climate change by measuring social movement activity, individual behavior changes and public pressure put on governments to reform (Norgaard, 2006, p. 347-348). Norgaard's research calls into question the "information deficit model" of climate change. Her findings debunk the common assertion in climate scholarship that individuals and governments will change their actions if only they knew the extent of the problem (Noorgaard, 2006. P. 348). 
Communication of climate change is just as important as the climate science itself. Communication and climate change research by Ockwell et al (2009) examines the disconnectedness between information on climate change and the persistent inaction from individuals and regulators. They argue that communication will play a central role in any solution to climate change. Ockwell et al. believe that the solution will not come from individuals or regulators alone and thus the issue of climate change needs to be communicated in a manner that appeals to values beyond materialism and self-interest and that this new discourse should be targeted to specific populations in varying ways (Ockwell et al, 2009, p. 305, 316, 320). Thus, culture and the various incongruities within localized communities is an important area of scholarship that can contribute additional insights into current research regarding communication and climate.

The purpose of this research is to add to the developing field of knowledge regarding climate change and communication. In addition, this research helps to satisfy the requirements of obtaining a Master of Science in Communication at Portland State University. The specific purpose of this research is to gain a better understanding of the ways that Portland residents conceive of and communicate about climate change. Particular attention will be paid to the culture of Portland residents, their lived experience and how the issue of climate change manifests itself in their everyday experiences. What do Portlanders know and believe about climate change? What are the sources of this 
information and how does the issue of climate change manifest itself in the everyday lived experience of Portlanders?

Norgaard's research was conducted primarily in Norway. Much like Portland, Norwegians are very knowledgeable of environmental issues and are seen as environmentally progressive. This current research in Portland, Oregon can offer additional insight and understanding of particular cultural practices that can potentially help uncover reasons for the behavioral disconnect between climate knowledge and climate (in)action. Additionally, a "city" focus on the issue of climate change is warranted as researchers Mike Hodson and Simon Marvin explain, “Cities are critical in our understanding of both energy and climate change (Hodson and Marvin, 2010, p.70)” They indicate that cities are largely responsible for climate change and also victims of climate change as well. They add that “Cities are the material representation of today's energy-intensive economies, where carbon based energy systems-oil, electricity and mobility systems- have made the huge agglomerations of cities and modern industrial systems possible (Hodson and Marvin, p. 71).” 


\section{CHAPTER TWO: RESEARCH QUESTION(S)}

This research seeks to describe the lived experience of Portland residents in relation to climate change and their individual behaviors. Additionally, this research seeks to describe the Portland resident's knowledge and conceptualizations of climate change. Thus, my primary research question is: "How do Portland residents describe the issue of climate change in relation to their own lived experience?” Additionally, this research asks: "Where do Portland residents obtain their information on climate change?” and "How do Portland residents understand the causes and consequences of climate change on their own terms?” 


\section{CHAPTER THREE: CONCEPTUAL FRAMEWORK}

This research project adopts an existential phenomenological perspective modified from the Lanigan (1988) and Van Manen (1990) articulations of phenomenology. Phenomenological research according to Van Manen is "the study of the lifeworld-the world as we immediately experience it pre-reflectively rather than as we conceptualize, categorize, or reflect on it (Van Manen, 1990, p. 9).” Van Manen continues that "Phenomenological human science is the study of lived or existential meanings; it attempts to describe and interpret those meanings to a certain degree of depth and richness (Van Manen, 1990, p.11).”

The term phenomenology appeared in philosophical writings as early as 1765 . Kant used the term to explain the difference between studying objects and events in our experience (phenomena) from the study of objects and events as they are in and of themselves (noumena) (Van Manen, 1990, p. 183). Hegel was the first to provide a "welldefined technical meaning” of the term phenomenology. (Moustakas, 1994, p. 26). Hegel viewed phenomenology as a science that describes "what one perceives, senses, and knows in one’s immediate awareness and experience (Moustakas, 1994, p. 26).” Phenomenology has a long history in both philosophy and sociology.

Van Manen emphasizes that all phenomenological research must begin in the 'lifeworld' or "the world of the natural attitude of everyday life” (p.7) in order to "bring us in more direct contact with the world (Van Manen,1990, p.9 ).” The term lifeworld originates in meaning from the German word Lebenswelt explained by Husserl as the “world of immediate experience" as it exists as an original experience. For example, a 
phenomenologist can describe a particular way a person lives, interacts and creates their world. The person is brought to the foreground in the research as the primary source for explaining, describing and generating knowledge about the lifeworld (Moustakas, 1994, p.48). Husserl believed that each lifeworld has certain structures or elements that can be identified and understood more completely when they are examined with a pretheoretical point of view. The lifeworld is "already there" or "pregiven" so the task of the phenomenologist is to approach the experience from "natural” or "naive” perspective (Van Manen, 1990, p.182).

This discovery oriented approach to human science research aims to be without presuppositions and prescribed sets of rules and procedures. Van Manen jokes, “Indeed it has been said that the method of phenomenology and hermeneutics is that there is no method (Van Manen, 1990,p. 30)!” Nonetheless, a wealth of previous scholarship exists and careful attention to the origins of phenomenology and the various approaches affords the human science researcher "a set of guides and recommendations for a principled form of inquiry that neither simply rejects or ignores tradition, nor slavishly follows or kneels in front of it (Van Manen, 1990, p. 30).” Communication scholar Richard Lanigan explains phenomenology as “a historical movement, a philosophy in the existential tradition, and it is a research method exemplifying a philosophy of science (Lanigan, 1988, p. 8).”

Phenomenology originated in Germany with the writings of Husserl and Heidegger. This movement also includes French theorists Merleau-Ponty and Sartre and now American human science researchers (Lanigan, 1988, p.7). Human science from a 
phenomenological perspective emerged from a desire to break from the more traditional sciences that failed to take into account non-material things (Moustakas, 1994,p.43).

Descartes argued that whatever exists in consciousness whether by intuition or reason can be relied upon to produce knowledge (Moustakas, 1994, p.44).

Husserl made tremendous contributions to the development of phenomenology. Husserl's method of inquiry has been called Descriptive Phenomenology or Transcendental Phenomenology. Husserl’s writings “emphasizes subjectivity and discovery of the essences of experience (Moustakas, 1994, p. 45).” Often referred to as the father of phenomenology, Husserl advanced the philosophy and practice of phenomenology through his addition of transcendentalism (Van Manen,1990, p.184). In particular, Husserl advocated that human science researchers adopt a transcendental subjectivity by bracketing their own lived reality to assist with describing "the phenomenon in its pure, universal sense (Wojnar and Swanson,2007,p.173).” Phenomenology, according to Husserl, aims at describing the world, how its constituted, and experienced through conscious acts (Van Manen, 1990, p.184).Primarily concerned with the discovery of meanings and essences in knowledge, Husserl reasoned that a difference does exist between facts and essences. In other words, an essence is the “essential nature of the Real” and everything else remains "left over" or "knowledge of the essential nature of the non-real (Van Manen, 1990, p. 27).” To continue, phenomenological descriptions describe the lifeworld as it is allowing what is brought forth to enter into our consciousness. Once there, the meanings and essences of this experience can emerge or reappear via intuition and self-reflection. The process blends 
together what is really present with what is imagined as present creating a unity between the real and the ideal (Van Manen, 1994, p. 27). The object or experience that the researcher is interested in does not have to physically exist. Non physical experiences can enter our consciousness in a very real, tangible and describable way. Husserl provides the example of the God Jupiter in support of non-material experiences in the lifeworld (Moustakas, 1994, p. 50). The end result of transcendental phenomenology is a description and enlightened understanding of a phenomena and its essences that helps to "enrich and clarify our knowledge and experience of everyday situations, events, and relationships (Moustakas,1994, p. 48).” However, there is no end result per se but rather the opportunity for new inquiries or ongoing reflection (Moustakas, 1994,pp. 50-51).

Heidegger was a student of Husserl. Heidegger influenced phenomenological philosophy through the recognition that humans cannot escape the lifeworld. Dasein (the human way of being in the world) is how Heidegger addressed larger social, political and cultural contexts. For Heidegger, the concept of Dasein is essential to what he calls "the forestructure of understanding”. Heidegger believed that the forestructure or in other words your past experiences, or sometimes referred to as sociocultural background is related to the way that you view the world. Thus, before a researcher engages in hermeneutic phenomenological inquiries, they must look into their own past experiences and biases first to assist in later interpretation. For Heidegger, interpretation is a circular process whereby the researcher moves in and out, back and forth blending together the participants' meanings with the researchers' understanding of the experience or phenomena (Wojnar and Swanson, 2007, p. 175). 
Merleau-Ponty’s brand of phenomenolgy has been described as "hermeneutical, metaphorical, and potentially transformative (Levin, 1991. p.116).” what is today referred to as existential phenomenological method. Merleau-Ponty’s contributions to phenomenology provide much of the theoretical foundation for Max Van Manen’s methodology discussed later. Merleau-Ponty views phenomenology as a rigorous and thorough science that seeks out the essence of an experience. He departs from Husserl in his views that situate people in a world that already exists before any reflection. Merleau-Ponty is existential in his approach to phenomenology because he views the world as a pre-given. His philosophy is not concerned solely with abstract notions of the individual or the body but rather a 'historical person' as they engage and interact with the world. According to this view, the truth does not exist within the person or inside of individuals but instead the truth is found in the world through experience. The foundation of Merleau-Ponty's conception of phenomenology is that people are beings that are situated and "never fully free but in a world never fully finished either: being born is simultaneously being born from and in the world (Sadala and Adorno, 2002, p.286).”

Another contribution of Merleau-Ponty to phenomenology is his discussion of the body. Meleau-Ponty views the individual as the body itself or the perceiving subject. Furthermore, a relationship exists between the body and the location in the world it inhabits. The lived body situated in a predetermined world does face conditions and limitations on the lived body but in no means is location entirely deterministic; Individuals still have choices (Sadala and Adorno, 2002, p. 286). Thus an ambiguity emerges as a result of the "dialectic relationship" between the lived body and the world. 
This ambiguity in Merleau-Ponty's philosophy also arises because he argues that there is no absolute truth and there is no absolute end. The questions answered offer new horizons for future research. This ambiguity should be embraced. Pheneomenolgy emerged as a science in reaction to positivism. People are not static beings that be explained by a series of facts and causalities. People are "eternally coming into being, always in the move, and therefore, in a dialectic without synthesis... always moving forward, in a coming-into being of possibilities (Sadala and Adorno, 2002, p. 286).”

Clark Moustakas merges and synthesizes the philosophical assumptions of phenomenology to applied social science research in an effort to explain the "core facets of human science research” (Moustakas, 1994, p.58).Moustakas lists nine items in his text entitled Phenomenological Research Methods to illustrate how the philosophy of phenomenology is integral to the research process. The first principle identified is that Phenomenology focuses on the "appearance of things...as they are given.” Furthermore, phenomenology considers the lived experience wholistically "from many sides, angles and perspectives until a unified vision of the essences of a phenomena or experience is achieved.” (Moustakas, 1994, pp.58-59).Meaning is sought from experiences and the essences are brought forth "through intuition and reflection...leading to ideas, concepts, judgements, and understandings.”(Moustakas, 1994, pp. 58-59). These experiences should generate questions that "sustain an inquiry, awake further interest and concern, and account for our passionate with whatever is being experienced (Moustakas, 1994, pp.58-59).” To continue, the subject and the object are integrated. Van Manen states, "My perception, the thing I perceive, and the experience or act interrelate to make the 
objective subjective and the subjective objective(Moustakas, 1994, p. 59).”

Intersubjectivity exists throughout the entire process of phenomenological inquiry. In other words, “self-insights” and "subjective perceptions” of what we experience in the world operate as a "co-presence" to the experiences of others even though the researchers perception remains primary (Moustakas, 1994, p.37). Finally, a carefully crafted research question must be posed in language that is direct and has the ability to "guide and direct me in the phenomenological process of seeing, reflecting and knowing (Moustakas, 1994, p.59) 


\section{CHAPTER FOUR: METHODOLOGY}

This research was strongly guided by the methodological approach of Van Manen (1990) and Lanigan (1988). Van Manen explains that this existential phenomenological approach to research is a "human science research approach" where the research question(s) act as the starting point and not the method itself (Van Manen, 1990, p.1). Phenomenological research is the study of lived experience as it presents itself. Van Manen's research methodology is “a philosophy of the personal, the individual, which we pursue against the background of an understanding of the evasive character of the logos of other, the whole, the communal, or the social (Van Manen, 1990,p. 7).” The main purpose of phenomenological research is to describe the 'essence' or 'nature' of a particular phenomenon. The phenomenon is described with 'depth and richness' (Van Manen, 1990, pp.10-11). In the end, the goal of this research is not, according to Van Manen, a way to generate communication theories that can "explain and/or control the world" but rather a method that offers "the possibility of plausible insights that bring us in more direct contact with the world (Van Manen, 1990, p.9).”

Phenomenological research such as this aims for descriptions of phenomena in what Van Manen refers to as our 'lifeworld'( lived time, lived space, lived body, and lived human relation). He explains, "The aim is to construct an animating, evocative description (text) of human actions, behaviors, intentions, and experiences as we meet them in the lifeworld (Van Manen, 1990, p.19)” Van Manen further explains his research methodology of one that is "presuppositionless" and guided by the research question(s) 
instead of a set of formal procedures, techniques or concepts. However, for the purposes of conducting phenomenological research, Van Manen does offer explanations of the six parts of human science research identified as:

(1)turning to a phenomenon which seriously interests us and commits us to the world;

(2)investigating experience as we live it rather than as we conceptualize it;

(3)reflecting on the essential themes which characterize the phenomenon;

(4)describing the phenomenon through the art of writing and rewriting;

(5) maintaining a strong and oriented pedagogical relation to the phenomenon;

(6)balancing the research context by considering parts and whole. (p.19)

The fifth part of Van Manen's method is not applicable to the current research under consideration. My research interests do not concern illuminating different pedagogical concerns in an educational setting. While Van Manen's book does emphasize the role of educational research and pedagogy within its explanations, examples and illustrations of hermeneutic-phenomenological inquiry, the philosophy and methods are just as applicable to other social science qualitative research endeavors (Van Manen, 1990,p.1). For the purposes of clarity, I will refer to the above parts of the research process using Van Manen's original numbering but omitting step 5 due to relevancy because my aim is not on how to better teach the science of climate change.

The research question is the starting point in phenomenological research, not the method. Van Manen writes, "to do research is always to question the way we experience the world, to want to know the world in which we live as human beings...the act of 
researching-questioning-theorizing is the intentional act of attaching ourselves to the world, to become more fully part of it, or better, to become the world...in doing research we question the world's very secrets and intimacies which are constitutive of the world, and which bring the world as world-into-being for us and in us (Van Manen, 1990, p. 5).” The research question aims to find out what something is 'really' like. It asks, "What is the nature of this lived experience (Van Manen, 1990, p.42)?” With phenomenological questions, the researcher asks and actually lives the answer to the question, "what is it like to have this experience?”(Van Manen, 1990,pp.44-45).

The aims of phenomenological inquiry differ from other research paradigms. Phenomenology does not seek to advance knowledge in order to manage or control human behavior. Instead, progress is viewed in terms of "humanizing human life and humanizing human institutions” or to "produce action sensitive knowledge” (Van Manen, 1990, p. 21). Phenomenology is not an empirical analytic science asking the usual who, what, when, where and to what extent using statistics, surveys and other quantitative methods. Instead, empirical phenomenological knowledge emerges out of descriptions of the lived experience. Phenomenological research is not conducted in order to make "empirical generalizations, the production of law-like statements, or the establishment of functional relationships (Van Manen, 1990, p. 22).” Borrowing from the writings of Merleau-Ponty, Van Manen explains how the "phenomenological attitude" is complex as it tries to balance both the particularities and the universalities of the lived experience. The descriptions should be full, rich and deep. Phenomenological descriptions are concerned with explicating both difference and uniqueness while at the same time 
waiting for the 'essence' or essential structures of the lived experience that are shared almost universally to emerge (Van Manen, 1990, p. 23).

Turning to the phenomenon

Lived experience is the starting point for this research. In fact, my own firsthand experience and interests in the research process aided in the current investigation and analysis. Engaging in this type of a phenomenological research project involved the self throughout every part of the process. My personal experiences and insights are central in this discovery oriented approach to human science research (Patton, 2002, p. 107). Specifically, this research examines the way that newly arrived Portland residents experience climate change in their everyday lives. Climate change is a lived experience in many ways. For example, each morning, Portland residents make decisions regarding how they intend to travel throughout their day. Some drive, others bike, take the bus, a Max train, streetcar, or walk. The notoriously wet weather of the Pacific Northwest presents these same residents with an additional consideration. Ride your bike in the rain? Sure! Other factors that play a role in our carbon footprint include choices to consume local food, recycle, and engage in energy efficiency efforts. These concepts and choices were all new to me when I moved to Portland, Oregon.

I grew up in rural Oklahoma. I am the second oldest child of five. My father worked in the oil fields of Oklahoma all through my childhood. On occasion, I would spend the night with him in a camper as the night watch crew to keep the crude oil flowing. For me at the time, it was all about staying out of the way, throwing rocks into the mud ponds full of drilling fluids, and popcorn at night with my dad in the camper. 
One of the largest employers in my hometown was Halliburton. At the time, I thought they made doorknobs and Christmas decorations. As a child, every year my baseball team was sponsored by McAdam's Pipe and Supply. Growing up, the oil industry in Oklahoma was where my Dad made a living for the family; A special place for me to hang out with my dad one-on-one. The oil industry to me was summer baseball, doors that could open and prettier Christmas' thanks to Halliburton. Once the oil fields dried up and most of the men in Bristow were laid off in the late 1980's, we moved to Kansas where both of my parents worked for Boeing in an aircraft factory.

I lived in Kansas and Kansas City Missouri until my arrival in Portland three and a half years ago. Immediately, I was experiencing a vastly different physical environment. My natural surroundings in Kansas did not include hikes in the mountains, coastal old growth forests, or the ability to put your feet in the ocean. Spatially, I was experiencing and developing a new relationship to the environment.

Culturally, I was exposed to a new way of life when I signed the lease to my first apartment. My first landlord spent thirty minutes teaching me about recycling and composting before she handed over the keys to my studio apartment. The lesson was thorough and nuanced including even descriptions of different grades of plastics. In that moment, all I was thinking was that she really did care about my trash. In Kansas, recycling was an option but not mandatory. Clearly, in my new home, experiencing an environmental culture shock, this was not the case.

My exposure and interest in issues of the environment and climate change were encouraged and nurtured when I enrolled in graduate school at Portland State University. 
My university is deeply committed to issues of sustainability and environmental scholarship. I further developed my involvement in environmental scholarship when I authored a paper that was accepted for the Western States Communication Conference. My university awarded me a sustainability travel grant so that I could travel to Anchorage, Alaska and present my ideas on media frames and climate change. While in Alaska, I attended the Fur Rendezvous, a celebration of Alaska that coincides with the Iditarod. I had my picture taken with an Inupiat woman and her granddaughter in their traditional attire. For my presentation I incorporated how climate change was adversely affecting the indigenous communities of Alaska. I personally felt connected for the first time to an environmental justice issue in a real and meaningful way.

As a graduate teaching assistant for the public speaking program, I required my students to give their final persuasion speech on an environmental topic. For an entire year, I guided students through the research and construction of speeches on a wide variety on environmental subjects. This year I was fortunate to receive a fellowship with the U.S. Fish and Wildlife Service working in the external affairs. As part of my fellowship I have spent the past year creating short outreach films for the protection of endangered and threatened species and habitats. In addition, I wrote and received a federal grant to take sixty high school art students to a national wildlife refuge to connect with nature and interpret climate change artistically.

Climate and climate change are both cultural lived experiences. The effects of climate change may at times be most felt locally, other times on a regional or even on a continental scale. Because my concern and awareness of climate change increased after 
arriving in Portland and starting graduate school, a phenomenological approach to the subject that personalizes inquiry regarding climate and my lived experience is warranted. Merleau-Ponty recognizes the value of research that does not detach or cut off the researcher from the world. He views the researcher as a subject of experiences that are “destined to the world (Cerbone, 2006,p.107).” I felt cultural pressure to conform to what I perceived as the Portland way of life. I was changed by my trips into the Columbia River gorge, the Oregon Coast, and backpacking Mt. Hood. My everyday lived experience changed tremendously. Lived space or spatiality is important to Max Van Manen’s approach to phenomenology. He writes:

Lived space (spatiality) is felt space. .... Lived space is more difficult to put into words since the experiences of lived space (as lived time, body) is largely preverbal; we do not ordinarily reflect on it. And yet we know that the space in which we find ourselves affects the way we feel. (Van Manen,1990,p. 102) My reflection and awareness of my lived space was heightened as a result of my recent move, thus my intention to interview newer residents of Portland, Oregon who share in this experience.

Dr. Kari Noorgard conducted research in Bygdaby, Norway regarding cultural denial or distancing of people in regards to climate change. She describes the population in her study as, "proud of their awareness of nature, environmentalism, and leadership on global environmental issues including global warming (Norgaard, 2006,p. 377).” Norgaard also indicates that Norwegians are highly educated, have high newspaper readership, and are less skeptical than Americans regarding climate change (Norgaard, 
2006, pp. 366-377). Norgaard identifies potential problems with replicating her research in the United States. To begin with, she wonders if people really know the information about climate change, if they view the science as controversial, and if people have enough time and money to give towards solutions. Norgaard also labels Americans as more apathetic than Norwegians (Norgaard, 2006, p. 376). However, Norgaard points out that a problem arises when societal and cultural views of climate change are compared to the political economy of Norway. Norway's average citizen enjoys an extremely high standard of living when compared to the rest of the world because of the enormous wealth generated by the production of North Sea Oil (Noorgaard, 2006, p. 359). Norgaards qualitative research indicated that even though citizens were educated about climate change, politically engaged and concerned for the environment, the issue of climate change was distanced from their everyday lives. She writes:

Community members collectively held information about global warming at arm's length by participating in cultural norms and by using a series of interpretative narratives to deflect disturbing information and normalize a particular version of reality in which "everything was fine”. As such, public nonresponse to global warming was produced through practices of everyday life. (Norgaard, 2006, p. 365)

To me, the City of Portland, Oregon is much like the descriptions of Bygby, Norway. Residents are very aware of environmental issues and many have made conscious efforts to reduce their carbon footprint. An article published in the Christian Science Monitor in 2005 describes how many people choose to relocate to Portland for its 
green sensibilities. The article describes how young and well educated people are drawn to Portland and a reason many people list is the ability to live in concert with your values, and environmentalism being one of them (Moore, 2005, no page). Portland, Oregon is seen as a model. The federal government recently sent officials to Portland to meet with local green entrepreneurs in an effort to connect with businesses that can supply them with more environmentally sustainable products (Read, 2011, no page). Our Mayor, Sam Adams recently delivered his State of City address where he stated, “We’re well positioned to not only recover, but to emerge from this recession an even stronger city...a Portland that is the city of cutting-edge innovation and culture, a deeply sustainable region integrated with nature, and a city that offers all of its citizens the most equal of opportunities (Adams, 2011, p.1)

The Oregonian reports that in 1993 Portland was the first U.S. city to adopt a carbon emission plan. The article also indicates that since 1990, "Portland's recycling rate has tripled to $67 \%$ of waste generated at homes and businesses. The number of bicyclists crossing bridges has increased five-fold. Bus ridership has doubled (Larabee, 2009, no page). Overall, it is clear that Portland aspires to be an eco-conscious city and takes great pride in being a model for sustainable development.

In a phenomenological investigation the phenomenon being researched can be an emotion, relationship, or a culture (Patton, 2002, p.104-105). In fact, the experience being investigated can be the lived experience of a place or certain space. Van Manen discusses the notion of "lived space" or spatiality and how "we become the space we are in (Van Manen, 1990, p. 102).” Lived space does not refer to distance or mathematical notions of 
space such as length and height. Our lived space is part of the fundamental structure of a person’s lifeworld (Van Manen, 1990, p. 102). Van Manen offers the examples of a large modern bank making an individual feel small or a wide open landscape that makes some feel free or perhaps even exposed. The lived space can also change the experience itself. For example, reading a novel on a crowded bus as opposed to reading the novel in your favorite chair at home(Van Manen, 1990, p. 203). The lived space is somewhat similar to notions of the home. Van Manen writes, "lived space is the existential theme that refers us to the world or landscape in which human beings move and find themselves home (Van Manen, 1990, p. 102).” Other factors such as being geographically close but feeling further apart can be caused by a river crossing or having to pass through high traffic roads or highways. Van Manen concludes, "So it appears that lived space is a category for inquiring into the ways we experience the affairs of our day to day existence; in addition it helps us uncover more fundamental meaning dimensions of lived life (Van Manen, 1990, p. 103).”

Research Purpose

This research seeks to uncover and describe the lived experience of Portland residents in relation to the substantive issue of climate change. More specifically, residents that recently moved to Portland from outside of Oregon. What do they know, where does this information come from, how does it influence their everyday routine? Other questions such as how they feel about climate change, what is their relationship to the issue and who bears the effects of climate change were explored through one on one interviews guided by questions and prompts but open to the description and experience 
that emerged in that moment. This research aims to "focus on descriptions of what people experience and how it is that they experience what they experience (Patton, 2002, p.107).” The goal or main purpose of this phenomenological research is to "transform lived experience into a textual expression of its essence-in such a way that the effect of the text is at once a reflexive re-living and a reflective appropriation of something meaningful: a notion by which a reader is powerfully animated in his or her own lived experience (Van Manen, 1990, p. 36).” In discussing lived space, Van Manen concludes that "the human being not only stands in a certain conversational relation to the world-the human being really is this relation (Van Manen, 1990, p. 116).”

\section{Investigating Experience as We Live it}

The second aspect of Van Manen’s methodology for researching lived experience involves data collection. The lifeworld is both the source and the object of phenomenological research. There are many sources of data in the lifeworld to help describe and unveil the fundamental nature of a particular lived-experience. "Gathering” or "Collecting" lived experience data in this research occurred through in-depth, conversational interviewing (Van Manen, 1990, p. 54). The word “datum” means something "given" or "granted". The data collected from lived experience recollections undergo a process of transformation because the descriptions, reflections, recollections can never be identical to the lived experience itself (Van Manen, 1990, p. 54). The gathering or collecting of other's lived experiences and the analyzing of those experiences are separated out for the purposes of explanation but should not be thought of 
as distinct from one another and should be seen as part of the same process (Van Manen, p. 63).

I followed Van Manen’s suggestions for producing a lived experience description. First and foremost, he suggests that the researcher produce their own livedexperience description. This helped orient myself to the experience in order to have a more refined sense of the experience before seeking descriptions from others (Van Manen, 1990, p. 64). I assisted the participants in their descriptions by keeping Van Manen's suggestions for creating a lived experience in mind while developing my interview questions and also during our conversations with follow up questions and prompts. He suggests that the person needs to describe the experience as they live(d) through it. This step tries to avoid causal explanations, generalizations, or abstract interpretations. Next, Van Manen suggests a description from the inside of the experience. This description centers on the feelings, mood and emotions of the participant during the experience. Van Manen additionally suggests that the descriptions focus in on a particular example, incident. A specific event, adventure, or happening can aid in the overall description. Another tip is to focus on experiences that stand out for their vividness or first time qualities. Attention to how the body feels, what the experience smells like, sounds like etc. will also shed light on the lived experience (Van Manen, 1990, pp. 64-65).

This research utilized phenomenological interviews with the purpose of "gathering experiential narrative material that may serve as a resource for developing a richer and deeper understanding” of Portland resident’s lived experience in relation to 
climate change (Van Manen, 1990, p. 66). The interviews were semi-structured with initial questions (Appendix A) and conversation prompts constructed but yet flexible and open to the unique experience of each participant. The interviews focused on the “experience as lived” by asking questions and prompts that were concrete and about specific instances, situations, people, or events (Van Manen, 1990, p. 67). Before interviewing began I made sure to have a strong orientation to the research question by answering all of my questions for myself and informally talking with friends, classmates and co-workers about my subject. The interviews were full of information such as stories, anecdotes, examples and descriptions of each participant’s experiences.

These data were generated from conversational interviews that were one-on-one and in-depth. Scholar Grant McCracken explains in The Long Interview that qualitative research which utilizes long interviews can often times result in "messy" or "unorganized” data. However, the advantage of utilizing data from in-depth interviews is that it also can result in research that is complex and has depth (McCracken, 1988, p. 18). Gathering interview data and analyzing the data in this phenomenological inquiry were two separate steps. I conducted a series of 19 interviews before analysis began. The research questions were formulated along with interview prompts and submitted and approved by human subjects. As I proceeded through the interviews, I adjusted or refined a few of the questions. For example, instead of asking "what does climate change look like” I fairly quickly switched to asking, "If you were to draw a picture, snap a photo or paint a picture of climate change, what would it look like?” This shift in the way I asked the question led to less confusion. Also, instead of asking "what climate 
change feels like” I instead asked the participants "how the issue makes them feel” and sometimes followed up with “how does this conversation feel?” One participant, Joan, burst into tears when asked about her feelings. The rest of this interview was rushed and mildly uncomfortable.

During the recorded interviews, I took notes. I also took time to mentally process or generally reflect on each interview after they occurred. I found that my ability to remain quiet increased with each interview. Instead of feeling compelled to really engage in back and forth conversation, I learned how to wait and listen. I also took notes post each interview highlighting or marking questions on my interview sheet that struck me as unique or vivid in the moments following our interaction. This process was different than in depth analysis that occurred after the completion of all the interviews. This was one way that I was able to "live with the interviews". I also found myself writing notes, tracking my thoughts and brainstorms as they occurred. My office at school and home became littered with post-it notes and folders covered in writing as notes or reminders to be used at a later date. (Seidman, 2006, p. 113)

\section{Positionality of the Researcher}

I integrated McCracken’s (1988) approach to qualitative research into this phenomenological inquiry. His approach positions the researcher's experiences, imagination and intellect at the center of the research endeavor. McCracken explains that research relying on in-depth interviews works best when the researcher matches their own experiences, ideas, and actions with the subject being investigated. He reasons that people think in relation to their own experiences (McCracken, 1998, pp. 18-19). Not 
setting aside personal experiences and beliefs of the researcher is advantageous because it allows the investigator to have a more intimate "acquaintance" with the object of study (McCracken, 1988, p. 32). In agreement with an existential phenomenological approach to research, McCracken instructs researchers to reflect on and document their associations, assumptions, and particular incidents relevant to the research subject (McCracken, 1988, p. 32).

This approach to research is inclusive of other methodological approaches to the collection and analysis of qualitative research data. McCracken recognizes that many options exist when conducting qualitative research. Sometimes, "full and intimate” access to those participating in the research is not possible. Thus, another argument is made in favor of including the researcher's personal experience and observations regarding the subject of the long interviews (McCracken, 1988, p. 28-28). There is a long history of social science research that incorporates autobiographical information. Atkinson (2006) points out that some component of the self is always present with any ethnographic work. He writes, “...the full meaning of reflexivity in ethnography refers to the ineluctable fact that the ethnographer is thoroughly implicated in the phenomena that he or she documents, that there can be no disengaged observation of a social scene that exists in a 'state of nature' independent of the observer's presence (Atkinson, 2006, pp. 401-402)." Often referred to as the "observer's paradox", a co-creation of data occurs when a researcher interviews an individual. It is far more likely that the researcher will "affect and interact” with the subject under investigation rather than remain a neutral and outside observer (Atkinson, 2006, p. 403). 
Incorporating elements of autoethnography is complementary to an existential phenomenological inquiry because the researcher's biographical personal account helps situate themselves within the research process. Ellis and Bochner(2000) believe that the subjectivity of the researcher should be foregrounded in research through the use of personal thoughts, feelings, observations and stories. Thus, autoethnographic approaches compel the investigator to describe and look critically at their own experience in relation to the research question(s). The researcher's own "experience" and "introspection” is to be considered a "primary data source” (Patton, 2002, p. 86). H.L. Goodall explains the advantage of incorporating autoethnography into qualitative research by stating, "we write or perform personal narratives as ways of explaining things, and our explanations reunite what we call the literature in a field or on a subject with the telling of a life story (Goodall, 2004, p. 187).” He continues, “the more subjective and personal it gets, the truer it is...Personal narratives are about communication as it is experienced in everyday life, which is always first person, deeply felt, rooted in our past, not always rational, and often messy (Goodall, 2004, p. 188).” My personal stories can help focus the research towards the everyday experiences of not only my own life but of the interview participants as well.

De La Garza’s (2000) creation centered approach published under her former name of Gonzalez also informed this research methodologically. She views ethnographic research work as a cyclical and emergent experience. Her approach also integrates the researcher's experience, history and cultural contexts (Gonzalez, 2000, p.623). The Four Seasons of Ethnography as a methodological approach embraces a notion of the research 
endeavor as cyclical instead of in a linear western approaches(Gonzalez, 2000, p. 625). The cycles of nature provide a "holistic ontology of circular order" where the research process is more fluid and dynamic. This approach also refuses to make claims of absolute knowledge but instead the results are reported with "tentative certainty” (Gonzalez, 2000, p. 628).

The benefits of pursuing research where the researcher is a "complete member researcher” (CMR) are explained by Leon Anderson (2006) in his modification of Ellis and Bochner’s method of Autoethnography. Anderson labels his approach as ‘analytical autoethnography’. The first component of this approach, CMR has the methodological advantage of the researcher having unique and intimate access to data and insight by virtue of belonging to the "social world under study" giving the researcher better understanding of "insider meanings" or an "added vantage point for accessing certain kinds of data” (Anderson, 2006, p. 389).” Anderson also emphasizes an 'analytic reflexivity' that tends to the role of the researcher that constantly examines their relationship to the research. Analytic reflexivity demands, "self-conscious introspection guided by a desire to understand both self and others through examining one’s actions and perceptions in reference to and dialogue with those of others (Anderson, 2006, p. 382).” Thus, through the comparison of interview data and personal reflections and storytelling, I can become more "visible and active in the text" demonstrating the “researcher's personal engagement in the social world being studied” including insights drawn from my own life (Anderson, 2006, pp. 383-384). This research approach is not intended to show off my abilities as a self-absorbed graduate student but rather it's an 
honest and personal "dialogue with informants beyond the self" and has a commitment to an "analytic agenda" that seeks to "gain insight into some broader set of social phenomena” (Anderson, 2006, p. 386-388).

This research utilizes an existential phenomenological approach where the positionality of the researcher at times draws from autoethnographic approaches to research. By incorporating multiple methodological approaches in research design, stronger links to both the subject being investigated and also to the existing literature base are made possible (McCracken, 1988, p. 65). This “flexible and inclusive” approach to research allows me to approach the social world or groups in a more complete and comprehensive way (Vryan, 2006, p. 405).

Traditional approaches to social science research have specific criteria regarding sample size. It is unreasonable to expect a single study to produce "universal, complete, or definitive knowledge...all studies are limited in various ways (Vryan, 2006, p. 406).” As a result, the importance of a large sample size of interviews was not a primary concern in this research design. Kevin Vryan explains that the goals of research should not be to simply replicate or mimic methodological strategies and accepted sample sizes but rather work towards research that can "help us better understand or explain people, experiences, and/or contexts (Vryan, 2006, p. 408).” He continues that, “...I do not believe that analytic autoethnography should definitionally require a sample representative of some set of people or even more than one informant (Vryan, 2006, p. 406-407).” Goodall is in agreement with Vryan when he states: 
Our worth in the public world is unlikely to be measured by a sample size, or an argument about methods, or the tedious language of our in-group speech, but rather by the value of our stories in the lives of people who read and use them (Goodall, 2004, p. 193).”

This research utilized the non-probability method of convenience sampling. Initial recruitment came from my own social network consisting of classmates, neighbors, friends and co-workers. After the initial interviews, I utilized snowball sampling asking those interviewed for referrals of others who may be willing to participate in this study (Patton, 2002, p. 237). The subject population of this research is Portland, Oregon residents. Specifically, only residents who have moved to Portland from other states with be included. This criterion was established so that participants could describe the uniqueness of their new environment in relation to their prior lived space. Like Norgaard, who also used this sampling technique in her study of Bygby residents, I sought out as wide a variety of individuals as possible. Most interviewees were asked to suggest other individuals that could help with the research by agreeing to be interviewed (Norgaard, 2006, p. 354). Nineteen interviews were conducted that ranged from 38 minutes to an hour and forty minutes. The sample was not restricted to one gender, ethnicity or age group. Instead, individuals were selected if they met the criteria of living in Portland, Oregon after moving from another state as an adult $\left(1^{+}\right)$. This research is interested in the lived experience of newer Portland residents who have made a conscious decision to live in Portland. Individuals were excluded from the sample if they had prior knowledge 
of my research interests in climate change, were lifelong residents of Portland, or moved to Portland from elsewhere within the state of Oregon.

In order to protect against bias in this convenience sampling, particular attention was paid to gathering information from a wide range of individuals from all parts of the city. Robert Weiss discusses convenience sampling and bias in the text, Learning From Strangers: The Art and Methods of Qualitative Interview Studies (1994). Weiss cautions the researchers not to select respondents that we know have a particular point of view or that are likely to have a certain outlook on the issue. For example, sampling at a Republican convention and then misleading the research by treating this sample as representative of all Americans. For this research, it was important to be aware and conscious of what Weiss calls an "adequate range on critically important dimensions (Weiss, 1994, p. 212).”

The dimension of neighborhoods and their own lived space and relationship to the larger city and people's lived experience should be considered one of these "critically important dimensions” regarding sampling bias. Carl Abbott explains in his book Portland: Planning, Politics, and Growth in a Twentieth-Century that Portland has its own unique views on neighborhood planning. The city is separated into neighborhoods based on whether you reside east or west of the Willamette River and north or south of the major street Burnside. Abbot writes, "Portland is a city with distinguishable neighborhood types arrayed in identifiable crescents around the downtown (Abbott, 1983, p. 206).” Each major neighborhood was represented in the interviews conducted for this research. 
The Portland Sustainability Institute recently published a report regarding the sustainability of the city of Portland and came to the conclusion that eco-districts or a neighborhood approach to accomplishing environmental goals is the best route. Ethan Seltzer, Professor of Urban Studies and Planning at Portland State University writes, “In Portland, neighborhoods are not business associations, urban renewal areas, major redevelopment sites, watersheds, or other geographic areas. They are, in fact, a specific kind of geography in Portland that scales up, institutionally and intentionally, to the scale of the entire city (Seltzer, 2010, p.10).” Thus, this examination of the lived experience of Portland residents in relation to climate change included representation from each major neighborhood (Southwest, Southeast, Northwest, Northeast, and North). Interview Process

Interviews were held during a two month period in March and April of 2011. Most interviews were conducted in the participant's home, their office or a coffee shop. Participants signed an informed consent agreement before each interview. After the interviews were completed, verbatim transcriptions were produced. The text of the transcriptions was made using recordings of the interviews. This research project converted each taped interview into an mp3. The converted sound file is stored on my primary computer and also individually "burned" onto a compact disc. Each disc is labeled with both the interview number along with the interviewees' self-selected name. The transcriptions are verbatim or put another way, word for word. Long pauses, laughing, crying, recording difficulties, or events that happened during the interview were notated (Patton, 2002, p.441). 
Ideally, I would have liked to transcribe all of the interviews myself. Issues of time lead to some transcriptions (eight total) being hired out to co-workers at Portland State University, past graduate students from my department and Odesk.com. This research utilized both types of transcriptions. Transcriptions completed by parties other than me were subjected to a quality control protocol. This quality control entailed a word for word checking of the transcription with corrections notated and corrected by me (Patton, 2002, p. 441-442). Specific instructions such as what verbatim transcriptions mean, notating all laughing, sighs, noises etc. etc. were given to increase the quality of the hired transcriptionists’ work (Seidman, 2006. P. 115-116). A completed transcription for each interview was printed and filed away to preserve the raw data collected from the interviews. Additionally, an electronic copy of each transcript is saved on my computer. Paper copies of each transcript were printed to allow notations and marking of key passages one transcript at a time. (Patton, 2002, p. 442)

Analytic Approaches to Data: Reflecting on the essential themes

The purpose of the third step in Max Van Manen’s methodology is to grasp the essential meaning of the lived experience. Van Manen remarks that this is both an easy and at the same time difficult task. Easy because what is being described exists in the ordinary, everyday world and complex because it is impossible to transform a lived experience into a textual representation that boils it down to just the essential components. He writes, “The insight into the essence of a phenomenon involves a process of reflectively appropriating, of clarifying, and of making explicit the structure of meaning of the lived experience (Van Manen, 1990, p. 77).” Van Manen continues his 
explanation of how to find the meaning or essence of a phenomenon by cautioning that meaning is not uni-dimensional. This methodology recognizes that meaning is "multidimensional and multi-layered” (Van Manen, 1990, p. 78). The reflection occurs during the crafting of a text by the researcher while reflectively analyzing the structural or thematic aspects of that experience (Van Manen, 1990, p. 78).

Themes emerged in this phenomenological reflection not through a rule-based process but rather through what Van Manen describes as “a free act of 'seeing' meaning (Van Manen, 1990, p. 79).” Phenomenological themes according to Van Manen are the structures of experience. When you look at a phenomenon as a researcher, you are looking for the themes or "the experiential structures" of that phenomenon (Van Manen, 1990, p. 79). Van Manen metaphorically describes themes as "knots in the webs of our experiences, around which certain lived experiences are spun and thus lived through as meaningful wholes. Themes are the stars that make up the universes of meaning we live through (Van Manen, 1990, p. 90).” The goal is to unearth something meaningful.

Themes can also be thought of as a boiling down or simplification that describes an aspect of the structure of the phenomenon (Van Manen, 1990, p.87). Van Manen addresses the questions of how themes emerge and how they relate the phenomenon. He views themes as a vehicle to "get at the notion". Themes help to get at the experience of climate change and everyday experiences. Van Manen also states that the theme "gives shape to the shapeless" meaning that the theme allows the essence of the experience to remain beyond mere description. The theme also describes the content of the notion but will always be some form of a reduction of that notion. In other words, there will always 
be other mysteries and meanings to unlock and no thematic analysis is capable of getting at the complete essence of an experience (Van Manen, 1990, p. 88).

McCracken describes the general analysis process of interview data in terms of a path that one travels. The information collected in this research such as field notes, observations and transcriptions were analyzed in order to travel from data to observations and then conclusions and finally a "scholarly assertion” (McCracken, 1988, p. 41). Once the interviews were recorded and transcribed, I began to determine what categories, themes, relationships, assumptions and so on emerged (McCracken, 1988, pp. 41-42).

When analyzing the qualitative interview data the first step was to look at each transcript one at a time examining each utterance or statement on its own terms. In other words, the words of the interviewee are treated like an "observation" that is accepted on face or “on its own terms” (McCracken, 1988, p. 42). This process occurred vertically first, meaning one at a time. I read each individual transcript and made initial notations. Once completed, I scanned all of the transcripts with my markings on them to preserve my thought processes after the initial vertical read. Next, I did a closer vertical read of each transcript. I focused in on every complete thought, utterance, or answer that was grouped with a follow up question. I made additional notations and physically deconstructed the transcript by cutting each statement out and taping it down to a piece of paper with my first two rounds of notations. Once every complete thought was processed I started the horizonalizing of the data. In other words, I looked at each statement in relation to the whole set of interviews and my own personal experience (Poulsen, 2011, 
Personal Correspondence, no page). I read each utterance and continually marked, labeled and categorized statements and descriptions that were similar. A physical representation of the themes at times emerged. During this horizontal read of each transcript, McCracken advises the researcher to mark and notate what it is in the data that "sets off" inside the researcher. The transcriptions did at times trigger what McCracken calls "the voice within" or the feeling of "I know what that is". This analytic approach to qualitative interview data privileges intuition. In fact, McCracken states that intuition is one of the researcher’s most powerful tools (McCracken, 1988, p. 44-45). Irving Seidman explains this as a "dialectical process" between the researcher and the data that relies on the use of the researcher's "intuition and intellect" to reduce the mass of information "to a manageable proportion (Seidman, 2006, pp. 126-127).”

Once each transcription has been horizontally read, I followed the advice of McCracken who instructs the researcher to go through the transcriptions and notate the initial observations. Constant notation helped with identifying the themes. I scanned the transcripts looking for similarities and relationships between each individual description (McCracken, 1988, p. 45). The analysis started to shift away from sole use of the transcripts to "observations and the pieces of text from which they sprang (McCracken, 1988, p. 45).” The next general step of analyzing the interview data was the judgment phase where I created what McCracken labels a “coral reef” or a hierarchy of themes. I "clustered together" or identified the interrelationships and differences of the emergent themes. Lastly, the themes were reduced into one statement or meta theme that attempted to capture the essence of the particular lived experience under investigation utilizing 
existing scholarship or “analytic perspectives” of the social sciences (McCracken, 1988, p. 46).

Identifying themes within qualitative interview data is a laborious and time consuming activity because the different individuals answer in their own way and thus the researcher spends a "a great deal of time sifting through responses to find patterns that have emerged at different points in different interviews with different people (Patton, 2002, p. 343).” The label pattern or themes are often used interchangeably in qualitative research but a theme is more general than a pattern. Patton explains that "the term pattern usually refers to a descriptive finding, for example, 'Almost all participants reported feeling fear when they rappelled down the cliff,” while a theme takes a more categorical or topical form: Fear (Patton, 2002, p. 453).” The task of identifying themes from qualitative interviews is an inductive form of analysis. Instead of the data being analyzed by a pre-existing framework, thematic analysis occurs when the researcher interacts with the data to uncover and describe emergent themes. (Patton, 2002, p. 453).Identifying the themes present allows the researcher to reduce the transcriptions to what is "significant" and "of interest". Instead of bringing a hypothesis to be tested, I approached this task with an "open attitude” (Seidman, 2006, p. 117). This crucial first step discussed earlier is the "winnowing process" where I looked for and labeled the "meaningful chunks" of data through a close reading of the interview texts (Seidman, 2006, p. 117).

Organization was a key component in the early parts of the data analysis. Interview notes and transcripts needed to be managed. Patton explains that the first step is "Identifying, coding, categorizing, classifying, and labeling the primary patterns in the 
data (Patton, 2002, p. 463).” Organization was aided by reading through field notes and interview transcripts and making constant notations on the data. This is what he calls "the first cut” at constructing topics (Patton, 2002, p.463). Moustakas discusses the processes and methods for phenomenological analysis of interview data in a very similar way to Patton and McCracken. Moustakas instructs phenomenological researchers to begin their analyses by; "horizonalizing the data and regarding every horizon or statement relevant to the topic and question as having equal value (Moustakas, 1994, p. 118).” Again, I completed two vertical reads of each transcript and then entered the process of horizonalizing described by Moustakas. The topics were given a tentative name and then sorted. (Seidman, 2006, p. 126)

Many researchers offer tips for the investigator tasked with identifying themes in qualitative interviews transcripts. I adhered to the advice of not beginning the initial coding with categories already in mind. Additionally, I did find that actively looking for utterances or ideas that have connections with other statements was beneficial. Seidman writes, "In a way, quantity interacts with quality. The repetition of an aspect that was already mentioned takes on weight and calls attention to itself (Seidman, 2006, p. 127).” Prominent themes that emerged strongly from the data did take the form of a pile or collection of statements from the participants that were similar and not necessarily tied to the same question. I also paid close attention to themes that were centered on conflict, expressed hopes, time (start, middle, and end), frustrations, class, ethnicity, gender, power, hierarchy, and expressions of community or solidarity (Seidman, 2006, p. 118). Becoming "immersed in the data" during the initial categorization assisted with the 
identification of themes. Patton explains that this methodological approach comes from "Grounded Theory” that "emphasizes becoming immersed in the data-being grounded-so that embedded meanings and relationships can emerge (Patton, 2002, pp. 453-454).” Not only was I "working” the data through processing each utterance, I was listening to the audio of each interview on my Ipod while in transit from one place to the other.

Formal coding followed this step. The initial horizontal read helped to identify the emergent themes. A second horizontal reading of each transcript allowed me to formally organize and notate passages that contained more than one theme. Each passage was also marked with interview name and number so that it could then be grouped into categories and given proper attribution later (Seidman, 2006, p. 126). As previously mentioned, each coded quotation or statement was then "cut and pasted” into each thematic category. For example, each statement referring to the potential theme of 'freedom' is notated and then grouped with the other 'freedom' coded statements (Patton, 2002, p. 463). These statements were then organized within each category from "most compelling excerpts” to least descriptive or explanatory (Seidman, 2006, p. 126).

Themes were isolated with a selective reading approach where the researcher reads and listens to the text several times isolating the statements or phrases that are essential or revealing within the descriptions continually asking what each one contributes to the understanding of the experience (Van Manen, 1990, p. 93). This research employed conversational interviews between the researcher and, participants centering on their lived experience of climate change. The collaborative quality of conversational interviews lends itself to thematic analysis. Van Manen states, "The 
conversation has a hermeneutic thrust: it is oriented to sense-making and interpreting of the notion that drives or stimulates the conversation (Van Manen, 1990, p. 98).” Describing the phenomenon

The fourth component of Van Manen's methodology, phenomenological writing is involved from the beginning of the research process and should not be viewed as the end or last step of the research process. Van Manen views human science research as a form of writing. Listening is key in order to have descriptions of the lived experience that are "sensitive to the subtle undertones of language, to the way language speaks when it allows the things themselves to speak. This means that an authentic speaker must be a true listener. (Van Manen, 1990, p.111).”

This phenomenological description includes the usage of anecdotes or stories. Anecdotes are a specific type of story that Van Manen finds useful in phenomenological writing. He does not view anecdotes as filler meant to "butter up" a text that is difficult or worse, boring to read. Instead, he writes, "[a]necdote can be understood as a methodological device in human science to make comprehensible some notion that easily eludes us (Van Manen, 1990, p. 116).” He also suggests varying one’s examples.

Once the themes were identified and formally coded, they were used to construct the phenomenological descriptions that seek to identify the "essence" or "meanings" of the phenomenon(a) (Moustakas, 1994, pp.118-119). Patten explains that after the "phase of illumination" where themes and patterns emerge and form clusters, the researcher then transitions into the "explication phase" of the research". This step is for the researcher to engage in a process that includes "focusing, self-dialogue, and reflection" to facilitate a 
"full unfolding of the experience (Patton, 2002, pp. 486-487)." This text aims to provide a "thick, rich description" that communicates the clearly to the reader. Patton writes, "Thick description in such a way that we can understand the phenomenon studied and draw our own interpretations about meanings and significance (Patton, 2002, p. 438).” Balancing the Research Context by Considering Parts and Whole The last component of Van Manen's phenomenological methodology for human science research involves balancing the research context by considering parts and whole. The context is very important to the methods employed during the research. Van Manen is asking the researcher to pay close attention to the actual experience being investigated and making sure that the collection of data through our own experience of the phenomenon, our reflections, descriptions, interviews, transcriptions, or other methods provide meaningful, rich data on the fundamental research question (Van Manen, 1990, p. 163).

The intelligibility of the phenomenon needs to be considered as well. Van Manen gives the examples of the "experience of birthing pain" as something that would be unintelligible to roughly 50 percent of the population (Van Manen, 1990, p. 166). This research examines the lived experience of climate change for Portland residents. Specifically, the research interviewed individuals who have moved here from another state as an adult. The research question centers on how they experience lived space and climate change. I believe from my own experience of moving here from Kansas that the intelligibility and awareness of lived space is heightened when you are in a new environment. One's lived space is heightened or brought to the forefront when it is 
relatively new to them and especially if different from your previous lived space. This freshness of perspective and the ability to compare behaviors and points of view between is why newer residents were the participants in this research. Additionally, individuals from each major neighborhood grouping throughout Portland were selected in an effort to understand the uniqueness and peculiarities of the different parts of the city in order to better understand the essences that combine to form the whole. 


\section{CHAPTER FIVE: THEORETICAL INFLUENCES}

\section{Cosmopolitanism Defined}

Kwame Appiah, begins his book entitled Cosmopolitanism: Ethics in a World of Strangers by describing the fundamental shift that modern society has undergone. Appiah indicates that we no longer resemble the smaller societies of the past because "in the last couple of centuries, every human community has gradually been drawn into a single web of trade and a global network of information (Appiah, 2006, p.xii).” Appiah believes that society should adopt not a "globalized" or "multicultural" perspective but rather a “cosmopolitan” perspective that facilitates a "global tribe” (Appiah, 2006, p. xiii). For Appiah, this is a universal stance that believes that "every human being matters and that we have shared obligations to care for one another (Appiah, 2007, pp.2377-2378).” The central tenet of this modern cosmopolitanism is that we are all first and foremost "citizens of a world of human beings (Nussbaum, 1994, p. 2). Thus, cosmopolitanism is a moral position in which "demographic, national or cultural identity does not constitute, of itself, a morally valid basis for making moral distinctions between people. ..the cosmopolitan individual should display: virtues such as tolerance, justice, pity, righteous indignation at injustice, generosity towards the poor and starving, care for the global environment and a willingness to take responsibility for change on a global scale(Hooft, 2009, p.8).”

Cosmopolitanism recognizes that we each live in our own unique communities but prioritizes our citizenship of the world community over that of our nation-state. There are three elements to the cosmopolitan view that each person in the world is equal. First, 
persons or human beings are the primary “units of concern” with familial, tribal, ethnic, cultural, religious or national concerns as secondary to the well-being and autonomy of the individual. The second element of cosmopolitanism is universality. Every human being is valued equally. The third component of cosmopolitanism is generality. Generality means that people have concern for everyone and not just those who belong to the same group such as French or Catholic or white (Hooft, 2009, pp. 4-5). Cosmopolitanism rejects the prioritization of other forms of identity because the identification of nationality, religion or ethnicity defines communities as distinct or different from one another and thus they can and often do become justifications for exclusion, or domination (Hooft, 2009, p.5). Appiah argues that all people are members of the global community and thus, certain responsibilities and expectations for one another emerge from that worldview that do not exist when we focus on nation-state or other forms of identity that highlight differences over commonalities (Hooft, 2009, p.6). Cosmopolitanism and Inevitability

Sociologist Ulrich Beck believes that we are now in a second age of modernity and that globalization throughout all parts of our lives has started to dismantle the integrity of national borders (Elliott, 2002, p. 9). It is because of globalization that modern society is now at a crossroads. The conversation regarding the international community and the morality of globalization is now thrust upon us. The structures of modernity are changing and unstable and so now is a key time for cosmopolitan investigations of our social world. We no longer can ignore discussions of "mutual concern, common interests and a shared fate” due to the new relatedness of humans 
across the globe. The "we” has started to encompass more of the "they" and thus we need to update our moral conceptions regarding our duties to other human beings (Parekh, 2003, p. 11).

History of Cosmopolitanism

Modern cosmopolitanism can be traced back to the ancient Greek philosopher Diogenes. When posed the question where he came from, he responded, "I am a citizen of the world.” Diogenes decided to define himself in a more universal manner. The Stoics further developed this notion of being a "citizen of the world" through their argument that "each of us dwells, in effect, in two communities—-the local community of our birth, and the community of human argument and aspiration” regarding all humans as “fellow citizens or neighbors (Nussbaum, 1994, p. 3).” The Stoics viewed all human beings as equal and this universal moral order to them was ordained by the gods (Hooft, 2009, p15).

Contemporary cosmopolitanism can also be traced back to Kant's views that global peace would come about as a result of the global expansion of trade. Kant theorized that states would not jeopardize or disrupt their economic interests through military engagement (Ley 2004, p. 159). Modern cosmopolitanism has also emerged from international arrangements, institutions or treaties that sought to protect human rights and peace. For example, the creation of the League of Nations following World War I and then later the creation of the United Nations after the horrors of WWII. Both of these organizations recognizes the existence and sovereignty of individual nation states and so cannot be categorized as cosmopolitan institutions. However, the world 
community's response to the atrocities of WWII did help establish universal norms and standards of behavior for crimes against humanity. Additionally, the International Criminal Court, The 1948 Universal Declaration of Human Rights, the International Bill of Human Rights along with other UN initiatives all illustrate how cosmopolitanism can be more than just an ideal or a moral aspiration. Cosmopolitanism can be "norms embodied in international institutions and in international law (Hooft, p. 18-19).” Must Shift Away From Nation-State

Modern cosmopolitanism challenges the liberalism that began with John Rawl's A Theory of Justice because Rawls fails to address the internationalization of liberalism. Instead, his conceptions focus on liberalism and the rights of individuals within one country. Appiah writes, "Liberals take it to be self-evident that we are all created equal, that we each bear certain inalienable rights, and them seem almost immediately to become preoccupied with looking after the rights of the local branch of the species, forgetting ...that their rights matter as human rights and thus matter only if the rights of foreign humans matter, too (Appiah, p. 620).” Sociologist Ulrich Beck believes that giving primacy to the "national gaze" creates "big blind spots" and "sources of error" because it limits our ability to witness inequalities that are transnational or global in nature. In fact, a nationalized perspective preserves the power and status of the privileged in the status quo in effect legitimating global inequalities. Beck views cosmopolitanism's ability to examine social and political actors from an inter-national rather than intranational perspective methodologically superior because an inter-national perspective 
more fully captures the realities of modernity such as the accelerated mobility of people and capital beyond nation state’s borders (Beck, 2007, p. 690).

American philosopher Martha Nussbaum agrees with Appiah and Beck that the time has come to shift our attention as social science researchers, philosophers, citizens and institutions beyond the confines our nation state sovereignty. Nussbaum critiques current liberal scholarship for accepting the irrational and arbitrary confines of national boundaries. Her position is that Americans are largely ignorant of the rest of the world and that the result of that inability to engage a broader view of the world solidifies the belief that our views, or ways of life are "neutral and natural" (Nussbaum, 1994, p.4) As an example, Nussbaum explains how an issue like the structure and nature of family and specifically parenting can benefit from an broader or global investigation. A cosmopolitan investigation of parenting would offer new insights to the typical Westernized two-parent familial structure where the mother is primarily the homemaker and the father is the breadwinner. A more globalized investigation would incorporate other familial traditions where child-rearing responsibilities are shared among extended family, the village, or other associations. With that additional perspective, researchers can transcend our own practices and realize that the two parent system is not the predominate method of child rearing globally. Additionally, this opens up avenues for other potential inquiries such as rates of child abuse in other familial structures compared to the Western model or the nature and support of women's work and so on (Nussbaum, 1994, p.4). 
Nussbaum is troubled by American emphasis on patriotism and national pride. From her perspective, “emphasis on patriotic pride is both morally dangerous and, ultimately, subversive of some of the worthy goals patriotism sets out to serve--for example, the goal of national unity in devotion to worthy moral ideas of justice and equality (Nussbaum, 1994, p.1)” Nussbaum believes that people should not have pride that they are granted freedoms due to their citizenship. Instead of celebrating the freedoms of your citizenship (an accident of your place of birth) we should instead pledge our allegiance to the well-being and freedom for the entire world community. She asks, "why should these values, which instruct us to join hands across boundaries of ethnicity and class and gender and race, lose steam when they get to the border of a nation (Nussbaum, 1994, p6)?” American moral exceptionalism is solidified by nation state patriotism. When American’s are taught to believe that “all men are created equal” and that everyone has the rights to "Life, Liberty, and the Pursuit of Happiness" it is always framed as something special and great about our nation. The cosmopolitan would reject those nationalistic sentiments and amend them to afford the same rights to all of humanity (Nussbaum, 1994, p. 6). It comes as no surprise then that nationalism and ethnocentrism are closely related. Declaring your identity first as American and then as citizen of the world entails a "morally questionable move of self-definition by an irrelevant characteristic (Nussbaum, 1994, p.2).” Divisions are created between the people of the world and the worth or worthiness of others becomes calculable and jeopardized when nationality takes precedent over common humanity. Only a cosmopolitan stance has the ability to overcome these divisions because our first 
allegiance is not to the nation state but rather what is morally good for all of humanity (Nussbaum, 1994, p.2).

Cosmopolitanism and the Social Sciences

The social sciences are suffering from what Ulrich Beck calls a "container theory of nation state societies”. Beck articulates that current scholarship accepts the "nation state gaze” as apriori and that our conceptions of society or sociological imagination is limited by the acceptance of borders. Blind acceptance of the territoriality of nation states within the social sciences fails to fully examine what actually occurs within those nation states. Beck states, "What occurs within the territory of sovereign states is not necessarily to be read as a national process. And vice versa: what appears to be, is labeled as, or even understood as "national”-big companies, flows of capital and culture-can be localized outside national territories, e.g., in another country or in the digital space (Beck, 2005, pp. 145-146).” In this new modernity, there are abundant examples of the "localization of the global (or non-national) within national territories and of the national outside national territories (Beck, 2005, p. 146).” This explodes the distinction or the ability to differentiate the national and non-national; The national and non-national overlap in many various configurations and thus can no longer be treated as mutually exclusive (Beck, 2005, p. 146).

The social sciences need to be reconfigured to account for the transnational realities of the second modernity. Methodological cosmopolitanism offers a perspective that can accepts that the national and international can no longer be differentiated. Beck writes, "This paradigmatic opposition of internationality and transnationality does not 
however justify a logical or temporal exclusivity, rather an uneasy co-existence of transition, a new form of the simultaneity of the non-simultaneous...what is lost in the national is gained in the transnational and vice versa (Beck, 2005, p. 148).” Beck summarizes, "Social structures- or social reality and dynamics, to put it more carefullyare being transnationalised. An appropriate epistemological change of perception, corresponding to this ontological transformation, is required-that is from a methodological nationalism to a methodological cosmopolitanism (Beck 2005, p. 147).” This shift to methodological cosmopolitanism accepts the incongruity of boundaries or the messiness of modern transnationalism, global inequality and its relationship to the local, individual or national spheres (Beck, 2007, pp. 688-699). Additionally, this new perspective brings to the foreground key concepts like "contingency, ambivalence, interdependence, interconnectedness" which facilitates "new perspectives on seemingly isolated, familiar, local, and national contexts (Beck, 2007, p. 701).” Cosmopolitanism and the Environment

As the processes of globalization erode the legitimacy of the nation state, a new and emerging global ethic or politics has begun to ferment. Transnational problems (the side effects of neo-liberalism) are directing us towards an inevitable cosmopolitan conversation. This conversation most assuredly includes environmental considerations (Saiz, 2005, p. 163-164). The recent tsunami in Japan illustrates the cosmopolitan concerns that can arise and transcend borders. Pollution, and in this case, radiation leaked from nuclear power plants does not adhere to national boundaries. Large amounts of radioactive materials were released into the global commons via the ocean and the 
atmosphere. Researchers are just now starting to study the far reaching effects from this disaster but nonetheless, it illustrates perfectly how the problem of pollution or environmental protection transcends nation state territoriality.

“The air does not obey national boundaries” writes Nussbaum. She offers this fact of life to underscore a very serious and pressing issue of our time. Our survival is intimately intertwined with others across the globe. Not only does the consumption of the developing world have disproportionately negative environmental consequences for others in the developing world, but also their intentions to globalize and attain the same high standards of living will eventually affect us as well (Nussbaum, 1994, p. 5). Angel Saiz believes that due to globalization and the transnational nature of environmental problems, liberal democratic nation states are ill-equipped to address global pollution concerns (Saiz, 2005, p. 165). In light of nation state's impotence regarding solutions to environmental damage, others have called for globalized governance to address the “ecological one-ness of the planet” (Elliott, 2002, p. 3). On a smaller scale, Appiah explains cosmopolitanism's individual conception of “ecological one-ness”. He writes, "The citizen of the world wants, as we all do, to make her own life. She wants to do it, as many do not, enriched by the experiences of people who are not at all like herself. But she also wants others to be free to make their own lives by their own lights, because their lights may be brighter, or at any rate brighter for them; but also, just because a good life is, among other things no doubt, one lived by your own lights. She wants too to contribute to making sure, not just that everyone has the negative liberties this entails, but also a fair share of the world's resources. Difference, then, but also universality- 
everybody matters (Appiah, 2007, p. 2390-2391).” This form of politics is one that values individuality and difference as long as it does not impinge on the well-being of others. Thus, if your consumption or everyday life is detrimental to others, you have a moral duty to change that behavior (Appiah, 2007, p. 2390).

It goes without mentioning that all humans should be assigned equal or valued equally in this world. We all share common needs, vulnerabilities, and so on. A cosmopolitan sense of equality and equal respect then implies that everyone should be given "equal consideration to their claims to the basic requirements of the good life (Parekh, 2003, p. 5).” Moral beings have both positive and negative duties towards the other. We have the negative duty to abstain from inflicting harm on others. Positively, we have a duty to help alleviate suffering or provide help to others within the limits of our resources or capabilities. As a matter of justice, a cosmopolitan individual accepts the duty to make sacrifices of what is not vitally important to our well-being in order to help others attain the basic conditions of their well-being (Parekh, 2003, p. 6). For example, we have a duty to help others in the case of a famine or stopping a bully from attacking another (Parekh, 2003, p. 9).

Well-being entails the satisfaction of basic needs like food, water shelter and also basic civil liberties. The ability to be an autonomous, free thinking person who can make a living, and plan a life of their own is another component to well-being. Lastly, those things that contribute to the will to live such as a sense of pride and self-worth also factor into well-being (Parekh, 2003, p. 6). Because at this time in the world we are directly and indirectly connected to others, we can no longer be indifferent to the consequences of our 
individual behaviors. We now live in a global moral community and that morality in relation to the well-being of others extends to environmental issues. "Disease and environmental damage know no boundaries, and one country's pollution or deforestation seriously affects the climate and hence the economic and physical well-being of others (Parekh, 2003, p. 10-11).” Thus, Appiah argues that what we need is not a world government that oversees global environmental concerns, but rather a new sense of global citizenship that considers the fate of all human beings (Appiah, 2007, p.2376). Cosmopolitanism and Climate Change

Climate change is a particular environmental issue that can help advance the cosmopolitan outlook. Climate change is a transnational issue that transcends international borders. The consumption of fossil fuels in one area of the globe has adverse effects on another part of the world. The International Panel on Climate Change has conducted tremendous amounts of research on global climate models and has helped to frame the issue of climate as a global risk. Ulrich Beck goes as far as stating, "climate change may yet prove to be the most powerful of forces summoning a civilizational community of fate into existence (Beck, 2010, p. 261).”

A cosmopolitan conception of the issue of climate change is not an apocalyptic vision of the future. Rather, cosmopolitans view the harms and risk of climate change as existing in the status quo. Beck labels climate change as a 'present future' that is real and knowable. Consequently, future scenarios of climate impacts are a 'future future' that are unreal and unknowable (Beck, 2010, p. 258). There are too many uncertainties in climate predictions due to many factors such as limitations in current knowledge about climate 
systems or inherent randomness of climate systems. Cosmopolitan conceptions of climate change must resist the urge for certainty regarding the future outcomes of our consumption of greenhouse gases (Hulme, 2010, p. 271).

Uncertainty about the future consequences does not negate the role that climate change has in our present day shared existence. For cosmopolitans, the issue of climate change "has become both a resourceful idea and a versatile explanation which can be molded and mobilized to fulfill a bewildering array of political, social and psychological functions (Hulme, 2010, p. 267).” The ability of climate change to transcend national borders is another reason why global citizens will inevitably be confronted with notions of global citizenship. Mike Hulme, a professor of climate change at the University of East Anglia states, “climate change...is making cosmopolitans of us all (Hulme, 2010,p. 268).”

Hulme examines three dualism of modernity that are relevant to cosmopolitan discussions of climate change. The first dualism is that he believes the boundaries between the natural-cultural are dissolved in the face of climate change. For Hulme, the distinction between natural climate change and anthropogenic climate change is illusory or ontological (Hulme, 2010, p. 268). Just as the nation state has begun to dissolve in this second phase of modernity, so too has the naturalness of our atmosphere. Due to years of industrialization and consumption of fossil fuels, we now have a hybrid climate or a "coproduced" climate that can be considered "post-natural” (Hulme, 2010, pp. 269-270). The term climate change, then must include an understanding of "the full entanglement of the natural and the cultural...we must view climate in its new clothing, a consequence of new human agency and a demonstration of the embeddedness of humanity in Nature (Hulme, 
2010, p. 269-270)." We cannot think of the climate as stable or seek to stabilize the climate. We are co-creators of this new hybrid climate and other factors such as volcanoes, oceans and trees help co-create this world (Hulme, 2010, p. 270).

The second dualism of modernity that is dissolved or altered considerably by climate change is the epistemological concerns between the present and future. The future is unknowable but the present and future are becoming increasingly entangled. Policy makers call for reductions of consumption in the present to bring Co2 levels in line with past levels at a future date. The future is precarious and impossible to know and thus cosmopolitans recognize this unknowability (Hulme, 2010, p. 273-274).

The last dualism of modernity that climate change is reshaping is the global-local category. Global climate change and local weather have become enmeshed (Hulme, 2010,p.269). Our experience of weather and climate has started to lose its "place based character”. The world is becoming increasingly smaller and so within a given year, many of us travel and experience many different climates. Additionally, online weather webcams and national news stories of freak weather occurrences and a national weather channel has increased an individual's ability to experience the weather beyond their locality. Through the media, we experience hurricanes in Florida, droughts in Africa, heat waves in Arizona or flooding and mudslides in Indonesia (Hulme, 2010, p. 272). Furthermore, discussions of climate change constantly speak of increases in the global temperature of the planet, global changes in the weather and global climate models. "It was not merely climate change; it was global warming. Global climate became a universalizing, deculturing and, and putatively, controllable entity in contrast to local 
weather-what humans had historically and experientially encountered (Hulme, 2020, pp. 272-2773).”

Environmental Justice and Cosmopolitanism

The impacts of climate change will be felt worldwide regardless of who contributed through fossil fuel consumption. The fact that the side effects or harms of climate change fail to respect national borders ensures that these effects will not be distributed equally across the global commons. For instance, the United States is only four percent of the world population and yet is responsible for 25 percent of Co2 emissions. Unequal consumption of fossil fuels is a transnational harm because the effects of that consumption are felt unequally by those who contribute the least to the problem. Those who consume the most will suffer the least (Elliot, 2002, p. 7). Recent researchers have documented that even when Americans believe that climate change is real and that humans are causing it, it remains a low priority issue due to a belief that only other remote areas of the world will feel the effects of climate change (Zhao, 2009, p. 704). This distancing of our consumption raises important environmental justice concerns. American consumption will disproportionately affect other nations less developed than the United States. Norgaard writes, "Poor people in some parts of the world already bear the brunt of the burden, while wealthy people in industrialized nations still feel climate change is abstract and distant from their daily lives...We know that global warming will precipitate the most extensive and violent impacts to date against the poor and people of color of the globe (Norgaard, 2009,p.3).” 
The cosmopolitan approach to climate change must include consideration of both the negative and positive moral obligations to the others. The negative obligation would be to reduce or stop the harm to the others by dramatically reducing the consumption of greenhouse gases in the developed world. The positive obligation would entail compensation for damage already done and a governance structure that at a minimum grants all parties autonomy within a "practical politics of consent" (Elliot, 2002, p.3-4 and 19). Moreover, the harms of climate are transnational, a cosmopolitan approach to environmental justice would recognize both the limits of individual autonomy and individual nation states in addressing the solution to this global problem on own their own (Elliott, 2002, p. 3-4). “An ecologically sensitive cosmopolitanism demands transnational environmental justice between peoples within a world society as well as, and possibly in preference to international justice between states in an international society (Elliott, 2002, p. 19).”

Cosmopolitan conceptions of environmental justice must address the governance issue regarding international regulations and the tendency for lesser developed nations to rendered powerless and defined as "objects to be acted upon, to be educated, consulted and informed, to be empowered from above or from outside, or as a source of knowledge to be appropriated and incorporated into the discourse of the global as and when needed (Elliott, 2002, p. 18).”

The Environmental Justice Movement

A detailed explanation of the environmental justice movement, its history, current struggles and transnational networks helps to clarify how this movement's values and 
goals complement cosmopolitanism. Environmental justice can be defined many ways. Some people use the term environmental racism and environmental justice interchangeably. Environmental racism can be defined as, "institutional rules, regulations, policies, and government or corporate decisions that deliberately target low income and people-of-color communities for locally undesirable land uses. Environmental racism is the unequal protection against toxic and hazardous waste exposure and the conscious or unconscious systemic exclusion of people of color from environmental decisions affecting their communities (Bryant, 2003, p.3).”

A single stable definition of environmental justice is not only impossible but not endorsed by the EJM. Conventional thinking regarding the environment is challenged by broadening the definition of environmental justice "by bridging issues of race, class, culture, and gender into the realm of environmentalism, grassroots environmentalist justice activists challenge the focus of traditional environmentalists on resource conservation, wilderness preservation, population growth, or similar issues...Activists have drawn on the legacy of the civil rights and social justice movements to reunite environmentalism with the spiritual and cultural traditions of people of color and the problems of the inner city (Holifield, 2001, p.79).” This conception of environmental justice came into existence in response to narrow interpretations of environmentalism. Theorists argued that the fundamental roots of environmental problems were not fully conceptualized and thus the solutions would be insufficient as well (Towers, 2000, p.458). While many argue for a broad conception of environmental justice, it helps to look at the broad alliances formed within the EJM to illustrate the scope of issues within 
environmental justice. The movement is large and decentralized with local, regional, national, and international organizations taking part.

The work of the EJM spans diverse ecosystems from inner cities to Native American Lands both here in the United States and abroad. Waste facilities, oil refineries, chemical plants, forests, and garbage dumps might be the focus of a particular campaign but the movement is made of diverse interests forming a broad alliance that has remained stable for years (Guauna, 2008, p. 470). It is because of the broad nature of the EJM's alliance and issue scope that allow for the movement to build alliances and maintain movement momentum. Grassroots agencies and government agencies each have conceptions of the term just like those fighting for cleanup of pollution at a Superfund site might have a different conception of environmental justice compared to those fighting for a waste water treatment plant (Holifield, 2001, p. 82). Simply put, broad definitions of environmental justice are best because "When we recognize the strengths and contributors of sister progressive movements, adopt and adapt strategies, and move forward together, we will have a much better chance of reaching our collective goals (Gauna, 2008, p. 472).”

The EJP seeks the prevention of environmental threats by eliminating harmful practices in housing, land use, industrial planning, sanitation, lead poisoning and so on. This framework seeks to uncover the underlying assumptions that contribute to and produce unequal protection from environmental hazards (Bullard, 2005, p.25). Within the environmental justice paradigm or EJP are several guiding principles. The first principle states that individuals have a right to be protected from environmental 
degradation. Additionally, the EJP adopts the public health model of prevention preferring to eliminate threats before harm occurs. An example of action pursued by the EJM under this principle is lead abatement programs in poor and minority communities (Bullard, 2005, p.26).

Another general principle for the EJP is the adoption of the precautionary principle for protecting workers, communities, and ecosystems. This principle states that before you take an action you have a duty to prevent harm if you have reasonable suspicion or scientific uncertainty regarding the safety of your action. In accordance with the Precautionary Principle, the burden of proof is shifted from the victims of polluters to those who do the harm. In the status quo, victims must prove that pollution exists or that they have been discriminated against. The environmental justice paradigm would instead require industry to prove their operations are safe prior to permits being issued (Bullard, 2005, p.28-29).

The EJP aims to "redress disproportionate impact” of environmental issues. This principle aims to attack unequal enforcement of regulations, protect human health from profit motives and correct unfair or inequitable pollution on poor and minority communities (Bullard, 2005, p.29). The Principles of Environmental Justice were adopted in 1991 at the First National People of Color Environmental leadership Summit (Bullard, 2005, p.2-3). In addition to the previously mentioned, other principles included affirming the sacredness and interconnectedness of all beings, that public policy should be free from any form of discrimination, the fundamental right to political, economic and political self-determination, the right to reparations from environmental injustice, 
opposition to military occupation, opposition to destructive multi-national corporations and the personal and consumer choice to reduce waste (Bullard, 2005, p. 300-301).

The structural working of the EJM and the networking required for grassroots political action must be examined. The model, structure, and tactics of the EJM are different from mainstream environmentalism. The EJM networks, makes connections and forms solidarity with a variety of interested parties and not just the nation state. The EJM cannot exist in isolation like a mainstream environmental organization. The EJM is a network of loosely affiliated civil rights, social justice, and environmental groups (Schlossberg, 1999, p. 108). This is a "new and more critical form of pluralism" in both theory and in practice. This is first because the understanding of perspective and culture are grounded in the experiences of individuals and their communities. Knowledge comes from that place and so the movement values equally diverse knowledge production. Perspectives emerge from an individual or communities social location (Schlossberg, 1999, p. 111). Critical pluralism accepts difference and that is why the opportunities for collaboration within the EJM are so successful and common (Schlossberg, 1999, p.112).

The concept of linkages aids in the success of the EJM. Adding a range of diverse issues to the environment creates a broader movement that forges solidarity that results in challenging multiple forms of domination (Schlossberg, 1999, p.117). This networking structure is inherently decentralized but sufficient enough for networking to occur due to the flexible and diverse. "Networks have formed at every level from the local to the international to the virtual, while building the connections between them (Schlossberg, 1999, p. 121).” An example is when a community successfully defends 
itself from a polluting industry and monitors the company and contacts others if they try the same tactic in another community. This type of decentralized networking facilitates efficient pooling and allocation of resources amongst varying groups when they make linkages or alliances with other organizations (Schlossberg, 1999 p.131).

The flow of ideas is also not centrally located in the EJM. Networks allow organizations to seek help from other groups who have expertise in law, government regulation, scientific research etc. Also, smaller organizations linking with national organizations to combat a local polluter is another structural possibility for the EJM but "Grassroots groups in the environmental justice network have been willing to work with the major groups, but the emphasis is on the "with". The movement has welcomed tactical alliances and meaningful partnerships, but has insisted on retaining local control over issues and campaigns (Schlossberg, 1999, p.132).” This is a new form of movement organization based on the strength of diversity. Difference is the EJM's means to create solidarity (Schlossberg, 1999, p.144).

Most recently, transnational movements for environmental justice have developed. Transnational corporate practices are transforming the EJM's conceptions of inequality and toxins. Social hierarchies and environmental degradation cross nation states boundaries. Modernization or industrialization throughout the world favors whiteness (Pellow, 2007, p. 226). In other words, "both race and class inequalities and chemical toxins operate and cooperate in ways that cause harm across social, spatial, and temporal boundaries (Pellow, 2007, p. 226). The idea of the boomerang is especially important when conceptualizing environmental justice on an international level. Think of 
toxics, race, class, social movements all creating a boomerang effect separately and in combination. The boomerang comes back to the original staring point when thrown. Toxins travel in a circle of poison much like the circle of a boomerang. Racism operates like a boomerang because it targets a class or race to then reap the benefits of the exploitation. Transnational movements produce the boomerang effect through networks that put pressure on all levels of government and foreign governments and then circling back to international activist and local voices. A circle or network of communication is created by the EJM on an international scale. Simply put, what goes around, comes around (Pellow, 2007, p.228-229). Future research should examine the processes of transnational movements for environmental justice since they have, "become quite sophisticated at combating global environmental inequalities through the engagement of a range of institutions, thus developing an emerging form of global citizenship and, by extension, a burgeoning transnational sphere (Pellow, 2007, p. 242).” Global Governance of the Environment and Cosmopolitanism A central feature of cosmopolitanism is that individuals must be free and that the political culture afforded to one, should be made equally available to all. Political participation or non-participation should be elective (Appiah, 1997, p. 634). As a consequence of globalization, the nation state's ability to legislate or control the rules regarding its own environment has diminished. The environment is increasingly being governed at an international level. (Saiz, 2005, p. 165) For example, the Law of the Sea Treaty through the United Nations limits the ability of a nation to dump waste, drill for minerals outside of their exclusive economic zone without permission or commit other 
environmental crimes against the global interest of maintaining clean and healthy seas. This is just one of many examples of the United Nations and its reputation as the main avenue for global environmental governance (Elliott, 2002, p. 17).

Through the United Nations, dating as far back as 1972, international efforts at protecting the environment have been undertaken. In 1983, an independent commission was established to set a course for international sustainable development. Later, in 1989, UN General Assembly declared that harm to the environment is one of the main global problems facing the world. In 1992, the Rio Summit adopted non-binding agreements that seemed to have a touch of the cosmopolitan ethic within them with language that called for the equitable and sustainable global partnerships to protect the environment. Unfortunately, none of these global declarations translated into substantial environmental gains and our environment continues to degrade (Elliott, 2002, pp.12-13).

United Nations governance and approaches to global environmental problems falls way short of cosmopolitan goals. Not only does the structure of governance at the United Nations give primacy to nation states, "the very groups and voices whose participation is essential...to the challenges of global environmental change remain distanced from the domestic and global practices of environmental governance (Elliott, 2002, p.20).” Furthermore, the interests of the nation state within the structure of the United Nations and their privileging of sovereignty claims comes at the expense of both cosmopolitanism and the environment (Elliott, 2002, p. 16-17).

Cultural differences are not valued within the United Nations. Classic development schemes that favor growth and industrialization for developing countries 
according to a Western model are advanced (Kapoor, 1999, p. 250-251). "World” meetings or conferences sponsored by the United Nations help contribute to the political and cultural fictions where issues such as overpopulation are raised and in turn the third world is blamed and cast as responsible for the worlds environmental ills without any mention of the true culprits of environmental degradation, developed economies (Kapoor, 1999, p. 257-258).

Critical and cultural theorist Dr. Priya Kapoor explains the normalizing effect that the Cairo Conference had regarding Western notions of progress and how the language of progress and development within a United Nations framework is far from global and in fact contributes to a universalization of whiteness. In discussions of development and progress, the third world is looked down upon and considered in need of solutions or emancipation through classic Western development schemes (p. 250). This discourse of development is all encompassing universalizing. Lacking any cosmopolitan acknowledgement of diversity, the ideal of modernity and mass consumption becomes a master discourse and is presented as the ultimate goal for all (Kapoor, 1999, p. 252-253). While this conference dealt with women's fertility rights, the application to United Nations governance regarding global governance of the environment is wholly relevant. Just as only donor nations made decisions in the Cairo conference, or the concerns of Western nations regarding abortions were privileged, the same can be said of the Rio Climate talks where developed nations refused to make concessions to lesser developed countries for economic reasons. In the face of cosmopolitan concern for the interests of all of humanity and also environmental justice concerns regarding governance, it is 
important to recognize that the United Nations has thus far failed to provide equitable forum for all of humanity to voice their concerns.

Sustainability, Climate Change and Cosmopolitanism

Many environmentalists have adopted the concept of sustainability or sustainable development as the solution to all of our environmental solutions. Sustainability was initially defined by the 1987 Brundtland Report as "development that meets the needs of the present without compromising the ability of future generations to meet their own needs (Medovoi, 2010, p. 130.” The idea that we can “green” our economy has gained popularity with individuals making choices in the grocery store, politicians legislating environmental policy and even C.E.O.'s of large corporations seeking a new share of the "green market". This notion of "greening" the economy has gained steam internationally as well (Mueller and Passadakis, 2009, pp. 54-55). Sustainability is a new buzzword that claims to provide an "environmentally ethical and conscious way of life. Businesses, cities, neighborhoods, buildings, and lifestyles can all be praised as sustainable or criticized as unsustainable (Medovoi, p. 129-130).” Sustainability is an economic strategy that seeks to help the environment through the restraint of the economy through market mechanisms. Unfortunately, this approach is still locked into an economic rationalization that prevents the emergence of a truly environmentally sustainable ethic (Leff, 2009, p. 103-104). An economic rationality precludes a true concern for nature and in fact can be tied to the degradation of nature through endless consumption driven by the market in search of profits (Leff, 2009, p. 102). Sustainable development is a 
short-lived fix to the problem of climate change and resource consumption only delaying the environmental effects of growth and consumption (Leff, 2009, p. 102).

Although the aims of advocates of sustainability are honorable, the philosophy itself fails to live up to all the hype. The word sustain inherently includes the negative concepts of to endure or withstand (Medovoi, 2010, p. 131).Opponent of Sustainability and critical scholar, Leerom Medovoi writes, “The political and ethical meaning of sustainability ...would refer to suffering at a withstandable level certain practices or processes that we would ultimately prefer to do without (Medovoi, 2010, pp. 131-132).” This is exactly the opposite in meaning of what environmentalist's desire in outcomes when they advance arguments in favor of sustainability. The philosophy of sustainability has a concept known as the 'triple bottom line accounting'. This phrase was coined by John Elkington in 1994 in an effort to encourage and convince companies to track their practices regarding economic, social and environmental sustainability. This concept of ‘triple bottom line' is a measurement of how sustainable a business is in each of those three areas. Sustainability seeks to prolong capital accumulation. Medovoi points out that the City of Portland's sustainability commissioner believes that the sustainability means, “wanting to stay in business forever (Medovoi, 2010, p. 132).” This makes it all too clear that the notions of a sustainable future still operates firmly in the capitalist modes of production that will inevitably lead to the monetary exploitation of nature (Medovoi, 2010, p.140).

Lived Experience and Cosmopolitanism 
The degradation of the environment cannot be solely pinned on corporations or nation states. Individual consumption and everyday experiences operate within the world of globalization. When individuals make choices to provide the everyday basic needs of their lives, they do not make those choices in a vacuum; individuals are not separated from the interconnectedness and transnational reach of globalization (Elliott, 2002, p. 5). Environmental degradation is accelerating at a never before seen pace and it's not because of cataclysmic events but rather from everyday practices of individuals (Elliott, 2002, p. 4). It is important that "everyday life becomes cosmopolitan: people have to conduct and understand their lives in an exchange with others and no longer exclusively in an interaction with their own kind (Beck, 2010, p. 258-259)." Part of the problem that prevents us from noticing how we ended up in the situation we are in is that we are often too focused on the consequences of environmental damage instead of the everyday conditions and causes (Beck, 2010, pp. 259-260). In conclusion, it’s important to undertake investigations of the everyday lived experience because the cosmopolitan vision is "not a matter of any official rhetoric of world fraternity, but of sharpening perceptions in everyday life, in politics and in scholarship, for the unbounded explosive force of social inequality in the age of climate change (Beck, 2010, p. 258).” 


\section{CHAPTER SIX: THEMATIC DESCRIPTIONS (Findings)}

\section{Description of Portland Residents}

It is most certainly a difficult task to describe an "average” Portland resident. In my brief three and a half years here, I have noticed many characteristics that a majority of residents have in varying degrees. This research begins with a description of an "average” Portland resident in an effort to both understand the people that populate the city itself, but also to introduce the reader to the interview participants who are the chief source of information for this phenomenological description and offer their descriptions of the residents of the Portland, Oregon. The names given were names chosen by the participants themselves. All participants agreed to participate in this research with the understanding that their identity would be kept confidential.

Brock, John, Lee, Jeff, Alan, Jack and Kevin are all participants with backgrounds that are very similar to mine. We are all white, male, in our mid-twenties to early thirties, educated, and gay. Brock is in school to become a pharmacist and Lee is studying at OHSU to be a lab scientist. Like me, Lee, Jeff and Alan are Portland transplants via Kansas. Brock also hails from the Midwest by way of Rockford, Illinois. Kevin emigrated from Northern California with a degree is in environmental science. He works for the city of Portland on issues of and sustainability and public policy. John and Jack both moved from the South. All eight of us garden, recycle, ride public transportation and bikes, and find ourselves swimming at the same place on the Colombia River every summer, Rooster Rock State Park. 
Kevin speaks as if he has seen the demographic breakdowns of Portland residents and laughs when asked to describe an average Portland resident. He states, “That's a silly question!” I responded, “There are a lot more silly questions.” His first response to the question was, “Ahh, your standard, yeah, you know, uh, educated, middle class liberal.” He described the residents of Portland as healthy, active, relaxed and civically engaged (Kevin, Personal Interview, March 30, 2011).

I met Brock through a mutual friend who invited me over for dinner. Brock had just moved into their house and shortly after introductions, I had my digital recorder out asking him questions. He was soft spoken when he explained his experience of being a Portland resident. He states, “One of the main stereotypes that I have thought of since I’ve very first moved here was that the average Portlander isn’t from Portland. In fact, they're probably not even from Oregon... (Brock, Personal Interview, April 3, 2011).

Jeff invited me over to his home for his interview. Jeff is white, college educated and a librarian for Portland Community College. He has lived in Portland for almost 12 years now, moving from Kansas after his college graduation. In a small, hot room in the second floor of his home in the inner southeast, he described how he moved here because Portland is "super-liberal”. Jeff recently sold his car and relies on a combination of biking, public transportation and walking to move throughout the city (Jeff, Personal Interview, March, 30, 2011).

Lucy is in her thirties and is a self-employed. She moved to Portland from Jackson Hole, Wyoming and believes that the residents of Portland are very helpful and nice to each other. She says: 
Oh, there's always been wonderful things where people help each other out. I mean, even small things in the grocery store. You have two things and someone in front of you has a whole basket and they let you go ahead...or you drop something, and someone chases you down the street and they go, 'You dropped this receipt' (laughter) You know. It’s like, 'Oh my god! Thank you!' (Lucy, Personal Interview, April 5, 2011).

Brock has noticed the politeness of Portland residents as well. He explains:

I do hear from like all sources that you'll never find the kind of polite bus culture that you find here. It's a big part of the city; It's a big deal living here...I always say 'thank you' when walking off the bus and probably so does the person in front of me and behind me stepping off the bus (Brock, Personal Interview, April 3, 2011).

Joan agrees with Brock and Lucy regarding how “overly nice” some PDX residents can be. Joan is a restaurant manager who moved here from Ohio four and a half years ago. Joan has a Master's degree in Art History and used to work as an adjunct instructor before the economy downturned. She remembers the first time she was in Portland, "I recall being in the checkout line at Zupans on Belmont and having a ten minute conversation with the cashier over nothing and thinking, my god, people are insanely friendly here” (Joan, Personal Interview, April 3, 2011).

Kevin, added:

Oh god, they're so chatty and friendly and you know, I just want to be left alone in the city. I don't want anyone to look at me, or notice me, or talk to me and in 
Portland, everyone wants to connect. And it's so weird, you know? Other big cities you can sort of disappear into the sea of people and there's just no sea of people here at all (Kevin, Personal Interview, March 30, 2011).

John, who moved here two and a half years ago from Alabama agrees that Portland residents are nice but not in the syrupy Southern way that he grew up with. He believes that Portland residents can be cold and closed to each other in public. He describes his point of view by saying:

Everyone here is nice but I think the Northwest is known for being a little cold and I think particularly people who are born and raised here are a little cold. They will give you information, give you the time of day if you ask for it, open a door for you but they don't...are not ever really pleasant about it and don’t seem open to meeting someone new...(John, Personal Interview, March 30, 2011).

Stan, another transplant from Kansas describes PDX residents as "People that are hand to mouth employed (Stan, Personal Interview, April 5, 2011).” He stays because of “The liberal mindset. I like the public transit. I like the creative young population. I like the geography, the mountains and the coast. I love all the outdoor opportunities" (Stan, Personal Interview, April 5, 2011). Stan rides his bike everywhere he travels unless he borrows his musician girlfriend's car. Eventually though, they are selling the automobile. Stan agrees with Jeff in that he moved here and others he knows moved here "because of the liberal ethos of it all” (Stan, Personal Interview, April 5, 2011).” He believes that Portland has "lots of people that are in to the outdoors. Lots of hikers and campers, 
people that don't have a lot of money...people that have been to college and not seeing a whole lot of prospects because of it (Stan, Personal Interview, April 15, 2011).”

Cindy is a single, straight woman who attends Portland Community College. Her goal is to obtain a degree in Social Work and help address issues of inequality. She made the choice to locate to Portland initially because of friends but the reasons she has decided to stay according to her is the culture, the music, theatre, and the free thinking mentality. Cindy volunteers with the Big Brothers and Big Sisters program in an effort to mentor a child and expose them to outdoor activities and exercise. Cindy is a government worker in her upper twenties. Before her current position she spent two years in Iraq in the Air Force. The transition into civilian life from Iraq to Portland was very eye-opening for her. When asked to described an average Portland resident she listed unemployed, environmentally conscious, a transplant like herself and artistic. She elaborates on the large number of unemployed people her age by saying:

It's Ok to not have a job... at 30 years old, and not be working towards anything at 30 years old. That it's okay just to...be, because...because you like to draw. That's all you need to do, is just like to draw, you don't...you're not held accountable for anything in this city. It's very slow. It's slow paced and, there's not very high expectations. For...for my...I would say for the people in my age group, and I'm 29, I , I can't tell you the number of people I've met that don't have jobs. That just blows my mind...I mean, they're okay with it because they're in touch with their "Portland-ness" because they play a flute in a flippin band (Cindy, Personal Interview, April 6, 2011). 
Jack is a soft spoken gay man in his twenties who lives in North Portland with his musician partner and the homeowner who makes medieval string instruments for a living. Jack has a similar observation to Cindy’s regarding the residents of Portland that he interacts with and observes. He remarks:

Everyone I know makes enough to get by, and for a lot of people living in Portland, that's enough because, you know, people are happy living in a place where there's like, so much to do, and you know, so much natural beauty to get away to. You know, there are a lot of really inexpensive ways to entertain yourself (Jack, Personal Interview, March 26, 2011).

Jack moved from Louisiana four years ago and currently works at a large plant nursery in Southeast Portland. During the interview we drank tea and afterwards, he hugged me and thanked me for the conversation. Georgette invited me into her home on one of the first sunny and dry days of the year. I rode my bike to her house and set at the kitchen table and discussed the Portland way of life previously described by both Cindy and Jack. Her boyfriend left to go skateboarding so that we could be alone. Her two dogs moved about the room as I first started to interview her. She is an Asian-American who grew up in Chicago and is in her late twenties. Georgette earned an undergraduate degree from the University of Kansas but moved to Portland to attend Montessori teacher training. She works as a server at two restaurants, a substitute teacher and seasonal caterer. Georgette adds to the "laid back" description of Portland residents by saying: Uhm, maybe being laid back is one thing. I was always uhm, I don't know...just worried about the details and keeping up on things and Portland's not as detail- 
oriented maybe...And the concentration on, you know, money is much harder in expensive cities so uhm, I feel like Portland isn't as focused on money or things like that. You need it to survive and live, but uhm, it’s more of the secondary (Georgette, Personal Interview, April, 3, 2011).

Jerrod, a native of Kansas City, Missouri has also noticed that the residents of Portland tend to be young, laid back and not overly ambitious. This Midwestern musician who works as a page at a downtown library has lived in Portland for three years. Jerrod is a single, straight man in his mid-thirties who shares a home in the outer Southeast. His other roommates are a straight couple and then another single female. They all play in various bands both together and separately. Jerrod explains the people of Portland as:

I guess, like working in the library, I feel like there's this cross section of, there’s the younger Portland of people that have moved in that have "taken over" in quotes....educated, I uh, probably college educated. Umm, and kind of interested in comfort I think, umm, as opposed to, I don't think people move to Portland for advancement and professional, at least the people I've met don't...Its just people that like, want to hang out, in their mid-twenties and just kind of chill, work, and live and drink...it doesn't feel like an ambitious place (Jerrod, Personal Interview, March 30, 2011).

Daisy is a relatively new resident to Portland. She moved here this year from New York City. She has her own experimental theatre company. She writes and produces experimental theatre shows for festivals with the help of her husband, a full 
time hospital administrator at OHSU. They moved here with their dog as a result of his new position. Daisy lives perched above Burnside in the northwest in a small condo that overlooks Forest Park and downtown Portland. She described Portland and its residents as a slower, depressed and lacking enthusiasm compared to her experiences in New York. Daisy currently does temporary work through an agency but has started auditioning for acting jobs. Daisy and her husband chose to locate to Portland because they wanted a smaller place where they could, in the D.I.Y. spirit, "build some things for ourselves (Daisy, Personal Interview, April 5, 2011).” Stan believes also that Portland is a very young, creative town full of transplants from other parts of the country. He describes Portland residents much like Daisy. People that are "anti-corporate, do-it-yourself types, creative, energetic, cynical of the establishment... People that are creative, that want to brew their own beer, do their own stuff, make their own sweaters (laughing)” (Stan, Personal Interview, April 5, 2011).”

Eliza invited me over for lunch in her large North Portland home that she shares with a female yoga instructor and a gay male who is a writer for a local newspaper. Their landlord lives next door and has fenced off much of their yard for her garden and chicken coop. Eliza informed me that they frequently receive eggs and produce, mostly greens grown year round, from their landlord. She is a co- owner of a retail shop downtown that sells vintage clothing. In addition, she works full time at the American Red Cross in an administrative capacity. Eliza has some college education but never finished her degree. As an East Coast transplant, it's somewhat not surprising that she describes the residents of Portland as "Passive aggressive”, "Passive” or "awkward". She states: 
I will say this, I've never experienced anything like this. In New York, people are always pretty direct with one another, you know exactly where you stand with them and there's not so much awkwardness...its always this inability to be direct. I don't know if its passive aggressive, it could be, but there's this passive way of communicating with people like you have to read their fucking minds and figure out what it is their thinking instead of just being 'I'm sad' or 'I don't like this' you know what I mean? It's always this big dance, this elaborate, like, thing around what people mean to say. Kind of annoying. (Eliza, Personal Interview, March 29, 2011).

Another East Coast transplant, Kierstan, moved to Portland from Philadelphia agrees with Eliza's description of passive behaviors in our city. During our interview, she explained how back home, if someone was driving the wrong way or not obeying the traffic laws that "it’s just normal to flip them off and go, "hey, fuck you buddy!” You know, pay attention alright? No one ever got offended back home” (Kierstan, Personal Interview, April 8, 2011). Kierstan described to me the Portland mentality that is more laid back, liberal and less aggressive compared to her life in Philadelphia. She is married to a Marine who has travelled back and forth between Iraq and Afghanistan for the last 5 years. She is white, almost 40 and a Culinary Institute of America trained Chef employed at a high- end seafood restaurant in downtown. She also holds an undergraduate degree in biology. Kierstan has lived in Portland, Oregon since 2007 and has managed several restaurants' front and back of the house operations. Kierstan does not like living in the 
city. This self-described "blue collar, country girl” has dreams of one day moving away from Portland and owning a bed and breakfast.

The laid back, less aggressive attitude was noted by Alan as well. He describes: I don't know, there's some very indecisive and overly nice or something. I think people are pretty polite here for the most part and try to be nice to other people. I think sometimes, it can come off like, is anybody going to do anything? Make a decision. Like, who’s going to get in line? (Alan, Personal Interview, April 7, 2011).

Alan moved to Portland 12 years ago from Kansas. He is in his late thirties with an undergraduate degree in English and a graduate degree in publishing from Portland State University. He lives just off NW $23^{\text {rd }}$ with his boyfriend from Nebraska. To make a living, Alan works as a server at one of the premiere Italian Restaurants in the Pacific Northwest. In addition, Alan also co-directs a new non-profit organization in Portland that hopes to travel to other states in order to teach recycling to youths.

The "laid back" way of life mentioned previously by others is mentioned again by Alex as a particular Portland quality. He states:

You can spot someone that doesn't live in a big city. So you can spot me when I go to a big city because I am slower than everybody else...Portland has a different-has a slower pace, which isn’t bad. It's just the pace it is, it makes everything-I guess the standard of living higher (Alex, Personal Interview, March 29, 2011). 
Alex is an unemployed gay Latino man who lives in the North Mississippi neighborhood. He is in his mid-thirties and survives with unemployment checks and under the table cash from DJ gigs and organizing club nights. When asked about Portland residents, Alex emphasized the do-it-for-yourself or D.I.Y. attitude of the Portlanders. Alex views his role as a citizen as a sort of “creator" or an "artisan" who is less concerned with doing something just to pay the rent or make a lot of money. Alex cares more about being the best DJ or having the best club night instead of making money. He believes that many people in Portland view their work in the same manner. He explains:

So every job, people care about everything. I mean, there are so many food carts and everybody cares about their food cart or cares about their job. I guess you know, the more you trickle out of the corporate world, I guess the less you start caring (about money) (Alex, Personal Interview, March 29, 2011).”

For the last three and a half years I have worked a variety of jobs to make ends meet. The first year I worked full time in the service industry as a bartender and restaurant manager. Later, I transitioned into graduate school at Portland State University while working full time at an insurance agency. As a graduate student I spent my first year teaching public speaking and the second year working in external affairs at the U.S. Fish and Wildlife Service. I also worked as a campaign advisor for Sho Dozono’s mayoral campaign, and volunteered at the City Club of Portland and the Oregon Gay and Lesbian Bar Association-OGALLA. Because of my varied work history, I feel like I have seen and interacted with many of the "types of residents" that live in Portland. 
Through my own observation, I do believe that Portland residents tend to be young or young spirited, educated, socially progressive, and environmentally aware. Often times, I feel similar to Georgette, the Chicago native who seems out of place with her four jobs compared to those around her. Many of my friends are unemployed or solely going to school. Others have transitioned out of school and only have to worry about working for a living. Many people that I have become friends with in Portland are creative freelance workers who have their own small businesses doing graphic design or photography. A few make their living hustling the club scene as DJ's or go-go dancers. Many people I’ve met string together a few part time gigs to make ends meet. But rarely do I meet someone like Georgette who works four jobs. Overall, I agree with the above descriptions of Portland residents as laid back, environmentally aware, slower paced, creative, do-it-yourself types who are engaged in their communities and almost always polite.

\section{Thematization}

Freedom

Freedom is a primary theme that has emerged from the eighteen conversational interviews. Each participant offered unprompted descriptions of how they feel living in Portland that often times centered on varying notions of freedom. I asked Jack what he found unique about living in Portland and he responded by saying:

I feel like many Portlanders, you know like, you know, simply have a total freedom and support of the general energy of the city. It's to like, really explore themselves... whether that be a umm, career path, or a creative artistic path, or a 
spiritual path. I feel like people ...feel a real sense of freedom to explore those parts of their lives (Jack, Personal Interview, March 26, 2011).

Delores describes the feeling of freedom in Portland in relation to the way people treat her and how she feels regarding her outward appearance. Delores spent ten years in Germany because her father was in the Air Force. She herself spent four years in the service and now works as an administrator at a federal office in Portland. She worried about being discriminated against for her outward appearance. She described this feeling to me by saying, "Everyone, umm a lot of people told me I would fit in because all my tattoos, because I had friends who have tattoos and they said Portland is just weird and they are open and laid back (Delores, Personal Interview, April 6, 2011).” When asked for a specific example she described how she was treated in Alabama recently when she volunteered for a temporary work transfer to help clean up the oil spill in the Gulf. She compares the South to Portland by saying:

I was there for a month and of course the South is totally different than here. And the looks I got because of my different hair colors and my tattoos. I told a friend I can't wait to get back to Portland where I fit in. It is easy, it is laid back and people don't care what you look like or how you dress or what color your eye makeup is or if your shoes don't match (Delores, Personal Interview, April 6, 2011).

Jack feels the same type of freedom of expression regarding outward appearances. He specifically mentions that residents feel free to wear: 
...handmade clothing, or like local clothing you might find at a vintage store that is, is sometimes tacky or like offbeat. It actually is beautiful in its own way...there's not a fear to wear mismatched clothing or to have a really, like, wacky hair style (Jack, Personal Interview, March 26, 2011).

Jack adds that this freedom is not only just felt by those who are pushing boundaries with their outward appearance. He describes the freedom he feels in Portland by extending it to all citizens by saying, "On the same note, you know, someone can wear something straight laced and not feel like they are being too conservative. You know? I feel like everyone’s kind of, mode of expression is, equally honored by others (Jack, Personal Interview, March, 26, 2011).” Jack lists this feeling of freedom as one of the reasons he moved here from Louisiana. In an excited and grounded voice he smiles at me and says, "I feel...I feel really free to be myself, to express myself...however rings true to me (Jack, Personal Interview, March 26, 2011).”

Lucy feels more satisfied living in Portland due to the freedom she feels compared to her time in Phoenix. In fact, she views the city of Portland as actually providing her that freedom. She explains:

So if I am really interested in food or knitting or anything, it’s here. I can get it. Where in Phoenix, I'd be the only one knitting. There's like one knitting store. And you're just like, is there something wrong with me? So here, it’s a little more validating, I guess? To explore who you are. Who you want to be (Lucy, Personal Interview, April 5, 2011). 
Georgette echoes this sentiment when she offers the reasons for her moving to Portland. She likes "The culture, the life..uhm, the personality of the town...just easy-going people and uhm, options...there's options for everyone.” When asked about what is unique about our city she says, “Overall, everyone’s very open...open to people and ways of life (Georgette, Personal Interview, April 3, 2011).”

Joan also has an all-encompassing description of Portland and the freedom that she feels. Towards the very beginning of our conversation she stressed:

This is the place you can be whatever you would like and let's celebrate being different...the norms of Portland are part of what attracted me to Portland...Progressive and tolerant attitude. I feel like people here are truly invested in making this a good place. People want to be here. (Joan, Personal Interview, April 3, 2011).

Eliza adds:

I think that there are people coming here because they have a vision of how they want to be and they live that out...people treat each other really well...people come here and they have an idea of what they want and they just do it...I'm in on something that not a lot of people are in on...I don't want to say it's a private joke but umm, I feel like I am living in a way that a lot of people my age have no idea about”. She feels fortunate to live in a town that has something for everyone “whether doing city things, or if you are queer or you're straight, or if you're into music or not into music or if you're into sports. I think people can come and do 
whatever they want and live in a way that I think other people don't really live in other places (Eliza, Personal Interview, March 29, 2011).

During our interview, Lucy remarks that she thinks there are a lot of gay people living in Portland. She attributes this to gay people being "accepted" in Portland and a lack of "narrow-mindedness”. She says:

And here, people are open minded and want a better life. They're kinda the Puritans that came from England to move here for a better life...Move here and they’re like ‘Okay! Leave me alone and let me have my happy little life here. That’s how I feel (Lucy, Personal Interview, April 5, 2011).

Jack specifically states in the interview that his decision to move to Portland was part of his coming-out process because "I was really looking to live in a place that, that there would be, umm, a kind of like social consciousness that would allow me to be more comfortable being out and gay” (Jack, Personal Interview, March 26, 2011). I feel similarly to Lucy and Jack. I have met countless individuals who have moved here from other parts of the country and world and upon arrival, only then did they begin to express and live how they truly wanted to be. My partner moved here with his wife and then in this environment, felt free to come out of the closet in his late thirties. A friend of mine that I met in a coffee shop in Southeast Portland has transitioned from male to female in the span of three and a half years. I watched as this person embarked on their own unique journey of self-actualization. This year, that friend who enrolled in school at Portland State University as a single man, graduates as a wife. But not all examples of living this freedom in Portland are that dramatic. 
John expressed a sense of culture shock as a gay man in public after he moved here from Alabama. He describes the differences in living an "out” life in Portland compared to being gay in public in Birmingham. He reflects on his former life by saying: You kind of have to watch yourself and keep some sort of composure at all times. But here, you don't. And so to be in public and have someone kiss me or hold my hand...it is, still kind of like, makes me umm, nervous. It makes me really nervous...so to be here and walk everywhere and never feel afraid, it took me a long time to get over that (John, March 30, 2011).

I share John's uncomfortable feelings towards public displays of gay affection. Sometimes this manifests itself when sharing a romantic dinner in a restaurant with my partner. On several occasions I have even expressed to my roommate that I worry about him when he walks alone. To me, my roommate seems "very gay” by his outward appearance and runway-esque model walk down the sidewalk. I have only lived here for three and a half years; my roommate was born and raised here. He has never had any trouble on the streets and for that matter, neither have I. For both John and I, the liberal and free "way of being" in Portland is something that takes getting used to. For my roommate, it's part of what created who he is. For many, I believe it's what keeps them here.

The freedom felt in Portland is embodied in a myriad of ways. Alan moved to Portland from Kansas twelve years ago and explains how he felt when he first arrived:

There were definitely things about being from the Midwest that I think I had to get over. Or there were differences between the kind of mentality here. Some of it 
was sexual relationship oriented. Like, there was a lot more people exploring polygamy and multiple partner stuff that I kind of had a natural distrust for...Again, another good example, I think perceptions of gender and stuff like that changed dramatically for me moving here (Alan, Personal Interview, April 7, 2011).

Alan clarifies that polygamy is not "his cup of tea" but that he is now more tolerant and understanding of that since moving here. He also explains that before, while living in Kansas, he would laugh and joke about transsexuals and transgendered people and only thought of them as "drag queens" instead of "people that were going through transitioning from one sex to another” (Alan, Personal Interview, April 7, 2011).

The lived experience of freedom in Portland takes many forms. This freedom manifests itself in the citizens of the city in many parts of their lives. The freedom to choose to have a job or remain unemployed, the freedom to dress and look however you want, feeling free to display affection to your partner in public despite the fact that you are a sexual minority or even the freedom to change genders are a few examples of this freedom lived. Throughout all of the interviews, the participants stressed the "mentality" or "way of life" in Portland that affords its citizens the freedom to choose how they live and occupy this space. In many cases, this freedom was given as the reason they chose to move to Portland.

Proximity

The second theme to emerge from the interview data was that of proximity. Proximity is defined by the Oxford English Dictionary as "nearness in space, time, or 
relationship”. Proximity as a theme clearly emerged through the participants descriptions of their lived experience in Portland, Oregon. No matter what neighborhood they lived in or mode of transportation they used to move throughout the city, Portland residents describe "being close to everything" as a benefit to living in their neighborhood. Stan has always lived in the Southeast when asked what he liked about where he lived he answered, "Just the shops, the proximity is the main benefit from where I currently live. Its twelve blocks from downtown. It’s just accessible” (Stan, Personal Interview, April 5, 2011). Brock lives in the same neighborhood as Stan and adds:

You can get around very easily walking or biking. A lot of things are pretty near and at your disposal...I guess this is true of all of Portland on your bike or on the bus, nothing is really too far away (Brock, Personal Interview, April 3, 2011). Proximity as a theme relies on being near something of use or value to the resident of the neighborhood being described. Many of the descriptions mirrored Joan's who lives in Northeast. She says, “Close proximity to downtown for sure. It's a block away from a grocery store” (Joan, Personal Interview, April 3, 2011). Georgette lives in a different neighborhood yet her description of her neighborhood's benefits closely resembles Joan when she explains that its, "Pretty quiet, but yet close to a lot of things that are popular, like the food carts, Belmont, Hawthorne, Laurelhurst Park...Uh, close to everything...restaurants, shops, coffee shops, umm-you can bike anywhere really” (Georgette, Personal Interview, April 3, 2011).

John lives in North Portland near the Mississippi neighborhood and describes his neighborhood as: 
...kind of like a small town in the middle of the city. It is kind of isolated. It is just, like, a stretch of four blocks that look like a tiny town, but then you can look right down the hill to downtown Portland so it’s sort of surreal...everyone here knows everyone else. Just sort of like a small town. You walk everywhere and everything’s right here within a few blocks (John, Personal Interview, March 30, 2011).

Alex lives in the Mississippi neighborhood of north Portland and uses mostly a car throughout the year. With nicer weather he rides a bike to get around the city. Alex agrees with John that their neighborhood is “Close to downtown but it’s kind of hidden away” and he also mostly just sticks to his own neighborhood (Alex, Personal Interview, March 29, 2011).

Daisy resides above the Northwest $23^{\text {rd }}$ street neighborhood and also describes proximity as a benefit to her everyday routine. Like Georgette, John and Alex, she likes that her neighborhood is close to but apart from what she desires. These residents all want proximity to things such as downtown, shopping, and entertainment. She says:

I like being able to walk anywhere. To the shops and the restaurants. I love being so close to the park. I like the view. I like being up on the hill. I like being removed from the hustle and the bustle but being really accessible to it.

Like Daisy, Alan lives in the Northwest neighborhood. He explains the benefits of living in his neighborhood. His explanation is so similar to many of the other research participant's answers that it is more about the way of living in Portland rather than the benefits of living in a particular neighborhood. Proximity to everything that one could 
want and need is a major theme that emerged throughout the discussions I had with the research participants. People from each of the major neighborhoods were included in this research but they all offered nearly identical descriptions much like Alan’s:

It's a shopping area. I live really close to a shopping district. There's a lot of little coffeehouses and restaurants and boutiques and stuff like that...I think it's convenient. It feels very alive and active. There's a lot of stuff going on. It’s very convenient for public transportation...there's a lot of grocery stores that are close within walking distance. There's a lot of stuff that's in walking distance that I don’t even need to take a bus to get to. (Alan, Personal Interview, April 7, 2011) Jerrod, from Kansas City lives in the South Tabor neighborhood in Southeast Portland. He likes that his life in this neighborhood is quiet, and close to Mt. Tabor but he would prefer his house a little closer in. When asked if he works near his home it became clear that his sense of proximity had shifted in Portland. He describes:

Stephen: And do you work near your home?

Jerrod: Uh, it’s hard to say, compared to where I used to live in Kansas City, yes. But I think Portland standards, not as much.

Stephen: Can you explain?

Jerrod: Umm, well in Kansas City, you have to drive everywhere, umm, and I think I worked, I used to work 13 miles from my house....When I lived in Kansas City....or otherwise I would work probably five or six miles, I think that is a more typical distance, five to ten miles. Whereas in Portland everything is a lot closer together so I would think of two or three miles being kind of a longish way and I 
don’t know, I suppose I live about a mile and a half or two miles from my work, which means, I mean it turns into a half hour commute, but I really earmark about 45 minutes for my commute. So that's about an hour and a half every day.(Jerrod, Personal Interview, March 30, 2011.

Stan likes the way he feels living in Portland. Proximity is very important to the way that he has ordered his life. So much so, he and his girlfriend have considered giving up their automobile. Stan rides his bike across the Hawthorne Bridge every morning to the Trader Joes in the Alphabet District of the Northwest. When asked if he worked near his home Stan said, “Near enough to where I can ride my bike. I work 30 blocks away, some 30 odd blocks away. 35-40 blocks away.”(Stan, Personal Interview, 4-5-11)

Most Portland residents I interviewed described their neighborhood in proximity to the downtown, shopping and entertainment. Often times, the participants reported a belief that their neighborhood had everything they needed. Many also indicated that if they tend to stick to their own neighborhood and that you see a lot of the same faces. Lee, commutes to school by bus. This clinical science student studying at OHSU summarizes the theme of proximity when he describes his ideal transportation:

Ideally, like, I would like to have everything within walking distance. Ideally, I would like more within the short public transit trip or bike trip you know? My ideal world would be, my neighborhood would have just everything I needed and I wouldn't have to go out unless I really wanted to get out of range. (Lee, Personal Interview, March 26, 2011). 
Kevin describes his experience of living in Portland and the reason behind the feeling of proximity to downtown, shopping and entertainment. He describes Portland as:

Umm, like a sleepy little town on a larger scale, you know? Part of the fact that it has all the different neighborhoods that it does that are pretty distinct, you know, lots of cities have neighborhoods but not often as distinctly different and sort of functional on their own as Portland's neighborhoods are. And in Portland, the neighborhoods have their own identity and I think that, umm, people tend to kind of live in a neighborhood, work in a neighborhood kind of state. Stick to their neighborhood a lot and I think that provides a real small town feeling because you're not constantly working on the full scale of the city like you would be in some other major cities. (Kevin, Personal Interview, March 30, 2011)

\section{Comfort}

When research participants were asked to describe their neighborhood and how it feels to live there, a clear theme of comfort emerged. The theme of comfort was expressed in different ways and also in response to other questions or points in the conversational interviews. For example, participant's descriptions connected comfort to issues of feeling safe or a liberal mindset. Alex described how he feels living in Portland by saying, "It feels-it’s comfortable. Right now, it’s very comfortable to live here.” (Alex, Personal Interview, March 29, 2011). Lee describes his neighborhood as "good and cozy” and later, “I just think it’s really sweet” (Lee, Personal Interview, March 26, 2011). Brock lives nearby Lee and describes the way he feels in his neighborhood: 
Feels comfortable. It feels like maybe because it’s Sunday and I went out walking today but it kind of feels like rustic Sunday all the time. Just the feeling of the houses and everything else. It feels like Sunday on the farm, even if you've never grown up on the farm. (Brock, Personal Interview, April 3, 2011)

Kevin describes the Buckman neighborhood in southeast Portland as, "inner city, high density, very walkable” (Kevin, Personal Interview, March 30, 2011). When asked how it feels he described it as, "Umm, it feels comfortable in that it's very safe and accessible and kind of anything you need is nearby and readily available” (Kevin, Personal Interview, March 30, 2011).

Jerrod describes the ways in which Portland residents comfort themselves. His explanation of comfort extends beyond the feeling of a particular neighborhood and instead is more inclusive of the ways in which residents choose to live their lives. He explains:

Jerrod: Umm, it feels like a pretty big consumer town, it feels really...I realize that there's a lot of people that are D.I.Y. and sort of trying to umm, like, do more with less, but it also feels...I get a real strong like, creature comfort sense about Portland. That Portland really likes to be comfortable. 
Stephen: How are people doing that? How are they comforting themselves?

Jerrod: Umm, I think through umm, there's a lot of pot here, there's a lot of drinking, there's a lot of Apple products, like smart phones, there's a lot of people with laptops like looking for YouTube fun things, you know, it’s like, entertainment. It’s all kind of entertainment. (Jerrod, Personal Interview, March 30, 2011).

This feeling of comfort also stems from the progressive or liberal mindset described by the research participants. Joan explained how she feels living in Portland as, "Pleasant. One thing I really like about Portland which perhaps some people would see as a negative is that I don't have to have unwanted arguments with insane conservative people which I am really grateful for.” (Joan, Personal Interview, April 3, 2011). Cindy describes the feeling she has living in Portland as, "Exciting...eyeopening...refreshing...mmm freeing....relaxing....very relaxed town.”(Cindy, Personal Interview, April 6, 2011) Lee, a Kansas transplant also finds comfort in the liberal mindset of Portland. He describes his feelings the following way:

Yeah, ya know, I really love living here. I love this city, umm, let's see for me I think Portland is a really great town. I like, the people here are really nice, you know. Its umm, I think it has a lot, umm, it’s very liberal which fits more with my mindset and my attitude towards umm, 
politics and towards, umm, what I'm looking for, you know? Umm, it really appears there's more opportunity for me here and in a lot of ways I feel more comfortable living here than say, living in the Midwest where I came from. (Lee, Personal Interview, March 26, 2011).

The theme of comfort also includes notions of safety. Participants described Portland as laid back, easy going and comfortable in part due to the lack of danger. Delores said, “I feel safe. I don’t feel there is anything bad going on. I feel if I leave my door unlocked, nothing is going to happen.” (Delores, Personal Interview, April 6, 2011). Residents expressed feeling comfortable in terms of not feeling threatened or in danger. Brock describes his feelings of comfort:

I guess mainly because I feel the absence of danger. I've never, it seems like that's something that you hear about, like how safe is the place that you are going to, that's something that's in your mind and for the longest time, I've just never had it in my mind that I really have to like, look over my shoulder no matter what part of town I'm in. I can't remember the last time I've been scared...I just don’t feel, I never felt it. I feel comfortable and so I guess more so than feeling safe. Like, what is safe but how much you don't feel that you're in danger? I've never felt it here. (Brock, Personal Interview, April 3, 2011). 
Comfort and Gentrification: My Observations on East $31^{\text {st }}$ Terrace to Southeast PDX I lived for eight years in the "inner city” or urban core of Kansas City, Missouri. I attended an Urban University and volunteered for KC-Debate, an urban debate league for at risk youths in public high school. Upon graduation, I worked as an assistant debate coach at a community college in Kansas City, Kansas. My time in Kansas City was spent working with at risk youth, many of them African American. Having lived now, in these two large metropolitan American cities that both straddle state lines, I have observed vast differences in the lived experience of each place, the prominence or absence of race in this feeling of comfort or discomfort in the city and also moments where the intersection of the LGBT community contributed to gentrification of historically African American neighborhoods.

In Kansas City, I rode public transportation as well. Specifically, I took the Troost bus to school every day. Once, on my way to class, a man boarded the bus and robbed everyone on at gunpoint until he exited from the back door of the bus. My neighborhood was a high crime, predominately African American neighborhood. I observed and talked with others about how suburban sprawl and white flight caused strong, historic African American neighborhoods to endure new inequalities such as divestment from the urban core, sub-par schools because of the lack of taxed based funding and highway construction to connect the suburbs that ripped through historic downtown neighborhoods. To me, economic retreat from the urban core combined with a fear of crime created numerous inequalities and hardships for the urban core. 
I moved to this part of Kansas City to live with my boyfriend at the time. Our rent was \$175 dollars a month and for someone in their early twenties, the price was definitely right. Our rent was so low because our landlord, another gay man, bought the house for $\$ 30,000$ through a city subsidized first time buyer homeowner program. Not to mention, the price was low because most people were fearful of living in that area. Our whole street, East 31st was owned by gay men except for one house. Large numbers of gays and lesbians bought homes in the surrounding neighborhood. I didn't feel safe or comfortable living in this part of town. I avoided the drive through ATM in my neighborhood because I had been approached by the same man, multiple times when I tried to use it. My house was broken in to when a contractor left a ladder unlocked in my fenced back yard. Once, while watching the television show Cops, I ran to the back window because that episode featured the KCMO police chasing someone through my alley (show was not live)! Car windows were smashed, gunshots fired, and drugs and women's bodies were being sold and consumed all around me. But many other things were happening there as well.

I learned to garden on east $31^{\text {st }}$ street. My roommate was an older gay man who taught me everything I know about plants and contemporary art. I also cultivated my first true love, and lived for 8 years in that house, on the "gay street” in Kansas City Missouri. I was able to live cheaply while finishing my undergraduate education and could afford to volunteer my time in the community. My neighbor’s Don and Tracy were a committed gay couple that had been together for 28 years. This community, our tiny street was rejuvenated by this couple when they bought four buildings on the block. They provided a "bubble" for the rest of us to feel at home or comfortable. They rented their apartments 
to gay couples when other buildings wouldn't. This tiny stretch of houses, a one-way street off of another one-way street, in the urban core was part of the slow gentrification of the surrounding area. Don and Tracy had an empty plot of land that the neighborhood used as a community garden. There was a real sense of community on this street. As the years passed, more and more of the community gentrified. Now, young straight couples bought homes in the area and looked to start their families. The city utilized imminent domain ordinances to tear down a neighborhood behind mine. All of a sudden, I lived half a block from a Home Depot, Costco, Super Cuts, a cell phone company, a national chain deli and physical therapy office. Gentrification or urban revitalization was happening all around in Kansas City.

In Portland, I do feel the sense of "comfort" and safety that was previously described by many of the research participants. For me, because of my experience in Kansas City, I am aware of the "whiteness" or absence of fear from "non-whites" that accompanies this feeling of comfort that many enjoy in Portland. The participants in this research also describe the average Portlander as white or acknowledged the gentrification in their neighborhoods. When asked about the significant problems facing Portland Kevin remarks:

Umm, I think probably equity. You look at, there’s certain groups in Portland who have just fallen way behind and have been sort of left behind. Umm, you know really. And these aren't unique to Portland, these are across the United States, umm you know, high dropout rates, umm, declining 
income levels, umm, loss of property and capital and just decreased quality of life. Whereas other people have seen an increase in that and that burden has largely been felt by the communities of color and people with disabilities and umm, probably seniors too...Umm and you know there's a lot of planning you look at, like, there's just a lot of unfair distribution of resources that happens at a city level. So you have for example, a huge chunk of the city that lives in East Portland yet it doesn't have sidewalks or it doesn't have streetcars and you know walkable amenities and things like that that make the inner city really livable. So it's sort of like, uhh, takes into question equitable distribution of government resources. (Kevin, Personal Interview, March 30, 2011).

Jerrod, another participant who lived in Kansas City like me adds, "Umm, it’s really White here. That's, uh, I don't know if I am really saying anything new that other people, yeah...so it’s really white.”(Jerrod, Personal Interview, March 30, 2011) Eliza, a person of color herself describes her neighborhood and gentrification in North Portland. She moved to North Portland because she had friends that lived in that part of town. She describes her neighborhood as being a mix of older residents, families, older African American residents "who have lived here historically" and a "bunch of people who are, you know, younger, we have younger families who have moved here from other places." 
When she first describes her neighborhood she states, "I like the fact that we have people of color here, that makes me feel more comfortable as a person of color myself.” (Eliza, Personal Interview, March 29, 2011). When I asked Eliza a follow up question about how she feels living in the neighborhood, her earlier description was clarified and complicated by these remarks:

I feel pretty good here, umm, it can be a little dangerous at night.(laughs) Umm, this area that I live in has been, is recovering from a period of really, umm, really deep economic hardship. The prostitution was really, there was a high level of prostitution happening here, a high level of crack houses umm, and drug dealers and prostitutes. Its kinda recovering from that but still has a bit of that. And that's kinda the reality, the day to day reality that there's people using and you can see their using and prostitutes get arrested and you know, pretty frequently, even when I have been walking home at night cars stop thinking I'm a prostitute...you know, I don’t feel like I am in danger every day, there has been a couple of times that I have been creeped out and freaked out but I never feel like I was in danger on a daily basis. (Eliza, Personal Interview, March 29, 2011). 
Not all discussion of the gentrification and the effects felt by those living in those communities are described as overtly as Kevin, Jerrod and Eliza describe them. Some of the research participants mention the neighborhood gentrification in a more positive light. John, a gay man describes the benefits of his North Mississippi neighborhood as, "Umm that it is, up and coming, that it is not that expensive yet. That it has come into a really large gay community.” (John, Personal Interview, March 30, 2011). Alex, a gay man of color describes this same neighborhood as “pretty” and “new”. Alex mirrors John’s description when he describes their neighborhood as, "It's an up and coming, gentrified neighborhood in Portland...the block I live in is very new; new stores, new-you know, kind of places that cater to people with incomes that generally weren’t here ten years ago” (Alex, Personal Interview, March 29, 2011). Alan describes his northwest neighborhood as “It's an old neighborhood that gentrified probably a couple of decades ago.” (Alan, Personal Interview, April 7, 2011). Lee, a gay man who lives in North Portland describes his neighborhood and the gentrification happening as something very similar to my experience in Kansas City. He states:

It feels like, umm, a neighborhood that is kind of in a transition. Uh, there's, one of the things I like about it, is that there (pause )it's a very mixed population. There are like, about you know, an equal number of black and white people represented, umm, from different kinds of backgrounds. It, and it feels very young and vibrant. Over the last, uh, five years a lot of the local businesses have 
been popping up and food carts and, umm,there’s like little local businesses started by, ya know, young people. So there’s a lot within walking distance. It's also been called by my friends the "gayberhood” because there’s like flocks of gay people kind of moving in because you know the housing is, it's less expensive than other more parts of town. (Lee, Personal Interview, March 26, 2011)

The theme of comfort and discussions of whiteness and gentrification emerged from casual, informal conversations regarding Portland. The focus of my research is on the lived experience of Portland residents in relation to climate change. Through conversations leading up to discussions of climate change and the participant's everyday behaviors, the theme of comfort revealed itself in response to different questions and subject matters. Because this was not the sole focus of my research efforts, the description of comfort should be seen as a conversation starter or a starting point for future phenomenological descriptions. The theme of comfort that emerged includes a general feeling participants reported having from just living in Portland, to feeling comfortable in a particular neighborhood, or comfort living in a liberal place or physical comfort due to the absence of danger. These discussions prompted me to reflect on my own feelings of comfort as a gay man living in Kansas City compared to Portland, Oregon. Taken all together, any description of the comfort I feel in Portland must be in relation to both my white gay identity and the gentrification of my lived space.

\section{Connection to Nature}


Another theme to emerge from my conversations with Portland residents was the connection to nature that people in Portland feel. I arrived in Portland on a greyhound bus from travelling from Seattle. The view from my window was otherworldly for me at the time. The environment I left behind, the plains of Kansas, were not as green or aweinspiring. The mountains were magnificent and foreign to me as well. Driving through the Colombia River gorge into Portland, Oregon was my first connection to my new natural surroundings. I spent the first few weeks hiking, visiting the ocean, and exploring my inner southeast neighborhood. It was late summer, and to me, it felt like a magical place. Brock, a fellow Midwesterner believes that his surroundings in Portland make him happier.

I just feel better...I like looking at green all around me. I like the fact that you can see hills...We're in the west coast and that means so close to the ocean. I think maybe just knowing that and experiencing the ocean and knowing that you're so close to it, I think it just...you learn what it means to live on a coast and you experience it for yourself. Being so close to the ocean, I think experiencing the ocean changes people...it's just awesome to look so far and as far as you see, it's just a fraction of how far it keeps going. It's one of the things of nature that humbles a person. (Brock, Personal Interview, April 3, 2011). 
Lee lists the "trees and the nature" of Portland as one of the first reasons why he moved to Portland. (Lee, Personal Interview, March 26, 2011). The first thing Eliza mentioned when asked about her neighborhood was how beautiful it was because it was “tree lined”. (Eliza, Personal Interview, March 29, 2011). Delores quickly mentions the trees as well when asked to describe her outer southeast community. (Delores, Personal Interview, April 6, 2011) Lucy, who lives in the heart of the downtown Pearl District, is just as quick to mention the "beautiful, hundred year old trees” right outside her doorstep. (Lucy, Personal Interview, April 5, 2011). Jack commented to me that he misses the big beautiful trees of his old neighborhood in the Southeast. He still described a connection the environment when he said, "Just to be able to, you know, to move around Portland and see all the various trees and shrubs and other plants that are displayed in People’s gardens, Umm, it’s constantly inspiring and affirming for the spirit.” (Jack, Personal Interview, March 26, 2011)

A strong connection to nature via the land also emerged from my interviews. Kierstan, the die-hard Philly girl who works as a chef described her connection to the land and herself by saying that:

I'm always outside growing things and stuff and it's like there's a difference in your everyday life on how you feel and on how your shits growing and it's yeah, I've always been aware that we're slowly destroying ourselves and this planet” (Kierstan, Personal Interview, April 8, 2011). 
When discussing what climate change looks like, Stan related his understanding of climate change to his own experience gardening by describing "the real or failed crops. Like last year, we had a little garden and the garden sucked. It's like unseasonable weather definitely affected the growing of produce.” (Stan, Personal Interview, April 5, 2011). Brock lived in a dormitory for most of last year yet still managed to connect with nature through the growing of food for his own consumption. I had never heard of anyone and the following description was very surprising to me:

In my freezer I kept seven and a half pounds of at least ten different kinds of sprouting seeds. I just got really big into that, sprouting in particular, container gardening. I didn't have the benefit of having a fantastic window...So I got south, southwest sun. So I just put in a little container garden...I loved it. Everybody should have a green thumb these days. People have really lost that but I think that we should be getting down and getting your hands dirty and watching things grow, bringing things to life from seed. It’s so inspirational. I think it really kicks up something creative and nurturing in people. (Brock, Personal Interview, April 3, 2011)

The strongest and most vivid connection to nature via the land was described by Lee. He shares a garden with his partner but also has his own community garden plot. Lee was on a waitlist for over four years for this particular garden plot. His description 
centers on community, the richness and history of the soil, and the spirituality and oneness with what he cultivates and digests:

I have four hundred square feet there, and it's really quite nice and its terraced and you know it's, (pause) The great about it is I think it’s been a kindergarten for probably thirty years or more so that's, I mean a continuous amount of working of that soil. I mean, the soil is really good. It's nice to be in that community group,...and share gardening tips and what not and help each other...You know, it’s really important to me to have as much food you know from the local areaas possible. Not just because that food is, I know its organic and good, because that's the food that is living right here with me in this neighborhood and the relationship I have with these plants by feeding them, by nourishing them and giving them what is necessary to thrive, they in turn give me the things that are necessary to thrive. And having them grown and having them live their lives in this very area, this very block that I live on, they have those adaptations, those things within them that make them uniquely suited for this spot, and somehow by eating those things, I am more suited for this spot. And I'm better, more fit, umm, you know, it's a multi-level kind of thing. 
It’s kind of a spiritual thing, a connection. (Lee, Personal Interview, March 26, 2011).

The last and most prevalent connection to nature behavior described by residents of Portland was the connection to nature via the sun. Every Portland resident lives for a day with sunshine. Every interview participant mentioned the summer, the sun, and the lack of sun as influencing their behaviors and mood. Kierstan mentions that When it's gorgeous out, like in the summer months I do get energized because you know when you're outside its clean...So I do feel energized when I do go outside...it’s not all about museums and being indoors and stuck inside. Get your fucking ass outside and go do something and then go hiking and all that kind of stuff. (Kierstan, Personal Interview, April 8, 2011).

Alan adds, "In the summer I feel really much more energetic and active with friends and socially connected. In the fall/winter I kind of get a little more seclusive and stay at home more and don't go out as much.” Alex echoes Alan’s description explaining that his life in Portland is seasonal and that he feels more energetic during the summer. When asked why he ended up moving to Portland in the first place Alex remarks, "It was beautiful-it was June-it was just like everybody was very happy.”(Alex, Personal Interview, March 29, 2011). Delores feels like Portland's mood depends on the sun. She describes this connection to nature as "When it is nice and sunny outside, you can tell everybody is so happy. But then when it switches to the rain, it is so miserable.” (Delores, 
Personal Interview, April 6, 2011). John adds to the description of the summer season or the sunshine affecting the energy of the city when he explains, "The spring is the hardest time to live in Portland because you know what the summer can be...its not warm here so we keep waiting for it so everyone is sad right now or anxious.” (John, Personal Interview, March 30, 2011). Jerrod explains, “In the summertime it is beautiful, it’s a wonderful place to be, it's such heaven on earth in the summer, in the winter time which is a long season...I'm about ready to move out of Portland permanently.” (Jerrod, Personal Interview, March 30, 2011).

I have never been so affected by the lack of sunshine in my life until I moved to Portland. I became more aware and connected to the sun and the summer months due to my new climate. For the last three years I have been fortunate enough to travel to the sun during holiday break from school. My family didn’t understand why I stopped coming home for Christmas once I moved to Portland. It wasn't until the years passed and we had numerous phone calls of "yes, it's still raining" or they visited me and saw firsthand how relentless the rain and lack of sunshine in the Pacific Northwest can be. I am not surprised when I see the suicide prevention signs on all the bridges crossing downtown. To me, there is a connection to the weather. Eliza shares in my frustration: The weather is getting to me and that is really hard. I have been seriously considering you know, living down south for a period of time and then coming back up here. You know, taking extended time away from the roughness in the winter time. (Eliza, Personal Interview, March 29, 2011). 
Not surprisingly, a fellow Kansan, shares in my earlier description of feeling connected to the sun and the seasons. Lee states:

The climate can be severe at times. Umm, I generally like it and, but I energetically feel very sun-centered in a funny way. When the sun's out, I'm happy. When it's not out, I don’t necessarily feel unhappy but my mood is very linked with the sun now and that is a new development from living in the Midwest where it wasn't...it's just my life wasn't so connected to the sun...I feel like my life is very seasonal here. When its summer the focus really is being outside and enjoying the natural beauty of the world around here...(Lee, Personal Interview, March 26, 2011)

The connection to nature theme encompasses the connection that residents have with the trees and plants of our community, the soil in their gardens, and the connection to the sun or lack of sun. This connection to nature was described as some as both the reason they moved here, and also a reason to locate elsewhere. Portlander's love to complain about the rain and the weather but our connection to nature actually structures our daily experiences. Participants described having more energy, being more active and social as a result of being connected to nature in some way. In addition, participants described spiritual connections to nature through the soil that they work or the awe inspiring experience of their surroundings. The connection to nature theme is not simply a whine about how it always rains in Portland or how last summer was too short. Instead, 
the connection to nature theme describes the structures of Portland residents' experiences and the different ways that this connection to nature manifests itself in their behaviors, mood and view the world.

\section{Green Pressure}

\section{Recycling}

The everyday routine of Portland residents is full of both environmentally friendly and harmful activities. Upon arriving in town and signing the lease to my new apartment, my landlord gave me a half hour lesson on recycling. This lesson was very in-depth and even included a tour of our building's area for trash, yard debris, and the separate containers for glass and then other for plastic and paper. The lesson was not a mere suggestion from my landlord of what I should be doing as a tenant but rather an expectation that this was the way things were done in Portland. I only re-used paper before moving to Portland. I did not recycle when I lived in the Midwest and to be honest, I still get caught by roommates throwing away items that should be rinsed out and put in our recycling container under the sink.

Not surprisingly, every Portland resident I spoke to for this research inquiry reported recycling as an environmentally beneficial behavior that they engage in every day. Kierstan, without hesitation states, "I recycle. I make a conscious effort to recycle...I do make a conscious effort to do the little steps that I can.” (Kierstan, Personal Interview, April 8, 2011) Alan responds the same way to Kierstan who drives a car for her primary transportation. Alan takes public transportation. (Alan, Personal Interview, April 7, 2011) Lucy gets very emphatic when I ask the question about what eco-friendly 
behaviors does she engage in daily. She says, "I swear to God I take out the recycling three times more than I take out the trash.” (Cindy, Personal Interview, April 5, 2011). Daisy also listed recycling first as an answer to this question. (Daisy, Personal Interview, April 5, 2011)

For Joan, she doesn’t even mention that she recycles until I ask her about it. Instead she lists not having a car and not leaving appliances plugged in. I ask if there are other daily behaviors that help the environment that she engages in and she responds, “Nothing comes to mind in particular”. When asked about recycling, she then explains she recycles paper, plastic and glass both at home and at work (Joan, Personal Interview, April 3, 2011). Jerrod had a description of his everyday eco-beneficial behaviors similar to Joan's. He has recycled for years yet he failed to mention this behavior until I asked about it. Once asked he explained what he recycled and that he tries to buy food items in bulk to minimize the packaging in the first place ( Jerrod, Personal Interview, March 30, 2011).

Lee responded with recycling as a daily behavior that he engages in and also gave a detailed description of how they modified their household trash service pick-up time which made them more aware of their waste:

Well umm, we get trash pickup once a month and so all the little bits of plastic that aren’t normally taken by the normal recycling, something that normally wouldn't be accepted, we collect. Like the clam shells and that stuff and plastic bags and we recycle that by hand at New Seasons. So 
generally, we try to minimize our trash in general, and umm, you know umm, recycle as much as we can. That way, we don’t fill up our trash bin which is only taken once a month...I mean we started weekly so we decided to try monthly and you know, it really worked and you find that you don't create as much trash and you're conscious about it. (Lee, Personal Interview, March 26, 2011).

John describes how he pressures or polices others in his home and at work to be better about what they are throwing in the trash bin:

John: We compost, we recycle, even though one of my roommates is not recycling completely, which is insane to me. I’m like, "how could you not recycle this?” Stephen: Do you find things in the trash and do you recycle things for him? John: Yeah, Yeah. Stephen: Ok. So you police the house?

John: And at work too. Which, my work doesn't do anything which is insane!

Alex shares John’s sentiments that “At this point it’s just very easy. Like you know before recycling it all seemed just very easy to throw everything away in just one big trash can. But now that seems weird.” (Alex, Personal Interview, March 29, 2011) 
Brock also adds, “I like to think everybody recycles these days but I don’t see it” (Brock, Personal Interview, April 3, 2011).

Jack describes his experience of moving to Portland from Louisiana and how it changed his everyday behavior. His description adds to the other participant's comments of recycling being especially easy in Portland and even expected when he states: Jack: Umm, and then there is recycling. (pause) You know, umm, cardboard and glass and metal is made really easy in Portland because we have great, recycle, like, the metro recycles a lot.

Stephen: Did you do that in Louisiana?

Jack: Oh no, in Louisiana there's almost like, no consciousness about recycling. I don’t think- I think there might be a building, like somewhere in the city where I grew up that there's a place where you can take your recycling to, but, I think most people don't know about that. (laughs)

Stephen: So this was a new behavior for you? Jack: Yeah, definitely, this is a new behavior, umm since moving to Portland. That like, I was definitely (pause) you know, I guess something that umm, I was really happy to participate in when I moved to Portland. So, it’s not something that I necessarily felt, uh, I felt pressure to do, 
because I was like excited and it was simply so easy. But I

guess, you know, that's something someone could feel

pressure to do upon moving to Portland.(Jack, Personal

Interview. March 26, 2011).

Jeff describes recycling as a norm of the city. He describes watching other people move to the city and says

There's an adjustment period for like-things like recycling are very important here to a lot of people. And they make it so easy and a lot of people still have a tendency to throw things away that are more appropriately recycled and that's considered pretty much negative by most people. (Jeff, Personal Interview, April 5, 2011)

\section{Transportation}

The participants described a wide range of environmentally beneficial behaviors that they engaged in. Not using an automobile by walking, biking or taking public transportation was cited by almost every participant. Out of the 18 participants in this research, 13 reported owning a car. Five of those car owning participants use their car for the majority of their transportation needs. In other words, they rarely take public transportation or ride their bikes to move throughout the city.

The participants described their everyday transportation behaviors to me. Many combinations of transportation were reported by the participants. For example, Daisy shares a car with her husband so she will either walk or ride the bus to wherever she 
needs to travel. (Daisy, Personal Interview, April 5, 2011). Lee owns a car and so does his partner. Like daisy, they travel together in one car but he primarily commutes 45 minutes to school each way. He describes the choice he makes for his daily commute: Stephen: How do you move throughout the city? What is your main mode of transportation?

Lee: Right now I'd have to say it’s a bus, but umm, you know, I do drive. I have a car, umm,I drive maybe once or twice a week...we do drive when it comes to getting groceries and stuff like that and large trips or like going out...Ideally I would like to have everything within walking distance...my ideal world would be my neighborhood would just have everything I needed and I wouldn't have to go out unless I really wanted to get out of range. (Lee, Personal Interview, March 26, 2011)

Cindy and Delores both use a combination of park and ride. Delores drives from her outer southeast neighborhood to a max station and then rides the train to the Lloyd district to her job (Delores, Personal Interview, April 6, 2011). Cindy drives from Multnomah Village in the Southwest to the Rose Garden and rides the Max three stops to her job. She explains that she rides the Max only because parking is free at the Rose Quarter. (Cindy, Personal Interview, April 6, 2011) Lucy and Kierstan drive every day and it is rare for either of them to ride any public transportation. (Lucy, Personal Interview, April 5, 2011, Kierstan, Personal Interview, April 8, 2011).Jack primarily uses 
his car to commute to work. He wrecked his bike last winter and has not replaced it yet. Almost guiltily he adds:

My ideal mode is by bike, but umm, but like I feel like having a car sometimes makes me a bit lazier...like I might sleep in until the last possible chance then might know the car will get me there on time...sleep over, you know, commuting by bike. (Jack, Personal Interview, March 26, 2011).

Alan relies on a combination of public transportation, walking and zip cars. He lives in the Northwest $23^{\text {rd }}$ street area so he rides both the bus and the streetcar. Last year he owned a car and experienced something very similar to Jack's previous description. Alan explains:

The thought of having a car is always nice because it's easier to get around but I really appreciate not having to spend all the money on it. There's a lot of complicated answers when it comes to that. I'm pretty content with not having a car. ..I kind of found that when I had it, I was using it too much for things I didn't need to. I'm really used to just getting around, walking and stuff. It’s nice to be able to just rent cars when you want them, for the weekend or whatever, to get out of town.(Alan, Personal Interview, April 7, 2011). 
Jeff relied solely on a car until recently. He now rides his bike and public transportation. He likes that "the blocks are pretty small so it’s easy to get around quickly; so you don’t spend as much time travelling. (Jeff, April 5, 2011). Brock actually sold his car to finance his move to Portland. He has lived here for nine years and he travels through the city "Mostly on foot, bike and bus" and that his ideal form of transportation would be his bike. He say’s “I don’t really have the need for a car.” (Brock, Personal Interview, April 3, 2011).

Georgette does have a car but she reports to me "in the winter I generally drive, and then in the summer I'll try to bike a lot more.”(Georgette, Personal Interview, April 3, 2011). Kevin is another with a car who makes the choice to bike and utilize public transportation based on the weather. He describes his transportation behaviors:

Stephen: How do you move throughout the city? What is your main mode of transportation?

Kevin: Ahh, well, I mean I have a car but I bike and walk a lot when the weather is nice so it's hard to say what the runner up is, I mean, I never drive to work so if your talking about my work transportation it would be bus followed by biking.

Stephen: Ok. When would you use your car?

Kevin: Like if it is dumping rain and I have to go somewhere in the middle of the night, or, if I want to get out of the city on a weekend or something like that. 


\section{Portland Pressure}

Jack and Lucy all mentioned feeling pressured to bike instead of using their cars. Jack tells me that "I have a lot of friends that ride bicycles, even to and from work, from ya know, relatively kind of large distances in my mind.” (Jack, Personal Interview, March 26, 2011) When asked if she feels pressure to conform to any norms of Portland, Lucy quickly and clarly states:

I feel very pressured to bike and not use my car...Like when I lived with my five roommates and I was the only one with a car. It was like, "Why are you taking the car? Blah blah blah blah blah!” ...I will do other things to make up for my car like composting, recycling, or eating local. So I would say that is the one thing that I do feel guilty about...having a car and driving it. (Lucy, Personal Interview, April 5, 2011)

Alan feels like "recycling and sustainability and stuff like that" are a norm in Portland. He mentions that he felt that it was voluntary where he lived in the Midwest “whereas here it’s expected” (Alan, Personal Interview, April 7, 2011). Stan doesn’t feel any “overt pressure” but more like "willful assimilation” into a green Portland culture. He describes this feeling as:

Here it's kind of taking that left mindset and kind of making it the main dominant paradigm of people. Do you know what I mean? It doesn't feel so fringe anymore to be, 
it doesn't feel fringe to be a cyclist, farmer’s market goer because that has kind of become the norm. (Stan, Personal Interview, April 5, 2011)

The pressure to be green or sustainable is also felt by Kevin. He works in an office that deals with environmental issues for the city of Portland. Something like grabbing a cup of coffee makes him the feel guilty. He expressed said, "I feel really guilty about having that paper cup” and to him that guilt is contextually based.(Kevin, Personal Interview, March 30, 2011) Lee also feels like the pressure is subtle and depends on the context of the groups you associate with.

There is a lot of subtle pressure-there's a Portland culture here. There’s a real greenness and recycling and umm, a certain pragmatic sort of, (pause) I would say active awareness about how to approach environmental issues that are coming... (Lee, Personal Interview, March 26, 2011)

Kierstan doesn't buy into the pressure to be green in Portland. Her dismissal of other's intentions does however help describe the general feeling or expectations around environmental issues in Portland. We have an interesting back and forth in a coffee shop in her neighborhood.

Kierstan: But I do feel though that Portlanders are kind of faking it that way. That they're just doing their stuff because this is what everybody else is doing and it's what 
the cool kids are doing in Portland. They feel like

Portland's kind of that way in a sense that it's clicky.

Stephen: So it's clicky around choosing the environment?

Kierstan: Yeah.

Stephen: With greenness?

Kierstan: Yeah. Because around the environment and

greenness and like the farming sustainability and all that.

And I feel like sometimes it goes a little over the edge. It's

like, “Dude, just live your life the way you want to. Don’t

follow everybody else and what they're doing and trying to

fit in!” (Kierstan, Personal Interview, April 8, 2011).

The participants in this research listed many environmentally beneficial behaviors that are part of their everyday lives. Other behaviors such as composting, gardening, buying energy offsets, turning out lights, not having children, and saving water were also reported with but with less frequency across all of the interviews. Recycling and transportation behaviors were the most frequently mentioned. The theme of pressure to be green emerged from the interviews. Research participants described an overall "green mentality" or "sustainable” way of life in Portland that favors recycling, public transportation and biking.

\section{Climate Knowledge}

My conversations with the research participants included moments that revealed the extent of each person's climate knowledge. I asked participants to describe how they 
became aware of climate change, where they get their information on climate change, if they talk about the issue with others and what they understand to be the causes and effects of climate change. The participants were unaware that the aims of this research centered on issues of climate change and their everyday experiences.

Through these conversations, two distinct themes of climate knowledge emerged. These two themes are not intended to group participants into one category or the other. The two themes should also not be viewed as a simple binary of those who are in "the know” regarding climate change and those who aren't. Instead, these two themes have emerged from the data to help describe two distinct themes that emerged from the participant descriptions.

The first theme is that of "disjointedness". Within this theme participants described a "basic understanding of climate change" that offered generalized explanations of the causes and effects. This theme contains patterns of individual passivity in relation to acquiring climate information. These descriptions of climate change often incorporated the experience of weather or natural disasters in explanations and also tended to describe a more apocalyptic vision regarding the effects of climate change.

The second theme of "cosmopolitan" emerged from these conversations. Participants described a very sophisticated and nuanced understanding of climate change. Participants actively sought out information regarding climate change. These descriptions acknowledged both the natural and manmade causes of climate change. The participant descriptions within this theme were more reluctant to rely on the weather as a climate 
change indicator. In addition, these descriptions were more specific when describing both what causes and will be the effect of climate change. Climate adaptation and uncertainty as opposed to apocalyptic scenarios were more often expressed in this category.

\section{“Disjointedness" and Climate Information}

Those who described to me a "basic understanding” of climate change reported using general types of sources for their knowledge. This category reports using mostly mainstream media and other people as their primary sources for what they know regarding climate change. Participants describe "happening upon” the information. Alex describes the places where he receives climate knowledge:

There’s no one source. I suppose you know, climate’s such a big -such a big story. You know, like it’s every month or so there is something about climate. So either-whatever news or whatever thing on the internet I am looking at that time. (Alex, Personal Interview, March 29, 2011)

Jack also relies on major U.S. media sources for his climate information. When asked where he gets his climate knowledge he explains that he visits the same two websites every day. His description illustrates a disjointedness towards climate change or a distancing through "not remembering" reading an article about climate change since Al Gore’s documentary came out five years ago:

Well I mean, NPR and the New York Times...I go to the sites every day, so anytime there's like an article on climate change that's where they come from...But I don't 
remember like, reading articles. I mean too recently anyway. Like it’s something that has been talked about for so long that I feel maybe like it’s (pause) it’s not, like, I don’t know, it’s just conjecture, but it’s like, I don't, I don't see like articles about climate change as often as was around that time that “Inconvenient Truth” came out. (Jack, Personal Interview, March 26, 2011).

Brock also gives a general response regarding the sources of his climate information without naming a particular news article, source or website:

This is probably almost like a really bad thing to say at this point but I get all my information from online. I guess that all sounds bad but I feel like, I mean everybody uses online...but everybody also knows there is just a bunch of bogus, junk online...Like, everybody can, I think, kind of spot the difference between these things these days. I don't have a T.V. I don't listen to the radio because all of these things are available online now. Yes, it’s my one-stop shop.(Brock, Personal Interview, April 3, 2011)

Jerrod described to me that most of his climate knowledge comes from sources that are around him such as his father, NPR, and general conversation:

Umm, I probably got it, I got the foundation of what I know from him (Dad). I wouldn't say probably, I did. Umm, any 
new developments, any new developments I guess I get

from NPR probably, umm, or ya know conversation.

(Jerrod, Personal Interview, March 30, 2011)

Delores describes relying on her husband for any information regarding news worthy events such as climate change. (Delores, Personal Interview, April 6, 2011) Georgette admits to not following the news regarding climate change and also relies on her significant other to inform her of newsworthy events:

I'm actually pretty bad about keeping up with the news.

Umm, the radio driving to work, I don't, generally don’t sit down and watch the news. If something- but you know-if I notice something's big in the newspaper, but I never buy a newspaper. Umm, kind of-kind of sheltered from the news in a way...If I see a big cover, cover news you know, front of the page, I'll look at that, read it. Uhm, Dave my boyfriend is a little more up-to-date, so he'll also inform me, but generally I don’t read- I don’t hear about it day-today, or keep up to it. (Georgette, Personal Interview, April 3, 2011).

Lucy also describes not seeking climate knowledge from the media and relying on others people as a source for what she knows:

I would say the people I'm surrounded with because it's really...We actually had this conversation last weekend 
where it's very overwhelming to try to get the correct information and what news source do you trust and how do you keep track of it. You could spend your entire day trying to get the world news that I've surrounded myself with people that that's their hobby...So I would say that's probably my main source. (Lucy, Personal Interview, April 5, 2011)

Kierstan avoids the news as well. Her husband has been deployed to both Iraq and Afghanistan and will likely be deployed again. When asked where she gets her climate knowledge she replies:

Ohh, I guess when I surf the web you know coz' I don't have cable and I don't watch news...I do check out the major websites and internet to stay informed. And just also through you know Portlanders talking. I mean, I know you guys have a lot of information for that. You're very informed on what's going on and I can count on you know, just people to tell me what is going on. (Kierstan, Personal Interview, April, 8, 2011).

\section{“Cosmopolitan” Climate Information}

Those participants that offered more sophisticated explanations regarding the causes and effects of climate change described their media consumption in a more specific and intentioned manner. Their climate knowledge was usually reported to be 
based on varied sources of information. Additionally, I noticed that participants with a science background or more formal educational training such as an undergraduate degree had more detailed and nuanced descriptions of climate change.

Cindy is a current student at Portland Community College and works as an administrative assistant at the U.S. Fish and Wildlife Service. She believes that she spends a lot of time consuming different media. When asked to describe her information sources for climate knowledge she lists, “Umm, I’d say like, Sciencedaily.com, New York Times, L.A. Times, Colorado Times, The Oregonian, MSNBC. Just media really.” (Cindy, Personal Interview, April 6, 2011).

Eliza describes a more active consumption of climate information from media sources. If she reads an article she follows it up by looking at different sources on the same subject. She specifically mentions NPR , The New York Times and National Geographic as her starting points for information. She states, "I might see an article and like, I'll read the article and just Google certain points of it, you know. I wouldn't necessarily call it fact checking but I just want more information I suppose.” (Eliza, Personal Interview, March 29, 2011).

Daisy provided a very cosmopolitan or engaged description of her media consumption regarding climate change. She explains that her information is:

From periodicals. The news less so. I mean, NPR does some good stuff on it but like the mainstream media not so much. I stick with periodicals, The New Yorker, Time, 
National Geographic, Atlantic Monthly. I get Mother Jones online but they're a little scattershot sometimes.

Jeff works in a library and like Daisy, obtains his climate information from a variety of sources and formats including non-U.S. media:

I generally read the news on the computer or listen to it on the radio or podcasts rather than-I don't watch television news ever. I listen to the -the news I listen to most often is the BBC and NPR. (Jeff, Personal Interview, April 5, 2011)

Stan is voracious with his media consumption. He describes where he obtains his knowledge on climate change:

All kinds of sources. I am a media junkie so I read all media. I read media to understand. I don’t subscribe to any, it's like you read media to read between the lines. I'll read right wing media or left wing media and I'll read scientific journals if I have to. All media, it's not one certain viewpoint. I try to take in all viewpoints.(Stan, Personal Interview, April 5, 2011)

Alan is similar to Stan and the most specific in his description of how he obtains knowledge about climate change compared to every other participant. Regarding climate, from lots of different sources actually. I like to look at, I mean, I have mainstream media. I don’t have cable anymore so I really don't watch CNN and all 
that stuff. But then also alternative forms of media like from Democracy Now, so more liberal and progressive stuff. Even Al Jazeera America, I'll listen to. I try to look around the rest of the world to different media outlets...(Alan, Personal Interview, April 7, 2011)

Alan continues by describing the way that the U.S. media distorts our understanding of climate change:

I think our media is run by corporations...I don't see how they can fairly talk about war and even things that they're participating in that are negatively impacting the environment...giving this thing where it's like, we'll give both sides a say and you get this population that's very confused because there's these people saying that this is completely ridiculous, we have no climate change going on. And so they've created this base where we can all be very confused about whether or not there is climate change. ...(Alan, Personal Interview, April 7, 2011)

Two clear themes emerged regarding how participants obtain their climate information. The first, “disjointedness” has descriptions that speak generally about utilizing the news, internet or other people as their sources of climate information. The information is often times passively acquired or even kept at a distance. The second theme of "cosmopolitan" contains descriptions that illustrate more sophisticated 
information gathering behaviors regarding climate change. This grouping of people are more specific in naming their sources of information, do not describe other people as a source of information, use a variety of media and formats (online, periodicals, podcasts, radio), and seek out information from sources outside of mainstream U.S. media.

\section{“Disjointedness" and the Causes of Climate Change}

Within the theme of disjointedness, descriptions regarding the causes of climate change tended to also be less sophisticated or more general. These descriptions did not go into much detail regarding the scientific processes involved in climate change.

Additionally, these descriptions often mixed discussions of the causes of climate change with the effects of climate change or with ozone depletion.

When I ask Eliza what are the causes of climate change she responds, "Umm, I think that we are spewing too much stuff into the air with our cars and factories and umm, I think it is having an effect on the ocean and I think when that happens it sets of the cycle...I remember... when I was a little girl... there was this big campaign...it was kind of a new thing and when you release those carbons in the air then they depleted the ozone layer... ” (Eliza, Personal Interview, March 29, 2011)

Alex responds to the same question and provides a description that demonstrates clear disjointedness from the issue of climate change:

Stephen: Do you know the causes of climate change?

Alex: You mean like, the-like fall and spring and summer?

Like that kind of climate change?

Stephen: No, like global warming climate change. 
Alex: Like global warming? Well, the melting of the-like the Ozone, that hole in the Ozone layer, I quess? You know the melting of the ice; Whatever, climate change.

Stephen: What contributes to that?

Alex: We do; Humans. Just our existence does really.

(Alex, Personal Interview, March 29, 2011).

Joan states the causes in very general terms by saying, "living”, “pollutants” and “making more babies”. (Joan, Personal Interview, April 3, 2011) So does Kierstan, “Uh, pollution, us humans, (laughs)...people, people err where used to not giving a shit.” (Kierstan, Personal Interview, April 8, 2011).

\section{“Cosmopolitanism” and the Causes of Climate Change}

Within in the theme of cosmopolitanism, the causes of climate change were described by the research participants in sophisticated and nuanced ways. These descriptions were also more specific in their explanations connecting specific industries, products or behaviors to the cause of climate change. In addition, these explanations also included detailed descriptions of scientific processes with recognition of both natural and anthropogenic causes of climate change.

Jerrod describes the causes as well as a personal connection to the pollution:

Well, I think it has to do with the burning of fossil fuels and that can be caused by just about every industry and cars so even like buying something with packaging, you're paying somebody to pollute the atmosphere which contributes to 
greenhouse gases. (Jerrod, Personal Interview, March 30, 2011).

Alan also describes the causes in relation to industry and industrialization of civilization and how our lives are "easier" but that the earth is impacted:

The causes of climate change, to me, seems to be oil and the consumption, the way that we have designed our civilization since oil has been discovered and in that time the different types of machines and machinery we've come up with to make our modern lives easier and more convenient has just kind of exponentially put out lots of different chemicals and Co2 and carbon emissions and stuff that seem to be having some sort of impact on the planet. (Alan, Personal Interview, April 7, 2011)

John, who has an art degree, offers a very scientific explanation:

John: From the release of carbon dioxide into the atmosphere. And that release, the buildup, kind of in the atmosphere keeping in the heat-you know from the inside. Stephen: What contributes to the buildup?

John: Power plants, cars, and then you know, kind of the cycle of like warming released from Co2 from the oceans too. Since the oceans warm and releases more $\mathrm{Co} 2$ as their warm, umm, I don’t know, not just power plants but I guess 
chemical processes in general. I guess like making plastic probably releases some too and other chemical processes too.(John, Personal Interview, March 30, 2011)

Daisy offers a sophisticated explanation of the causes of climate change and how the effects of increased emissions can lead to chain reactions in the ocean environment that can release more carbon:

Well there are a couple right. So the main issue is the carbon emissions. The way that that affects the temperature of the earth in terms of trapping heat into our atmosphere and then you get melting of the ice caps.....and then the $\mathrm{pH}$ balance of the oceans because of carbon emissions is causing massive deaths of all these fish and then you have these algae blooms and it causes really bad impacts on the ecology of the oceans. (Eliza, Personal Interview, April 5, 2011).

Stan, a Reed College graduate describes both the natural and anthropogenic causes of climate change. This explanation is a more nuanced understanding of climate because he connects his understanding of nature to the activities of humans and how they interact:

I think it's a combination of factors. I don't subscribe to the idea that it’s solely man made. I think the earth has cycles obviously. ..Obviously there's huge amounts of carbon 
dioxide that are created by fossil fuels that can cause climate change but there's also natural cycles of the earth's cooling and warming. I think the rates of change in climate is alarming and has to be attributed to man to a certain degree whether or not that is an urgent disastrous thing. (Stan, Personal Interview, April 5, 2011)

Lastly, both Lee and Kevin offer very detailed and in depth explanations that connect intricate scientific concepts of climate science to our daily behaviors. Both have a background in science. Lee is studying to be a clinical lab scientist and Kevin earned a degree in Environmental Science. Lee’s description connects human history, deforestation and modernization to climate change. In addition, he includes a detailed description of the thawing of permafrost in Siberia and Canada resulting in the thawing of peat bogs that result in more emissions (Lee, Personal Interview, March 26, 2011). Kevin's description is the most complete explanation. He explicitly connects our daily behaviors to the causes of climate change:

The greenhouse gases are released through a variety of means but you know everything from humans farting to the way we grow our food...the main contributors are combustion of fossil fuels because that takes carbon that has been sequestered under the earth and releases it into the atmosphere. Umm, you also have greenhouse gasses emitted from landfills where we put our waste... and that 
turns into methane which is a really potent greenhouse gas.

Also greenhouse gasses that are in refrigerants...(Kevin, Personal Interview, March 30, 2011)

The theme of "Cosmopolitanism" with regards to the causes of climate change emerges from the participant descriptions that specifically connect our daily behaviors to the greenhouse gas emissions. Furthermore, these descriptions take into account the natural and anthropogenic connections to the causes of climate change. In addition, the participants' descriptions offer more specific and detailed explanations of the climate science demonstrating a personal connection or investment in understanding the causes of climate change.

\section{Disjointedness and Climate Effects}

Disjointedness as a theme also extends to discussions of climate effects. Participant descriptions that separate or detach themselves from the consequences of climate change through sweeping generalities applied to the world demonstrate disjointedness from the effects of climate change.

When asked, who feels the effects of climate change, Stan responds, “The global population. Everyone. Even the corporate elite.” (Stan, Personal Interview, April 5, 2011). Cindy also replies with the all-inclusive, “Everybody....every living organism on earth.” I follow up with, who is responsible? She quickly responds, "Everybody.” (Cindy, Personal Interview, April 6, 2011). Her response, while inclusive of her in both the responsibility and consequences of climate change, it implies a level of culpability that 
simply is not shared equally by all. Thus, this is an example that includes a disjointedness or detachment from her own share or role in the effects of climate change.

Another common answer to the question of who feels the effects of climate change is described by Alex. He thinks "Probably-probably the low-lying islands I think are going to feel the effects of climate change.”(Alex, Personal Interview, March 31, 2011) This response also detaches the effects of climate change from the individual by distancing the phenomenon far away to an unspecified island. John paints a similar picture by saying:

I guess people are feeling the effects now, just like people in the coastal towns that are seeing rising, you know, shore lines, which is slow, it's just so slow, I think people expect like the weather to change overnight and it just doesn't. (John, April 30, 2011)

John's description separates the effects of climate change from the lived experience of Portland, Oregon and instead locates the harm in coastal towns. Additionally, the theme of disjointedness is illustrated in his description of time. He does mention it is happening now but that the effects are extremely slow. This description distances the individual from the present effects of climate change pushing the problem further away. Kierstan also describes time in reference to the effects of climate change. She believes that "our children and our grandchildren are going to feel the effects, the little ones, we won’t.”( Kierstan, Personal Interview, April 7, 2011). 
Jack focuses his answer on "you know, like people, you know who rely on their food sources for like, certain birds and fish...like human cultures around the world don't have access to as many animals to eat” (Jack, Personal Interview, March 26, 2011). This description is not specific to any one location but clearly disconnected from the place he lives. Even though I'm certain Portlanders probably eat their fair share of birds and fish.

Other descriptions regarding the effects of climate change were very apocalyptic, doom and gloom, end of the world scenarios. These descriptions illustrates the disjointedness of the individual from the effects of climate change because they feel separated or not connected to potential solutions. These descriptions deny the possibility of a choice or solution. Apocalyptic scenarios disconnect the individual from the future because they view the future as something similar to an act of god.

I asked Jack if he talks about climate change with friends or family: See, with my family, umm, I try to avoid political conversations, but it will come up a few times of the year. Like my mother, she is all caught up in like end of the world and like revelations and all that stuff so like whenever it comes up, it's not about like what we can do to solve the problems but like, you know, the world's going to end so I better be prepared. (Jack, Personal Interview, March 26, 2011).

"Total ruination of us as a civilization" is how Kierstan views the consequences of climate change. (Kierstan, Personal Interview, April 8, 2011) Joan thinks that the 
planet will be “unlivable” (Joan, Personal Interview, April 3, 2011). Daisy describes

"huge, cataclysmic problems across the food chain. ..anytime you follow the logic out it's pretty cataclysmic” She imagines this world to look like a "wasteland” or "apocalyptic desert” (Daisy, Personal Interview, April 5, 2011) Delores described it as “Makes me feel like the world is ending” (Delores, April 6, 2011).

\section{“Cosmopolitanism” and the Effects of Climate Change}

The theme of cosmopolitanism emerges throughout the descriptions of the effects of climate change in several ways. To begin with detailed, specific descriptions show a connection and willingness to learn about the issue of climate change. Furthermore, these detailed descriptions also demonstrate a willingness of the participant to engage or connect with me on the subject of climate change. Several of the descriptions given were very lengthy and took quite a bit of effort and thought. Usage of the "we” instead of “some people” or "other people” demonstrates a cosmopolitan orientation to the issue of climate change. And lastly, the participant's detailed expressions of concern for others that will bear the disproportionate burden of the effects of climate change, demonstrates cosmopolitan concerns consistent with the idea of a "global citizen” that Nussbaum (1994) described. That concern in relation to climate change is cosmopolitan because it is not separated or detached from their responsibility or consumption.

Eliza’s description illustrates connection through the repetition of the word "we" and a genuine, universal concern for others:

Well, effects of climate change, well of course we are going to have un-availability to food and natural 
resources...I mean water and good soil that's clean. And we are going to have difficulty in producing food, that's really the basis of it, we are going to have difficulty in fishing, we are going to have difficulty raising you know, crops. That's going to be the long and short of it. That's really what we are talking about here isn’t it? This climate change is all going to affect the way we eat and how we live, how we breathe, like clean air and clean food. ..I think that whether you are rich or poor, whether you are this or that, everyone deserves that, I don't care where you are from, everyone deserves a meal. (Eliza, Personal Interview, March 29, 2011)

Lucy does admit that we will not feel the effects of climate change but does describe the theme of connection by tracing the effect back to her as a cause:

Not us. I'd say the person on the other end. The far end of the spectrum of me. Animals are probably more effected or affected. People living in third world countries are affected more than I am. You know, we're talking and I’m sitting here drinking a cup of coffee and the person that picks the coffee is the incredibly poor person. Where my three dollar cup would probably feed them for a week. You know it’s sad and it's hard not to think of that and feel selfish. It's 
just the way the world is... because the chain that it came from...it affects me the least. (Lucy, Personal Interview, April 5, 2011)

Alan also describes a Cosmopolitan connection to the effects of climate change but in relation to others :

People in third world countries the most, people that are already at the bottom of the ladder that are already having a hard enough time getting drinking water and food. Those are the people that feel it first I think more than anybody. And then I think instead of it trickling down, it climbs up the ladder over time and eventually we'll all feel it much more. But I think the more money you have as individuals and families and countries then the less it's going to impact you right away. But I think we're probably already seeing that it's happening in other parts of the world that it's significantly already having an impact.

Lee describes a scenario where the effects do not lead to the collapse of civilization but that we will feel the effects of climate change and have to adapt through a fundamental rethink. This description demonstrates a particularly cosmopolitan connection because of the positioning of himself within the "we" and also the connection is demonstrated by a willingness to change: 
I'm not thinking that that civilization will collapse completely but umm, I think that people are really going to have to adapt and if things get bad enough things could really collapse, but umm, I think we are going to have to do a really big re-think on,,,its so fundamental when you think about what scarcities is and why we have an economy that's driven on constant expansion and constant, starting to create scarcity so you can profit off of that...(Lee, Personal Interview, March 26, 2011).

Alan adds to this description of adaptation instead of collapse. His description aligns with the inevitability arguments advanced by Ulrich Beck. Alan describes a world where we will have to eventually face the effects of climate change and make changes as a whole world:

I think we are at the point now where we need to figure out how to live with it. And that means that I think we have to admit there are certain things that we're not going to be able to stop and we need to admit there are certain things that are going to happen and we need to figure out how, how we can change, what can we do now to start preparing for that. How can we, if there are cities that need to be moved, how do we start doing that? I think it can also be a bright picture if we can actually get our act together and 
figure out how to work better as a species, as a whole world. (Alan, Personal Interview, April 7, 2011)

The fundamental choice or radical re-think was also described by Alex: It’s interesting. I mean, you know, I feel like if climate-if this is really occurring like as quickly as some people would like to believe then it’s almost like a doomsday-like ideal. Because we'd be put in a bottleneck situation where we're destroying civilization really and we would have to make a choice about what we're doing to be more environmental or to do something really; we would have to change everything.(Alex, March 29, 2011).

Brock continues with this cosmopolitan explanation of climate change. The theme of connection is present when he talks of the world having to make a choice and if not, he will address it and so will others. The description of the inevitability also connects him to the effects of climate change. He also does not subscribe to apocalyptic scenarios but rather something more hopeful:

It looks like something I can’t imagine because it means complete change. It looks like people coming together and mobilizing in thought and spirit and body. Or it looks like people scattering and cities falling. It looks like an ultimatum. I guess that is my final answer...It feels like instigation. It feels like it’s going to happen whether we 
choose to address it or not. So we can try to address it together or I'll address it myself. That's when people start making bank runs and building panic rooms and things like that. People will address it themselves if they have to in private. It will be addressed.

\section{Cosmopolitanism and Climate Behavior}

Participants were asked if climate change influences their everyday behaviors. Most people did answer yes to this question and gave reasons of driving less, walking and biking more, and choosing public transportation. Jeff's description was disjointed; he did not connect his environmentally helpful behaviors to the issue of climate change:

I don’t know, like climate change specifically. But I try to

live with a greater awareness of being more environmentally-responsible in terms of like I said before; recycling and trying to conserve energy, and use less, waste less. (Jeff, Personal Interview, April 5, 2011)

Alex who recycles, rides a bike, and public transportation, and reduces waste answers no outright. He offers another reason for his environmental behaviors:

Well, it’s for other reasons that affect me know. I think recycling is probably more-like it's sanitary-it's a sanitation label, I mean sanitation issue, I think.(Alex, Personal Interview, March 29, 2011). 
In spite of solely using a bike for transportation, Stan also answers no. He also offers another reason as to why he does not connect his behavior to climate change:

No. I would say the main political reason that I bike and all that is to wean off of the fossil fuel which I find is a political problem. It fuels American hegemony in the world and I think that they (cars) destroy cities.(Stan, Personal Interview, April 5, 2011)

Georgette is an avid bicyclist even though she owns a car. She responded no to the question as well:

Umm, nope. I don't think every day, but-and that's where people can get lost sometimes is because it's not every day they, they don't realize the effects of everything.(Georgette, Personal Interview, April 3, 2011).

Everyone who participated in this research and offered descriptions of their everyday, lived experience reported more than one environmental beneficial behavior that helps to reduce greenhouse emissions. However, not all participants connected those behaviors to the problem of climate change. The connection of these behaviors to the issue of climate change for others was unclear or not direct. They expressed a general awareness or concern for the environment in relation to their behavior but it was disjointed from the issue of climate change specifically. 


\section{CHAPTER SEVEN: DISCUSSION}

The purpose of this phenomenological inquiry was to describe the lived experience of Portland residents in relation to climate change and their individual behaviors. This research also sought to describe Portland resident's knowledge and conceptualizations of climate change. The primary research question that guided this inquiry was "How do Portland residents describe the issue of climate change in relation to their lived experience?” This research also asked "Where do Portland residents obtain their information on climate change?” And "How do Portland residents understand the causes and consequences of climate change on their own terms?”

Through in-depth conversational interviews, six themes emerged from the data. The first theme of Freedom emerged from the participant’s descriptions of their lives. Residents reported feeling free in many parts of their lives. This feeling of freedom includes but is not limited to their outward appearance, sexuality, gender, etc. The theme of freedom emerged from descriptions that continually referenced a "Portland mentality" or "way of life" that honors individual expression.

American's are typically viewed as placing considerable value on individualism and the freedom that they feel as Americans. (Martin and Nakayama, 2008, p.89). Identities are multiple; I am not just an American but am also a native Kansan, a Portlander, a gay man, a brother and student. (Martin and Nakayama, 2008, p.88). Identities are dynamic because the social forces giving rise to any particular identity are always changing. (Martin and Nakayama, 2008, pp.90-91.) In the United States, regional 
identities remain important. (Martin and Nakayama, 2008, p.103). The Pacific Northwest's identity compared to the Midwest's is vastly different as experienced by me and described by several participants.

The descriptions of the lived experience on Portland, Oregon demonstrated a strong cosmopolitan emphasis on individual autonomy and freedom. Appiah (1997) labels this as a "cosmopolitan love of variety" where the society is not homogenous but still holds on to certain universal beliefs.(Appiah, 1997, p.635). Portland residents are proud of where they live. They expressed a Portland way of life that values freedom, individuality, a connection to nature and concern for others. This study interviewed people who made a conscious decision to move to Portland. Many described the average Portland resident as a transplant from someplace else. People move, and like me and the participants of this study, large amounts of people are relocating to Portland, Oregon. Appiah states, "We cosmopolitans can be patriots, loving our homelands (not only the states where we were born but the states where we grew up and the states where we live); our loyalty to humankind-so vast, so abstract, a unity-does not deprive us of the capacity to care for lives nearer by.” (Appiah, 1997, pp. 622-623). Most of the Portlanders that I interviewed illustrated a truly cosmopolitan life in their strong patriotism to Portland, their neighborhood and its beliefs in conjunction with a recognition and concern for others globally.

The second theme of proximity revealed itself in descriptions of the resident's lived experience. This theme describes an aspect of the lived space of Portland, Oregon residents. The theme of proximity revealed a desire to have close proximity to 
downtown, shopping, and entertainment. Regardless of what neighborhood participants resided in, they overwhelmingly spoke to having almost everything they could want or need in close proximity to their home. Additionally, the participants described a close proximity to community, entertainment and shopping no matter what neighborhood they resided in.

The third theme that emerged from the lived experience descriptions is the theme of comfort. Residents described feeling comfortable due to the open minded feeling of Portland. Safety concerns were also expressed as an integral part of this feeling of comfort. My experience in Kansas City compared with my own feelings of comfort in Portland revealed a relationship between Portland's whiteness or absence of large communities of color in the urban core. Participant descriptions of their neighborhoods revealed both explicitly and implicitly processes of gentrification in the lived spaces that residents reported feeling comfortable and safe in.

This feeling of comfort that emerged from participant interviews could point towards environmental justice concerns at a more localized level in cities like Portland, Oregon who are actively pursuing sustainability efforts throughout the city. The description of unequal distribution of resources on a city wide scale by Kevin illustrates that some communities are being left out when resources are allocated towards sidewalks, bike lanes, light rail etc. As Portland continues to undertake more sustainability projects or even climate change adaptation projects in the future, we should always be mindful of our past and continue to seek solutions for all of Portland's resident's. 
Oregon's first constitution prohibited blacks from entering the state. Before WWII there were only 2,000 blacks living in Portland and in the 1920's there were nearly 200,000 KKK members in Oregon. (McGregor, 2003, np). Specifically, the city of Vanport, Oregon offers a critical point in history that can help inform the theme of comfort and the potential inequalities created through sustainability efforts. Vanport was built to accommodate the large number of ship builders that moved to Portland to work for Henry Kaiser. In 1944, Vanport was Oregon's second largest city with 40,000 residents, including 6,000 African Americans. When the flood of 1948 occurred, 18,000 people were left homeless. 25\% of the homeless were African American. Portland State Professor Michael McGregor explains:

This created a dilemma: with so many of the people the city had always termed "undesirable" in need, how would Portland respond? The city’s response was not a clear victory for integration and human rights, but it gave hints that positive change was possible. Many whites ignored those left homeless, hoping they would leave the state or expecting the small Albina community to care for them. Many others, however, welcomed the suffering into their homes, giving them temporary shelter and, in the process, coming to know members of a minority community for the first time. (McGregor, 2003, np).

Part of the lesson for me regarding Vanport in relation to unequal development in Portland is the hopefulness expressed by McGregor when he writes, "the Vanport flood, by confronting people with a clear choice between callousness and compassion, allowed the first trickle of change to flow.” (McGregor, 2003, np). Much has improved since the 
times of Vanport, but the disjointed and sometimes incoherent consequences of economic development in Portland has traditionally harmed the African American community and remnants of that history are present in the descriptions of the comfort felt by participants and the role that gentrification of traditionally African American communities plays in creating that feeling of comfort.

A strong connection to nature emerged as another theme amongst the participants. This connection to nature was expressed in relation to the trees, gardening and responsiveness to the sun. This theme demonstrated the ability of nature to order the lived experience of individuals through a connection to the sun. When the sun is out in Portland, so are the residents.

Pressure to be green or environmentally sustainable revealed itself in the data. Portland residents describe feeling pressure to recycle correctly, cut back on disposable waste, drive less and bike more. Within this theme were descriptions that considered the "green mentality" to be the dominant paradigm or way of life in Portland, Oregon.

The last theme to emerge is the theme of disjointedness and cosmopolitanism. Specifically, this theme revealed the disjointed ways that Portland residents described the issue of climate knowledge. This disjointedness was reported regarding climate information gathering, the causes of climate change, the effects of climate change and whether or not residents feel like their behavior is connected to climate.

The meta-theme that emerged from this inquiry is that of disjointed cosmopolitanism. To be disjointed can mean simply, not connected. However, 
disjointedness regarding climate change and the lived experience of Portland residents is better understood as fractured or incoherent. The word disjointed implies an interruption or disruption in a connection.

Disjointedness emerged as a meta-theme for several reasons. Overall there are gaps between our ideas of who we are as a community and what we actually do. First, it's important to recognize that there are clear tensions or moments of disjointedness in not only each of the themes themselves but also in relation to each other. For example, the theme of freedom that values an individual's choice is incoherent when combined with the theme of pressure to be green. Kierstan explained that she likes how close everything is to her neighborhood (proximity) and that she could walk (pressure) but it's her choice (freedom) to take her car if she wants.

For me, I live with the disjointedness between my own knowledge of environmental problems and my actual behaviors. I buy plastic water bottles everyday even though I am outraged when I see pictures of the great Pacific garbage patch. I have spent a year making outreach films for threatened and endangered species yet I bought a fur pelt at an auction in Anchorage, Alaska while presenting a paper at a conference on the environment. I spent a considerable amount of time writing and servicing a federal grant to teach children about climate change yet I leave the light on in my closet all the time. If given the choice, I would prefer to have a car and drive. The disjointedness in what we know, believe, and actually do are lived everyday on a city wide scale.

Dr. Kari Noorgard researched the residents of Bygdaby, Norway in relation to their everyday lives and climate change. The residents there were much like Portlanders; 
educated, environmentally aware and also she found, a relationship to climate change where citizens have a sense of "knowing and not knowing” People are aware about environmental problems in Bygaby but it is not part of their everyday lives. There is a disconnect between this abstract information and their everyday lives. This is the same disjointedness that emerged from this research. Participants described many environmental behaviors that they do, yet in some cases failed to link these behaviors to climate change. Also, like in Bygaby, participants could describe the causes and effects of climate change, yet choose to distance themselves from actually taking any action or even talking with others about the issue. (Noorgard, 2006, p.365, 357).

The theme of comfort illustrates the incoherence regarding the comfort attributed to the open-mindedness of Portland but at the same time this comfort occurs in a predominately white city. The theme of freedom not be viewed as separate from the theme of comfort when people express feeling safe and comfortable partially due to gentrification. The new Census figures on Portland are very revealing. Portland is the whitest major city in the United States and the trend in Multnomah County indicates that people of coloring are leaving the urban core. Over 10,000 people of color have moved from the urban core since 2000. In addition, my neighborhood is now $85 \%$ white. (Hannah-Jones, May 6, 2011) A recent article in the Oregonian quotes Sabiya Prince, an anthropology professor from Washington, D.C . She is quoted as saying, "We are now seeing people return to the cities, and it's an issue of personal taste and convenience...The early pioneers of gentrification have been gay people, artists, emptynesters, people who didn't necessarily have kids and didn't have to be concerned about 
putting their kids in the schools...But they are the ones who also have access to the loans." (Hannah-Jones, May 6, 2011) I cannot help but feel troubled by this gentrification; especially after observing this trend in both Kansas City and Portland.

Disjointedness between our ideals of sustainability and freedom exists in Portland, Oregon. Judith Mowry, who works on issues of gentrification in Portland stated, "I am so saddened by these numbers... This is not a healthy, sustainable city; this is not who we want to be." (Hannah-Jones, May 6, 2011). Sustainability was initially defined by the 1987 Brundtland Report as “development that meets the needs of the present without compromising the ability of future generations to meet their own needs" (Medovoi, 2010, p. 130.). Sustainability is an economic strategy that seeks to help the environment via the restraint of the economy through market mechanisms. Unfortunately, this approach is still locked into an economic rationalization that prevents the emergence of a truly environmentally sustainable ethic (Leff, 2009, p. 103-104) Perhaps, this “greenness" or "Portland way of life” is actually contributing to the gentrification in Portland. Perhaps this is a localized environmental justice issue unique to the development of Portland, Oregon. Could sustainability or the greening of Portland be one of several reasons why 10,000 people of color moved away from the core of the city? Perhaps, this community’s ability to "meet their own needs" was compromised in some way by Portland's aggressive sustainable development.

On an encouraging note, it seems as though cosmopolitan thoughts regarding climate change were emerging within the descriptions of the Portland community. Several expressions of cosmopolitanism emerged in this research when participants spoke 
of coming together as global citizens, or connecting their consumption in Portland to the detrimental impacts elsewhere. Nussbaum (1994) offers a simple definition to introduce the idea of cosmopolitanism. She believes that it starts with recognition that we are “citizens of the world” (Nussbaum, 1994, p.2). The residents of Portland that I spoke to clearly expressed this cosmopolitan conception of citizenship when they spoke in terms of a "global we” or connected their own consumption to the effects felt elsewhere.

To be a cosmopolitan, one must think of themselves as a citizen of the world. Appiah (2007) explains that "the universal concern that underlies cosmopolitanism means that it matters to me that every human life should go well.” (Appiah, 2007,p.2381) Regarding the environment, Appiah refers to this as, "the conditions necessary for a common life.” (Appiah, 1997, p.629). In relation to this study, these universals that guarantee that the basic conditions of life are met were expressed by participants in relation to access to clean water, air, food or even a general respect and protection of the natural environment.

Cosmopolitan expressions from Portland, Oregon residents also emerged in their descriptions that called for a fundamental rethink on the way that or economy and governance structures operate. Ulrich Beck (2005) believes this is one of the first steps to reaching a Cosmopolitan perspective on a larger scale. His view, that the world economy and the state have now fused into a "meta-power" was expressed in various ways by the participants in this study. (Beck, 2005, p.150). Corporate control of the media, wars being fought over resources, global consumption patterns, exploitations of the poor, are a few examples or cosmopolitan concerns of Portland residents. 
Notions of inevitability regarding climate change and the "forced choice" that many participants spoke of is another sign of the emerging cosmopolitanism in Portland, Oregon. Resident's descriptions indicate an understanding of what Beck (2005) labels "the incongruity of borders" within a system of globalization.(Beck, 2005, p.144) Those I spoke to recognized that their carbon footprint has effects beyond their own locality or even national border. Participants spoke of the issue of climate change as something that the world will inevitably have to face. Brock specifically labeled the issue of climate change as an “ultimatum” for the world (Brock, Personal Interview, April 3, 2011).

The emerging cosmopolitanism perspective on climate change illustrates the Meta Theme of disjointedness. As expected, not all participants made expressions of globalized concern for others unless they were further disconnecting from the issue of climate change by exporting the impacts of warming to a distant and remote tropical island.

The cosmopolitanism emerging in Portland, Oregon is one that is still disjointed and at times, contradictory and incoherent with the lived experience. Before I asked any participants a single question regarding environmentalism or climate change, I asked the question, "What significant challenges do you see the world facing?” When talking with Brock, he brought up the issue of climate change unsolicited. His answer illustrates and best summarizes what I feel is the disjointed but emerging cosmopolitan perspective in Portland, Oregon.

Stephen: What significant challenges do you see the world facing? 
Brock: One thing big, whether you subscribe to climate change and other things that face us globally, without having to argue about any of those topics, you can say as a world, we're not, certainly not prepared to face anything together. I don't think this world, our civilization has ever felt like a global unity. If you ever really thought about the prospect of, total sci-fi here but, if you've ever thought what if like, we were visited by aliens and they were hostile? Wouldn't that make you immediately think, if you really felt that happening, just really imagined it, you would think that every person you saw is your brother and sister and part of your family and every human on the planet is united on this front. Maybe it doesn't have to be that, maybe it could just be a comet that we know or an asteroid impact. Something like that or if it were real climate change and whether or not we caused it, we're certainly not doing anything to change it. (Brock, Personal Interview, April 3, 2011)

\section{Limitations and Strengths}

This inquiry was my first attempt at a comprehensive qualitative inquiry. As a novice researcher, I struggled with the scheduling component of this research. In relation to the Four Seasons of Ethnography, I would definitely be a season pusher. The "winter 
season” was too short for an inquiry of this size. Additionally, I would have liked to have interviewed several of the participants a second time. This research would have benefitted from a few more in-depth follow-up interviews that sought clarification and elaboration, especially regarding questions of individual behaviors that occur on a daily basis. The participants in this research were acquired from a convenience sampling from my own network of social acquaintances, work colleagues and referrals from initial participants. Recreating this research by having others ask the same interview questions of additional subjects could potentially help increase the validity of the themes that emerged throughout this project.

A strength of this research is that my own lived experience as a resident of Portland was integrated into every step of the research methodology. Van Manen’s approach asks, “what is it like to have this experience?”(Van Manen, 1990, pp. 44-45) Positioning myself within the inquiry allowed me to identify authentic descriptions that rang true or matched my own experiences as a resident of Portland; I was able to ask more probing follow-up questions or allow the participant to explain in more detail certain aspects of their lived experience because often times, I shared in that experience. Intersubjectivity existed throughout this phenomenological inquiry. In other words, my "self-insights" and "subjective perceptions” of what I experienced as a resident of Portland operated as what Moustakas (1994) describes as a "co-presence" to the experiences of other residents. As a new resident of Portland, the lived experience I inhabited and the reflections made on the "lifeworld" enriched the research due to the 
freshness of my move to Portland and ability to compare this experience with "lifeworlds" from my past.

\section{Significance of the Research/ Future research}

This research will help fulfill the requirements of a Master of Science degree in Communication at Portland State University. Additionally, as a result of this research endeavor, I discovered a deeper and more complex awareness and understanding of my own lived experience of Portland culture and politics. It is my hope that this research will identify new "horizons" or areas for communication scholars to explore the issue of climate change at a more localized level. This research could act as a starting point for research that seeks to connect the issue of climate change to the lived body. For example, current research being done by the Portland Center for Sustainability could look at the lived experience of those within their "Eco-districts" to help add to the growing research on lived space and climate change. Finally, it is my hope that this research can be an example of how the social sciences can and should be included in discussions of climate change. The solutions to global climate change will not come exclusively from scientific advancements, governmental regulations or individual behavior changes. Thus, it is important to examine the issue of climate change from as many theoretical and methodological vantage points as possible. This research can join the other voices from the social sciences that investigate the issue of climate from a human science perspective in an effort to add complexity and continuity to the ongoing discussions of climate change and our everyday lives. 
I was fascinated by the overt and implicit descriptions of gentrification and the gay community's role in the process. Future research could focus in on one or two specific neighborhoods in relation to this dynamic between these two groups. Further inquiry regarding the reasons why individuals with many environmentally beneficial behaviors did not connect those to climate change is another area ripe for further investigation. Knowing the "why” behind individual behavior choices in relation to lived experience could help add to the growing body of climate scholarship.

\section{Conclusion}

This research helps shed light on the lived experiences of Portland residents in relation to climate change. The descriptions provided by the participants illustrated the many ways that climate change and our everyday lives can be incoherent, unclear, or disjointed. The themes of freedom, proximity, comfort, connection with nature, green pressure and disjointed cosmopolitanism stand alone as viable descriptions of the lived experiences of Portland, Oregon residents in relation to climate change. The meta-theme of disjointed cosmopolitanism illustrates the interesting ways that residents of Portland view the issue of climate change and how a fractured, disjointed or emerging cosmopolitan perspective of climate change manifests itself in their everyday lived experiences. 
Disjointed Cosmopolitanism 


\section{Works Cited}

Abbott, C. (1983). Portland: Planning, politics, and growth in a twentieth-century city. Lincoln: University of Nebraska Press.

Adams, S. (February 2011). "State of The City Address" Office of Mayor Sam Adams. www.mayorsamadams.com

Antilla, L.(2008) Self Cencorship and Science: A Geographical Review of Media Coverage of Climate Tipping Points. Public Understandings of Science. 1, 1-17.

Appiah, A. (2006). Cosmopolitanism : ethics in a world of strangers (1st ed.). New York: W.W.Norton \& Co.

Appiah, K. A.(January 01, 1997). Cosmopolitan Patriots. Critical Inquiry, 23, 3, 617-639.

Appiah, K.A. (April, 2007). New Dimensions of Citizenship: Keynote Address: Global Citizenship. Fordham Law Review, 75, 2375-2390.

Anderson, L. (January 01, 2006). Analytic Autoethnography. Journal of Contemporary Ethnography, 35, 4, 373-395.

Atkinson, P. (January 01, 2006). Rescuing Autoethnography. Journal of Contemporary Ethnography, 35, 4, 400-404.

Beck, U. (January 01, 2007). Beyond class and nation: reframing social inequalities in a globalizing world. The British Journal of Sociology, 58, 4, 679-705.

Beck, U. (January 01, 2010). Climate for Change, or How to Create a Green Modernity?. Theory, Culture and Society, 27, 2-3.

Beck, U. (1999). World risk society. Malden, MA: Polity Press.

Bryant,B.(2003). Our backyard: A quest for environmental justice. (eds.) Visgilio, G. R., \& Whitelaw, D. M. Lanham: Rowman \& Littlefield Publishers.

Bullard, R. D. (2005). The quest for environmental justice: Human rights and the politics of pollution. San Francisco: Sierra Club Books.

Cerbone, D. R. (2006). Understanding phenomenology. Chesham: Acumen.

Denzin, N. K., \& Lincoln, Y. S. (2008). Strategies of qualitative inquiry. London: SAGE. 
Elliott,L.M., \& University of Warwick. (2002). Global environmental (in)equity and the cosmopolitan project. Coventry: University of Warwick.

Gauna, E. (January 01, 2008). El Dia De Los Muertos: The Death and Rebirth of the Environmental Movement .Environmental Law, 38, 2, 457.

Goodall, H. L. J. (August 01, 2004). Commentary: Narrative Ethnography as Applied Communication Research. Journal of Applied Communication Research, 32, 3, 185-194.

Hodson, M., \& Marvin, S. (June 01, 2010). Urbanism in the anthropocene: Ecological urbanism or premium ecological enclaves?. City, 14, 3, 298-313.

Hooft, S. v. (2009b). Cosmopolitanism : a philosophy for global ethics. Montreal ; Ithaca: McGill-Queen's University Press.

Holifield, R. (January 01, 2001). PROGRESS REPORT - Defining Environmental Justice and Environmental Racism. Urban Geography, 22, 1, 78.

Hulme, M. (May 28, 2010). Cosmopolitan climates: Hybridity, foresight and meaning. Theory,Culture and Society, 27, 2, 267-276.

Kapoor, P (1999). Whiteness: The communication of social identity.(eds) . Nakayama, T. K.,\& Martin, J. N. Thousand Oaks: Sage Publications.

Lanigan, R. L. (1988). Phenomenology of communication: Merleau-Ponty's thematics in communicology and semiology. Pittsburgh, PA: Duquesne University Press.

Larabee, Mark (October 28,2009) Portland Adopts Ambitious Goal to Reduce Area's Carbon Footprint. Oregonlive.com

Levin, D. M. (January 01, 1997). Liberating Experience from the Vice of Structuralism: The Methods of Merleau-Ponty and Nagajurna. Journal- British Society for Phenomenology, 28, 2, 116-141.

Leff, E. (October, 2009). Degrowth, or deconstruction of the economy: Towards a sustainable world. Critical Currents no. 6, 1010-107.

Ley, D. (January 01, 2004). Transnational Spaces and Everyday Lives. Transactions of the Institute of British Geographers, 29, 2, 151-164.

Martin, Judith and Nakayama, Thomas K., (2008). Experiencing Intercultural Communication: An Introduction. Third Edition. New York, New York. McGraw-Hill. 
McCracken, G. D. (1988). The long interview. Newbury Park, Calif: Sage Publications.

McGregor, Michael. (2003). The Vanport Flood \& Racial Change in Portland. Oregon Historical Society. The Oregon History Project.

http://www.ohs.org/education/oregonhistory/learning_center/dspresource.cfm?resource_I $\mathrm{D}=000 \mathrm{BC} 26 \mathrm{~B}-\mathrm{EE} 5 \mathrm{~A}-1 \mathrm{E} 47-\mathrm{AE} 5 \mathrm{~A} 80 \mathrm{~B} 05272 \mathrm{FE} 9 \mathrm{~F}$

Medovoi, L. (January 01, 2010). A Contribution to the Critique of Political Ecology: Sustainability As Disavowal. New Formations, 69, 129-143.

Moore, E.A. (April 26, 2005) In Portland, Living the Green American Dream. The Christian Science Monitor.

Moustakas, C. E. (1994). Phenomenological research methods. Thousand Oaks, Calif: Sage.

Mueller, T. \& Passadakis, Alexis (October, 2009). Green Capitalism and the climate: It's economic growth, stupid! Critical Currents, no. 6, 54-61.

Nisbet, M., \& Kotcher, J. (January 01, 2009). A Two-Step Flow of Influence?. Science Communication, 30, 3, 328-354.

Norgaard, K. M., \& World Bank. (2009). Cognitive and behavioral challenges in responding to climate change. Washington, D.C: World Bank.

Norgaard, K. (January 01, 2006).We Don't Really Want to Know\&rdquo. Organization \& Environment, 19, 3, 347-370.

Nussbaum, M. (1994) Patriotism and Cosmopolitianism, Bostonreview.net/br19.5/Nussbaum.php

Ockwell,D.,Whitmarsh, L., \& O'Neill, S. (January 01, 2009). Reorienting Climate Change Communication for Effective Mitigation. Science Communication, 30, 3, 305327.

Parekh, B.(January 01, 2003).Cosmopolitanism and Global Citizenship. Review of International Studies, 29, 1, 3-17.

Patton, M. Q., \& Patton, M. Q. (2002). Qualitative research and evaluation methods. Thousand Oaks, Calif: Sage Publications.

Pellow,D.N. (2007). Resisting global toxics: Transnational movements for environmental justice. Cambridge, Mass: MIT Press. 
Read, R. (February 1, 2011) Feds Look in Portland for Ways to Green up the Government. Oregonlive.com

Sadala, M. L. A., \& Adorno, R. C. F. (February 01, 2002). Phenomenology as a method to investigate the experience lived: a perspective from Husserl and Merleau Ponty's thought. Journal of Advanced Nursing, 37, 3, 282-293.

Saiz, A. V. (January 01, 2005). 'Globalisation, Cosmopolitanism and Ecological Citizenship'. Environmental Politics, 14, 2, 163-178.

Seidman, I. (2006). Interviewing as qualitative research: A guide for researchers in education and the social sciences. New York: Teachers College Press.

Seltzer. E. (September, 2010) Making EcoDistricts: Concepts and Methods for Advancing Sustainability in Neighborhoods. 1-19.

Schlosberg, D. (1999). Environmental justice and the new pluralism: The challenge of difference for environmentalism. Oxford: Oxford University Press.

Towers, G. (January 01, 2000). Applying the Political Geography of Scale: Grassroots Strategies and Environmental Justice. The Professional Geographer, 52, 1, 23-36.

Van Manen, M. (1990). Researching lived experience : human science for an action sensitive pedagogy. [Albany, N.Y.]: State University of New York Press.

Vryan, K. (January 01, 2006). Expanding Analytic Autoethnography and Enhancing Its Potential. Journal of Contemporary Ethnography, 35, 4, 405-409.

Wojnar, D., \& Swanson, K. (January 01, 2007). Phenomenology. Journal of Holistic Nursing, 25, 3, 172-180.

Zhao, X.(January 01, 2009). Media Use and Global Warming Perceptions. Communication Research, 36, 5, 698-723. 
Appendix A: Participant Chart

\begin{tabular}{|c|c|c|c|c|c|}
\hline Participants & $\begin{array}{l}\text { Self-Chosen } \\
\text { Name }\end{array}$ & $\begin{array}{l}\text { Location of } \\
\text { Interview }\end{array}$ & Occupation & $\begin{array}{l}\text { Participant's } \\
\text { Neighborhood }\end{array}$ & $\begin{array}{l}\text { Approximate } \\
\text { Age }\end{array}$ \\
\hline$\# 1$ & Lee & $\begin{array}{l}\text { His home- } \\
\text { Kitchen } \\
\text { table }\end{array}$ & Student & $\begin{array}{l}\text { Inner } \\
\text { Southeast- } \\
\text { Buckman }\end{array}$ & 36 \\
\hline$\# 2$ & Jack & $\begin{array}{l}\text { His Home- } \\
\text { Kitchen } \\
\text { table }\end{array}$ & $\begin{array}{l}\text { Cashier at } \\
\text { nursery }\end{array}$ & North & 28 \\
\hline \#3 & Eliza & $\begin{array}{l}\text { Her Home- } \\
\text { Breakfast } \\
\text { nook }\end{array}$ & $\begin{array}{l}\text { Small } \\
\text { Business } \\
\text { Owner } \\
\end{array}$ & Northeast & 37 \\
\hline$\# 4$ & Alex & $\begin{array}{l}\text { His Home- } \\
\text { studio apt } \\
\text { sat on bed }\end{array}$ & $\begin{array}{l}\text { Unemployed } \\
\text { DJ }\end{array}$ & North & 38 \\
\hline$\# 5$ & John & His Home & $\begin{array}{l}\text { Operations } \\
\text { Manager }\end{array}$ & North & 26 \\
\hline$\# 6$ & Jerrod & $\begin{array}{l}\text { His Home- } \\
\text { Sat on } \\
\text { chairs in his } \\
\text { bedroom }\end{array}$ & $\begin{array}{l}\text { Bank Teller } \\
\text { Musician }\end{array}$ & $\begin{array}{l}\text { SouthEast } \\
\text { Mt. Tabor }\end{array}$ & 38 \\
\hline \#7 & Kevin & $\begin{array}{l}\text { His Home- } \\
\text { Sitting area } \\
\text { in bedroom }\end{array}$ & $\begin{array}{l}\text { Government- } \\
\text { City } \\
\text { employee }\end{array}$ & $\begin{array}{l}\text { Southeast } \\
\text { Buckman }\end{array}$ & 39 \\
\hline$\# 8$ & Joan & $\begin{array}{l}\text { My House- } \\
\text { sitting area } \\
\text { in attic }\end{array}$ & $\begin{array}{l}\text { Restaurant } \\
\text { Manager }\end{array}$ & Northeast & 42 \\
\hline$\# 9$ & Georgette & $\begin{array}{l}\text { Her House- } \\
\text { Dining } \\
\text { table }\end{array}$ & Server & Southeast & 27 \\
\hline$\# 10$ & Brock & $\begin{array}{l}\text { His House- } \\
\text { sat on his } \\
\text { bed }\end{array}$ & Student & $\begin{array}{l}\text { Southeast } \\
\text { Hawthorne }\end{array}$ & 25 \\
\hline$\# 11$ & Jeff & $\begin{array}{l}\text { His House- } \\
\text { hot } \\
\text { bedroom }\end{array}$ & Librarian & $\begin{array}{l}\text { Southeast } \\
\text { Hawthorne }\end{array}$ & 37 \\
\hline$\# 12$ & Daisy & $\begin{array}{l}\text { Her House } \\
\text { Living } \\
\text { room }\end{array}$ & $\begin{array}{l}\text { Artist } \\
\text { Theatre } \\
\text { Actress }\end{array}$ & Northwest & 41 \\
\hline$\# 13$ & Stan & $\begin{array}{l}\text { His House } \\
\text { Living } \\
\text { room }\end{array}$ & $\begin{array}{l}\text { Manager of } \\
\text { grocery store }\end{array}$ & $\begin{array}{l}\text { Southeast } \\
\text { Hawthorne }\end{array}$ & 43 \\
\hline$\# 14$ & Lucy & $\begin{array}{l}\text { Coffee shop } \\
\text { on NW } \\
\text { 23rd }\end{array}$ & $\begin{array}{l}\text { Small } \\
\text { Business } \\
\text { Owner }\end{array}$ & $\begin{array}{l}\text { Southwest } \\
\text { Pearl District }\end{array}$ & 32 \\
\hline
\end{tabular}




\begin{tabular}{|l|l|l|l|l|l|}
\hline$\# 15$ & Cindy & $\begin{array}{l}\text { At her Job- } \\
\text { office }\end{array}$ & $\begin{array}{l}\text { Government } \\
\text { employee }\end{array}$ & $\begin{array}{l}\text { Southwest } \\
\text { Multnomah } \\
\text { Village }\end{array}$ & 31 \\
\hline$\# 16$ & Dolores & $\begin{array}{l}\text { At Her Job- } \\
\text { Office }\end{array}$ & $\begin{array}{l}\text { Government } \\
\text { Employee }\end{array}$ & Southeast & 28 \\
\hline$\# 17$ & Alan & $\begin{array}{l}\text { His Home- } \\
\text { living room }\end{array}$ & Server & Southwest & 39 \\
\hline$\# 18$ & Kierstan & $\begin{array}{l}\text { Coffee } \\
\text { Shop on SE } \\
\text { Division }\end{array}$ & Chef & Southeast & 44 \\
\hline
\end{tabular}


Disjointed Cosmopolitanism

Appendix B

Theme: Freedom (selected quotes from Interviews)

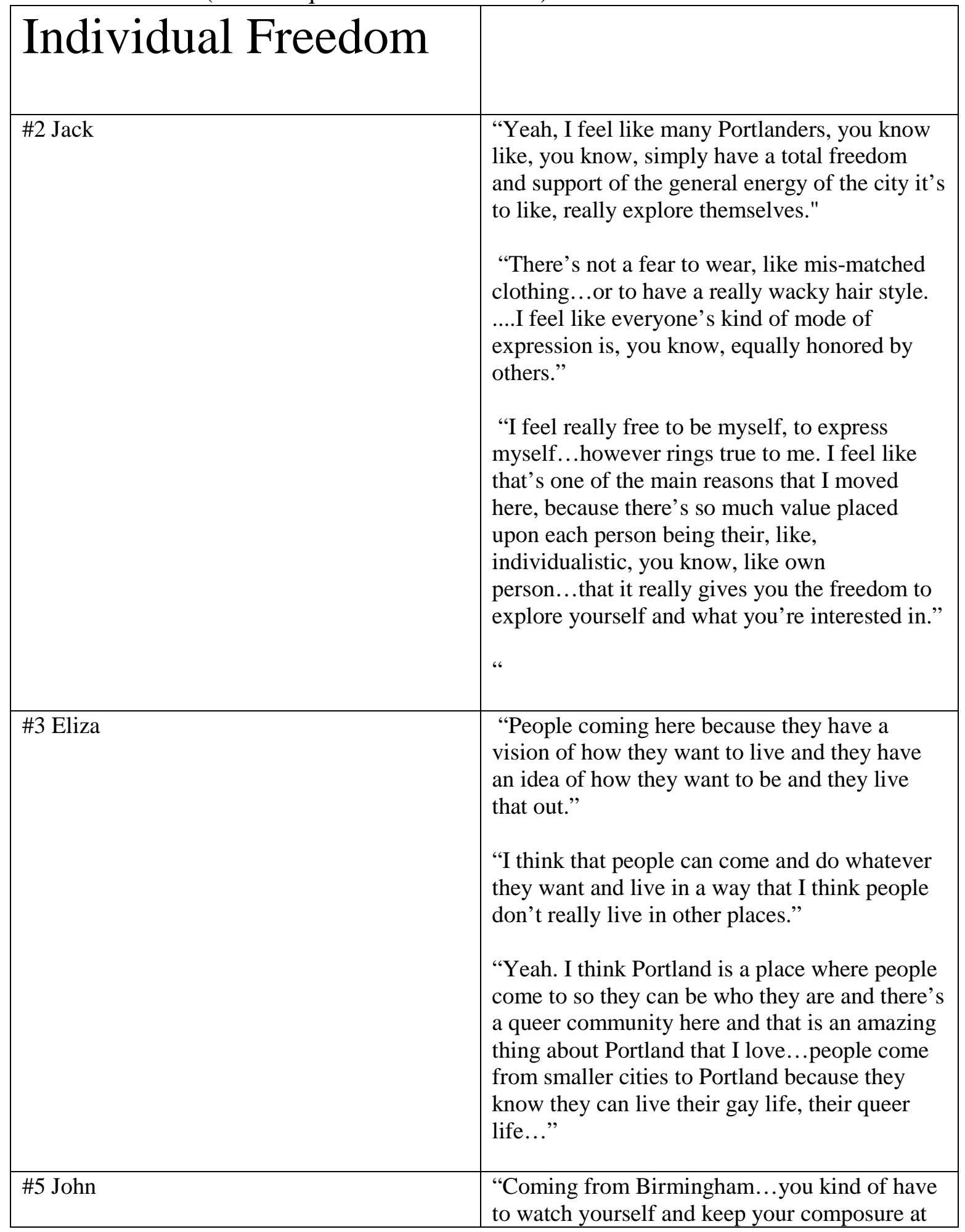




\begin{tabular}{|c|c|}
\hline & $\begin{array}{l}\text { all times. But here, you don’t. And so, for to be } \\
\text { in public and have someone kiss me or hold my } \\
\text { hand, it is still kind of, like, makes me ummm } \\
\text { nervous, it makes me really nervous.” } \\
\text { “ }\end{array}$ \\
\hline \#8 Joan & $\begin{array}{l}\text { “you can be whatever you like and let’s } \\
\text { celebrate being different.” } \\
\text { "I guess you'd be condemned more for being a } \\
\text { Republican. (laughing) I feel like this is a much } \\
\text { more tolerant place.” }\end{array}$ \\
\hline \#9 Georgette & $\begin{array}{l}\text { “There’s a lot of people who do their own } \\
\text { things, who are really independent or } \\
\text { individual...like overall, everyone's very } \\
\text { open...open to-people and ways of life.” }\end{array}$ \\
\hline \#10 Brock & $\begin{array}{l}\text { "You have the freedom to do what you want as } \\
\text { long as you don't impede the freedom of } \\
\text { anyone else to live as they want to live. I quess } \\
\text { that's mjust the bottom line. I'm glad that there } \\
\text { are people like Al Gore who use their position } \\
\text { to say really unpopular things but it was just } \\
\text { that unpopularity that made so many talk about } \\
\text { that." }\end{array}$ \\
\hline \#14 Lucy & $\begin{array}{l}\text { "I think there are a lot of gay people here. But I } \\
\text { think it's more.... what's the word....it's } \\
\text { accepted? I think there's not no much narrow } \\
\text { mindedness. I think its that all the people from } \\
\text { the country who are not narrow } \\
\text { minded....moved here," } \\
\text { "Move here and they're like okay. Leave me } \\
\text { alone and let me have my happy little life here. } \\
\text { That's how I feel.....This is the new } \\
\text { world...Does that make sense?" }\end{array}$ \\
\hline \#16 Delores & $\begin{array}{l}\text { "I love it. Before I moved out here, my husband } \\
\text { was like, you would fit in just great. I have a } \\
\text { whole bunch of tattoos on my arm so I was } \\
\text { afraid I wouldn’t be able to get a job or } \\
\text { anything, Yeah, it feels like home,it feels great } \\
\text { to be here...It is easy, it is laid back and people } \\
\text { don't care what you look like or how you dress } \\
\text { or what color your eye makeup is or if your } \\
\text { shoes don't match...the oldest people down to } \\
\text { the youngest, they have no judgment really, } \\
\text { they are cool.” }\end{array}$ \\
\hline \#17 Alan & "There were just differences between the kind \\
\hline
\end{tabular}




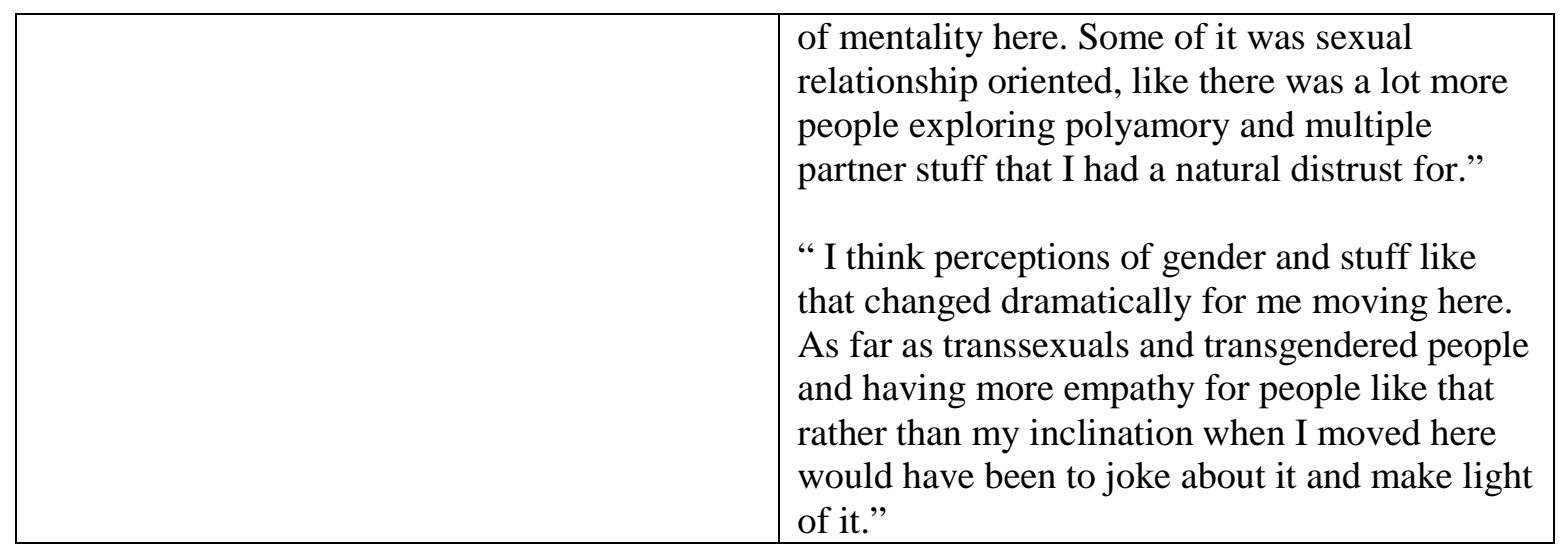




\section{Appendix C}

Theme: Green Pressure (Selected quotations form interviews)

\begin{tabular}{|c|c|}
\hline \#1 Lee & $\begin{array}{l}\text { "There is a lot of subtle-There’s a Portland } \\
\text { culture here. There’s a really greenness and } \\
\text { recycling and umm certain pragmatic, sort of, I } \\
\text { would say, umm, active kind of awareness } \\
\text { about how to approach environmental issues } \\
\text { that are coming...” } \\
\text { "There's certain things about Portland like the } \\
\text { way biking is supported here, umm, and the sort } \\
\text { of green kind of mentality that is more } \\
\text { prevalent than you have seen in a lot of places.” } \\
\text { "You know, the biking thing, about you know } \\
\text { just like, I-there is a sort of , umm... which } \\
\text { made me very anti-car.” }\end{array}$ \\
\hline \#2 Jack & $\begin{array}{l}\text { "I didn't really feel pressure, umm on the whole } \\
\text { you know, except get a bike and ride it, cause } \\
\text { that's something, you know like after I moved } \\
\text { to Portland I realized that I wanted to do, and } \\
\text { yeah, I really feel a pressure about that." }\end{array}$ \\
\hline \#7 Kevin & $\begin{array}{l}\text { “...an example could e you know, using } \\
\text { a,bringing a paper cup into the office...I might } \\
\text { be in a rush coming from a meeting and like, } \\
\text { god, I need caffeine but I didn't bring my mug } \\
\text { and so I get a paper cup at the coffee shop but } \\
\text { then when I walk in my office, I feel really } \\
\text { guilty about having a paper cup.” }\end{array}$ \\
\hline \#9 Georgette & $\begin{array}{l}\text { "When I was in Chicago some girl just totally } \\
\text { opened her cigarette pack and threw the plastic } \\
\text { out the window and it's just like, it shocked me } \\
\text { to think that people still did that...Uhm, in } \\
\text { Portland, people move to Portland and they } \\
\text { learn quickly. I feel like, cause it is a way of } \\
\text { living in Portland, to stay up on that." }\end{array}$ \\
\hline \#11 Jeff & $\begin{array}{l}\text { "There's an adjustment period for like-things } \\
\text { like recycling are really important here to a lot } \\
\text { of people. And they make it so easy that a lot of } \\
\text { people still have a tendency to throw things } \\
\text { away that are more appropriately recycled and } \\
\text { that's considered...like considered pretty much } \\
\text { negative by most people.” }\end{array}$ \\
\hline \#13 Stan & $\begin{array}{l}\text { "It doesn’t feel fringe anymore to be, it doesn’t } \\
\text { feel fringe to be a cyclist, farmer's market goer } \\
\text { because that has kind of become the norm.” }\end{array}$ \\
\hline \#14 Lucy & "I feel very pressured to bike and not use my \\
\hline
\end{tabular}




\begin{tabular}{|c|c|}
\hline & $\begin{array}{l}\text { car... I will do other thinngs to make up for my } \\
\text { car. Like composting, recycling, or eat local. So } \\
\text { I would say that's the one thing that I do feel } \\
\text { guilty about...having a car and driving it.” }\end{array}$ \\
\hline \#15 Cindy & $\begin{array}{l}\text { "Yes and no, I suppose. Yes because you want } \\
\text { to....but no, because this town isn’t } 100 \% \\
\text { sustainable, I mean, there’s errors being made } \\
\text { all over the place... as far as environmental } \\
\text { issues are concerned...so yea, I do feel pressure } \\
\text { because I want to be a part of that movement, } \\
\text { but also if I didn’t...fully immerse myself in } \\
\text { that movement, um...I think it would be okay } \\
\text { too, because people waste all over this town.” } \\
\text { "If at lunch, sometimes he'll say something } \\
\text { about throwing my paper plate in the trash, as } \\
\text { opposed to going down to the compost.” }\end{array}$ \\
\hline \#17 Alan & $\begin{array}{l}\text { "But I think that's a big difference than being in } \\
\text { the Midwest because its so voluntary there. You } \\
\text { kind of have to go out of your way to do it } \\
\text { whereas here, it's just expected." }\end{array}$ \\
\hline \#18 Kierstan & $\begin{array}{l}\text { “Portland's all about keep it green and keep it } \\
\text { weird. ..but I feel Portlanders are kinda faking } \\
\text { that way. That they're just doing their stuff } \\
\text { because this is what everybody else is doing } \\
\text { and it's what the cool kids are doing in } \\
\text { Portland. They feel like Portland's kind of that } \\
\text { way in its sense that it’s clicky...dude, just live } \\
\text { your life how you want to. Don't follow } \\
\text { everybody else and what they're doing and } \\
\text { trying to fit in.” }\end{array}$ \\
\hline
\end{tabular}


Theme: Connection to Environment (Selected quotations for interviews)

\begin{tabular}{|c|c|}
\hline \#1 Lee & $\begin{array}{l}\text { "The climate can be severe at times. Umm, I } \\
\text { generally like it and, but I energetically feel } \\
\text { very sun-centered in a funny way. When the } \\
\text { sun's out, I'm happy. When it's not out, I don't } \\
\text { necessarily feel unhappy but my mood is very } \\
\text { linked with the sun now and that is a new } \\
\text { development from living in the Midwest where } \\
\text { it wasn't...it's just my life wasn't so connected } \\
\text { to the sun...I feel like my life is very seasonal } \\
\text { here. When its summer the focus really is being } \\
\text { outside and enjoying the natural beauty of the } \\
\text { world around here...” } \\
\text { "I have four hundred square feet there, and it's } \\
\text { really quite nice and its terraced and you know } \\
\text { it's, (pause) The great about it is I think it's } \\
\text { been a kindergarten for probably thirty years or } \\
\text { more so that's, I mean a continuous amount of } \\
\text { working of that soil. I mean, the soil is really } \\
\text { good. It's nice to be in that community } \\
\text { group,...and share gardening tips and what not } \\
\text { and help each other...You know, it's really } \\
\text { important to me to have as much food you } \\
\text { know from the local areaas possible. Not just } \\
\text { because that food is, I know its organic and } \\
\text { good, because that's the food that is living right } \\
\text { here with me in this neighborhood and the } \\
\text { relationship I have with these plants by feeding } \\
\text { them, by nourishing them and giving them what } \\
\text { is necessary to thrive, they in turn give me the } \\
\text { things that are necessary to thrive. And having } \\
\text { them grown and having them live their lives in } \\
\text { this very area, this very block that I live on, } \\
\text { they have those adaptations, those things within } \\
\text { them that make them uniquely suited for this } \\
\text { spot, and somehow by eating those things, I am } \\
\text { more suited for this spot. And I'm better, more } \\
\text { fit, umm, you know, it’s a multi-level kind of } \\
\text { thing. It's kind of a spiritual thing, a } \\
\text { connection.” }\end{array}$ \\
\hline \#2 Jack & $\begin{array}{l}\text { "I was really looking to live in a place that, that } \\
\text { there would be, ummm, a kind of like, social } \\
\text { consciousness that would allow me to be more } \\
\text { comfortable being out and gay; and I was also } \\
\text { looking to live somewhere that was } \\
\text { environmentally conscious, that was close to } \\
\text { nature." }\end{array}$ \\
\hline
\end{tabular}




\begin{tabular}{|c|c|}
\hline \#3 Eliza & $\begin{array}{l}\text { "The weather is getting to me and that is really } \\
\text { hard. I have been seriously considering you } \\
\text { know, living down south for a period of time } \\
\text { and then coming back up here. You know, } \\
\text { taking extended time away from the roughness } \\
\text { in the winter time." }\end{array}$ \\
\hline \#5 John & $\begin{array}{l}\text { "The spring is the hardest time to live in } \\
\text { Portland because you know what the summer } \\
\text { can be...it's not warm here so we keep waiting } \\
\text { for it so everyone is sad right now or anxious." }\end{array}$ \\
\hline \#6 Jerrod & $\begin{array}{l}\text { "In the summertime it is beautiful, it's a } \\
\text { wonderful place to be, it's such heaven on earth } \\
\text { in the summer, in the winter time which is a } \\
\text { long season...I'm about ready to move out of } \\
\text { Portland permanently." }\end{array}$ \\
\hline \#7 Kevin & $\begin{array}{l}\text { "Portland has some things that tends to really } \\
\text { excel in than other places in the country, umm } \\
\text { continually ranked you know, the greenest, } \\
\text { sustainable city in the United States, if not the } \\
\text { world, umm continually ranked, with } \\
\text { exceptionally high things like recycling rates } \\
\text { and bike commuting, umm has the highest } \\
\text { participation in civic engagement in the United } \\
\text { States..." }\end{array}$ \\
\hline \#10 Brock & $\begin{array}{l}\text { "I just feel better...I like looking at green all } \\
\text { around me. I like the fact that you can see } \\
\text { hills...We're in the west coast and that means } \\
\text { so close to the ocean. I think maybe just } \\
\text { knowing that and experiencing the ocean and } \\
\text { knowing that you're so close to it, I think it } \\
\text { just...you learn what it means to live on a coast } \\
\text { and you experience it for yourself. Being so } \\
\text { close to the ocean, I think experiencing the } \\
\text { ocean changes people...it's just awesome to } \\
\text { look so far and as far as you see, it's just a } \\
\text { fraction of how far it keeps going. It's one of } \\
\text { the things of nature that humbles a person." } \\
\text { "In my freezer I kept seven and a half pounds } \\
\text { of at least ten different kinds of sprouting seeds. } \\
\text { I just got really big into that, sprouting in } \\
\text { particular, container gardening. I didn't have } \\
\text { the benefit of having a fantastic window...So I } \\
\text { got south, southwest sun. So I just put in a little } \\
\text { container garden...I loved it. Everybody should } \\
\text { have a green thumb these days. People have } \\
\text { really lost that but I think that we should be } \\
\text { getting down and getting your hands dirty and }\end{array}$ \\
\hline
\end{tabular}




\begin{tabular}{|c|c|}
\hline & $\begin{array}{l}\text { watching things grow, bringing things to life } \\
\text { from seed. It's so inspirational. I think it really } \\
\text { kicks up something creative and nurturing in } \\
\text { people.” }\end{array}$ \\
\hline \#14 Lucy & $\begin{array}{l}\text { "I could see maybe some other people in the } \\
\text { country would say.... what's the word? Oh, I } \\
\text { can't think of it. Like we feel better about } \\
\text { ourselves kinda like because we're aware, but } \\
\text { other people might look at us being snobby and } \\
\text { kinda high and mighty because you know, } \\
\text { "Yeah, I might drive my car, but I recycle.” } \\
\text { Does that make sense? I don't know how to put } \\
\text { it. But anyway. But I just feel better living here } \\
\text { because I feel like I'm just doing better to the } \\
\text { earth or the environment.” }\end{array}$ \\
\hline \#16 Delores & $\begin{array}{l}\text { "When it is nice and sunny outside, you can tell } \\
\text { everybody is so happy. But then when it } \\
\text { switches to the rain, it is so miserable." }\end{array}$ \\
\hline \#17 Delores & $\begin{array}{l}\text { "In the summer I feel really much more } \\
\text { energetic and active with friends and socially } \\
\text { connected. In the fall/winter I kind of get a little } \\
\text { more seclusive and stay at home more and } \\
\text { don't go out as much." }\end{array}$ \\
\hline \#18 Kierstan & $\begin{array}{l}\text { "When it's gorgeous out, like in the summer } \\
\text { months I do get energized because you know } \\
\text { when you're outside its clean...So I do feel } \\
\text { energized when I do go outside...it's not all } \\
\text { about museums and being indoors and stuck } \\
\text { inside. Get your fucking ass outside and go do } \\
\text { something and then go hiking and all that kind } \\
\text { of stuff.” } \\
\text { "I'm always outside growing things and stuff } \\
\text { and it's like there's a difference in your } \\
\text { everyday life on how you feel and on how your } \\
\text { shits growing and it's yeah, I've always been } \\
\text { aware that we're slowly destroying ourselves } \\
\text { and this planet” }\end{array}$ \\
\hline
\end{tabular}


Disjointed Cosmopolitanism

Appendix D

Meta Theme: Disjointed Cosmopolitanism (Selected quotations from interviews)

\begin{tabular}{|c|c|c|}
\hline Theme & Cosmopolitan & Disjointed Cosmopolitanism \\
\hline Climation Information Source & $\begin{array}{l}\text { \#3 Eliza: NPR, The New York } \\
\text { Times and National Geographic } \\
\text { as her starting points for } \\
\text { information. She states, “I might } \\
\text { see an article and like, I’ll read } \\
\text { the article and just Google certain } \\
\text { points of it, you know. I wouldn’t } \\
\text { necessarily call it fact checking } \\
\text { but I just want more information } \\
\text { I suppose.” } \\
\text { \#11 Jeff: “I generally read the } \\
\text { news on the computer or listen to } \\
\text { it on the radio or podcasts rather } \\
\text { than-I don’t watch television } \\
\text { news ever. I listen to the -the } \\
\text { news I listen to most often is the } \\
\text { BBC and NPR.” } \\
\text { \#12 Daisy: “From periodicals. } \\
\text { The news less so. I mean, NPR } \\
\text { does some good stuff on it but } \\
\text { like the mainstream media not so } \\
\text { much. I stick with periodicals, } \\
\text { The New Yorker, Time, National } \\
\text { Geographic, Atlantic Monthly. I } \\
\text { get Mother Jones online but } \\
\text { they’re a little scattershot } \\
\text { sometimes.” } \\
\text { \#13 Stan: “All kinds of sources. I } \\
\text { am a media junkie so I read all } \\
\text { media. I read media to } \\
\text { understand. I don’t subscribe to } \\
\text { any, it’s like you read media to } \\
\text { read between the lines. I’ll read } \\
\text { right wing media or left wing } \\
\text { media and I’ll read scientific } \\
\text { journals if I have to. All media, } \\
\text { it’s not one certain viewpoint. I } \\
\text { try to take in all viewpoints.” } \\
\text { Times, The Oregonian, MSNBC. } \\
\text { Just media really.” } \\
\text { \#17 Alan: "Regarding climate, } \\
\text { \#15 Cindy: "Umm, I'd say like, } \\
\text { Tiencedaily.com, New York }\end{array}$ & $\begin{array}{l}\text { \#2 Jack: “Well I mean, NPR } \\
\text { and the New York Times...I } \\
\text { go to the sites every day, so } \\
\text { anytime there’s like an } \\
\text { article on climate change } \\
\text { that's where they come } \\
\text { from...But I don't } \\
\text { remember like, reading } \\
\text { articles. I mean too recently } \\
\text { anyway. Like it's something } \\
\text { that has been talked about } \\
\text { for so long that I feel maybe } \\
\text { like it’s (pause) it's not, like, } \\
\text { I don't know, it's just } \\
\text { conjecture, but it's like, I } \\
\text { don't, I don't see like } \\
\text { articles about climate } \\
\text { change as often as was } \\
\text { around that time that } \\
\text { “Inconvenient Truth” came } \\
\text { out.” } \\
\text { \#4 Alex:”There's no one } \\
\text { source. I suppose you know, } \\
\text { climate’s such a big -such a } \\
\text { big story. You know, like } \\
\text { it’s every month or so there } \\
\text { is something about climate. } \\
\text { So either-whatever news or } \\
\text { whatever thing on the } \\
\text { internet I am looking at that } \\
\text { time.” } \\
\text { \#10 Brock: “This is } \\
\text { probably almost like a really } \\
\text { bad thing to say at this point } \\
\text { but I get all my information } \\
\text { from online. I guess that all } \\
\text { sounds bad but I feel like, I } \\
\text { mean everybody uses } \\
\text { online...but everybody also } \\
\text { knows there is just a bunch } \\
\text { of bogus, junk } \\
\text { online...Like, everybody } \\
\text { can, I think, kind of spot the } \\
\text { difference between these } \\
\text { things these days. I don’t } \\
\text { have a T.V. I don’t listen to } \\
\text { the radio because all of }\end{array}$ \\
\hline
\end{tabular}




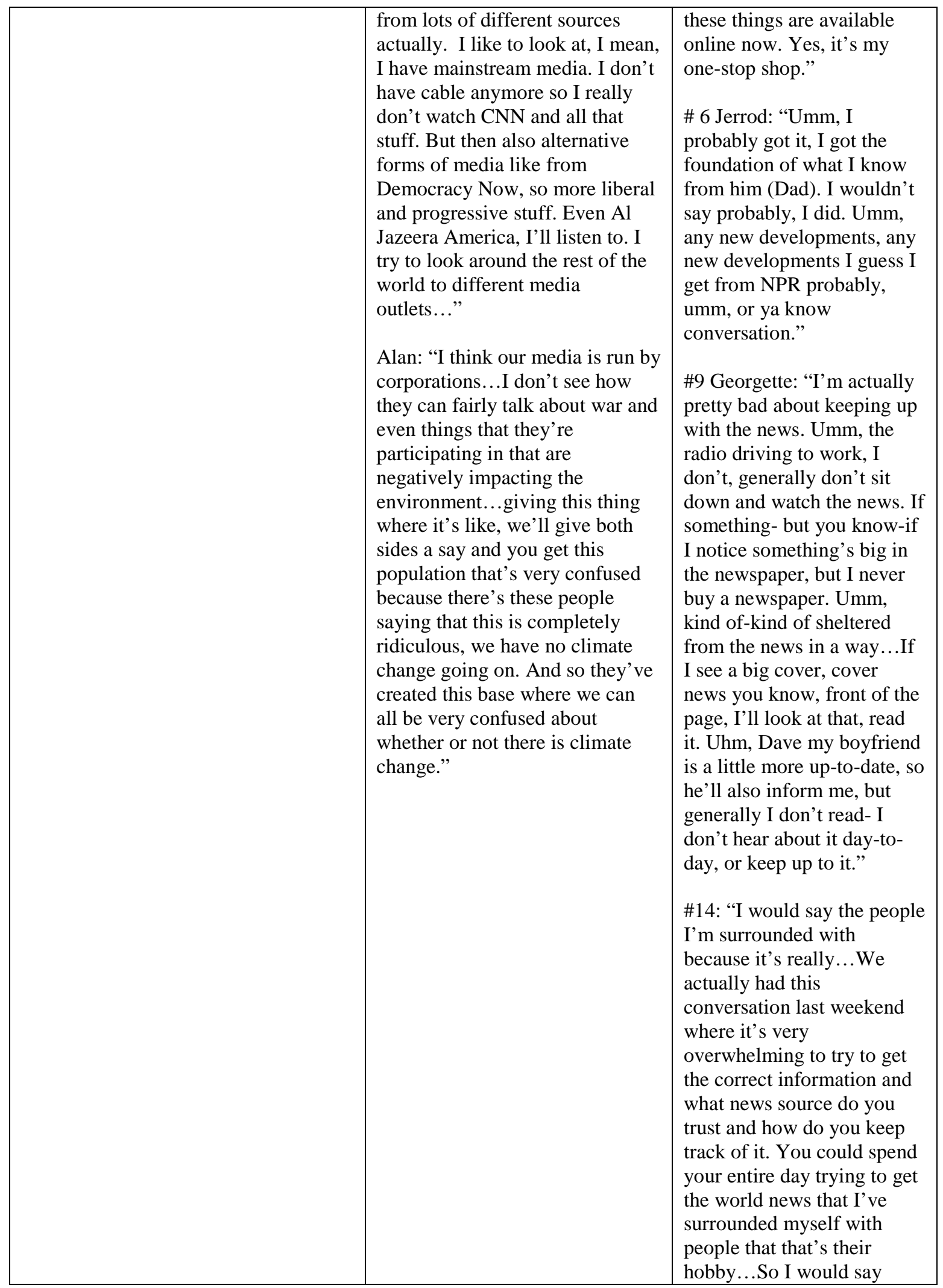




\begin{tabular}{|c|c|c|}
\hline & & $\begin{array}{l}\text { that's probably my main } \\
\text { source." }\end{array}$ \\
\hline Community/Connection to others & $\begin{array}{l}\text { \#3 Eliza "I think there is a strong } \\
\text { sense of community, it's a social } \\
\text { city, I think that is the most, that } \\
\text { is the most striking comparison } \\
\text { between Portland and any other } \\
\text { city I have lived in." }\end{array}$ & \\
\hline Causes & 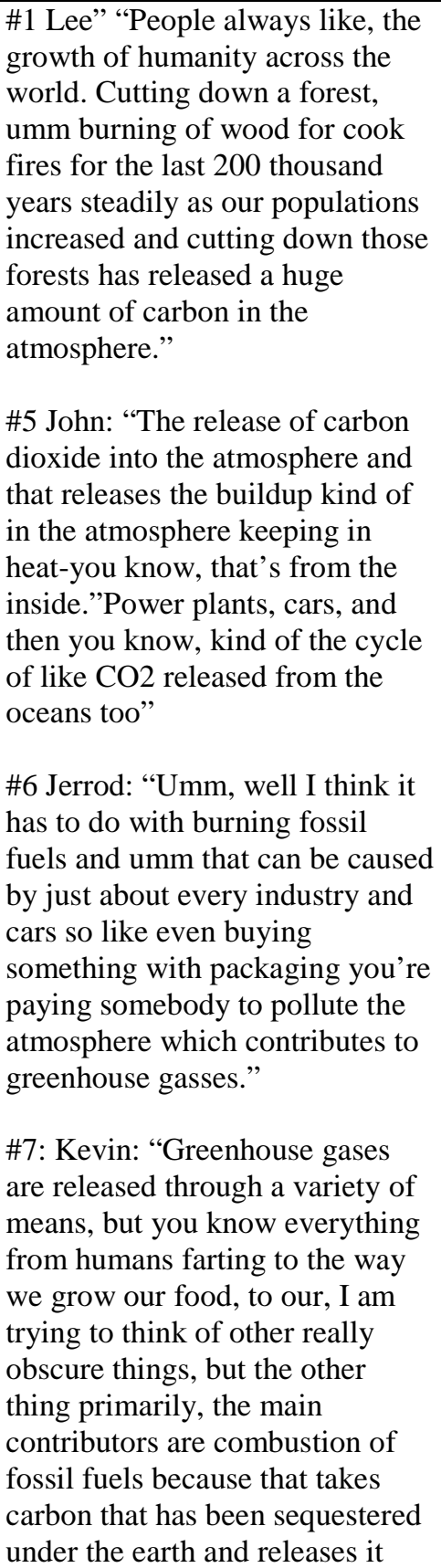 & $\begin{array}{l}\text { \#3 Eliza: “There was this } \\
\text { big campaign to stop the } \\
\text { umm, stop the chloroform } \\
\text { carbon in refrigerators and } \\
\text { umm air conditioning and } \\
\text { hairspray. Like hairspray } \\
\text { had like chloroform carbons } \\
\text { in them and when you spray } \\
\text { them, they went into the } \\
\text { atmosphere and killed the } \\
\text { ozone layer." } \\
\text { \#4 Alex: "Like global } \\
\text { warming? Well, the melting } \\
\text { of the ice-like the ozone, the } \\
\text { hole in the ozone layer, I } \\
\text { guess? You know, the } \\
\text { melting of the ice; whatever. } \\
\text { Climate change.” } \\
\text { \#4 Alex: "Stephen: Do you } \\
\text { know the causes of climate } \\
\text { change? } \\
\text { Alex: You mean like, the- } \\
\text { like fall and spring and } \\
\text { summer? Like that kind of } \\
\text { climate change? } \\
\text { Stephen: No, like global } \\
\text { warming climate change. } \\
\text { Alex: Like global warming? } \\
\text { Waking more babies.” the melting of the-like } \\
\text { the Ozone, that hole in the } \\
\text { Ozone layer, I quess? You } \\
\text { know the melting of the ice; } \\
\text { Whatever, climate change. } \\
\text { Stephen: What contributes } \\
\text { to that? } \\
\text { Alex: We do; Humans. Just } \\
\text { our existence does really.” } \\
\text { moing. Talking. }\end{array}$ \\
\hline
\end{tabular}




\begin{tabular}{|c|c|c|}
\hline & 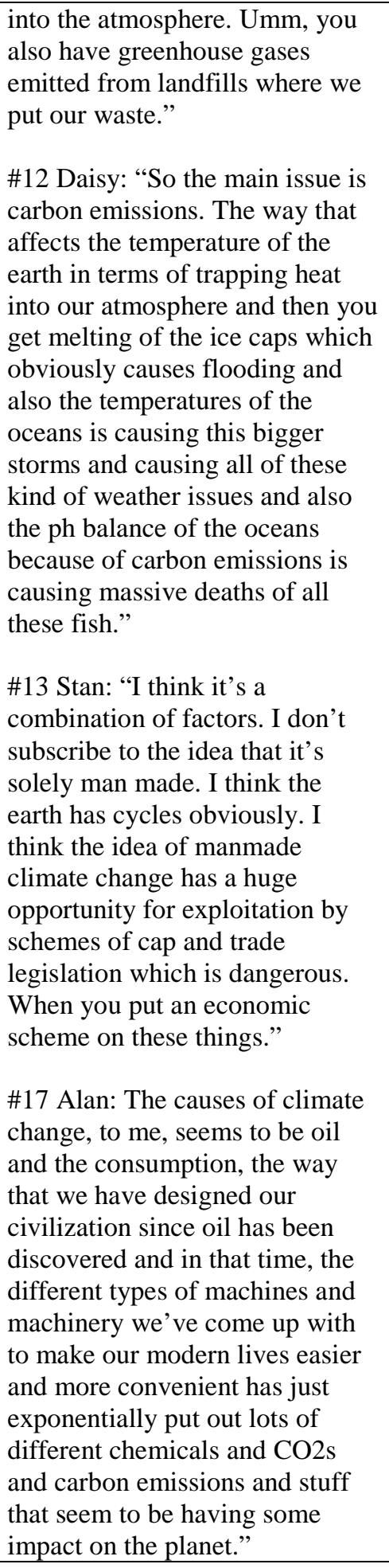 & $\begin{array}{l}\text { \#9 Georgette: "Whm [sighs] } \\
\text { well so we hear like, uhm, } \\
\text { yeah the gases-natural gases } \\
\text { and I don't know...Uhhm, } \\
\text { pollution and all the garbage } \\
\text { and waste sure is affecting } \\
\text { it.” } \\
\text { \#17 Kierstan: Uh, } \\
\text { pollution...us humans...for } \\
\text { bad climate change for } \\
\text { normal is just mother } \\
\text { nature.” }\end{array}$ \\
\hline Effects of Climate Change & $\begin{array}{l}\text { \#1 Lee: "So the idea that whether } \\
\text { we're putting out more carbon } \\
\text { right now is going to, whether or } \\
\text { not it's going to impact the }\end{array}$ & $\begin{array}{l}\text { \#4 Alex: "Probably- } \\
\text { probably the low lying } \\
\text { islands I think are going to } \\
\text { feel the effects of climate }\end{array}$ \\
\hline
\end{tabular}




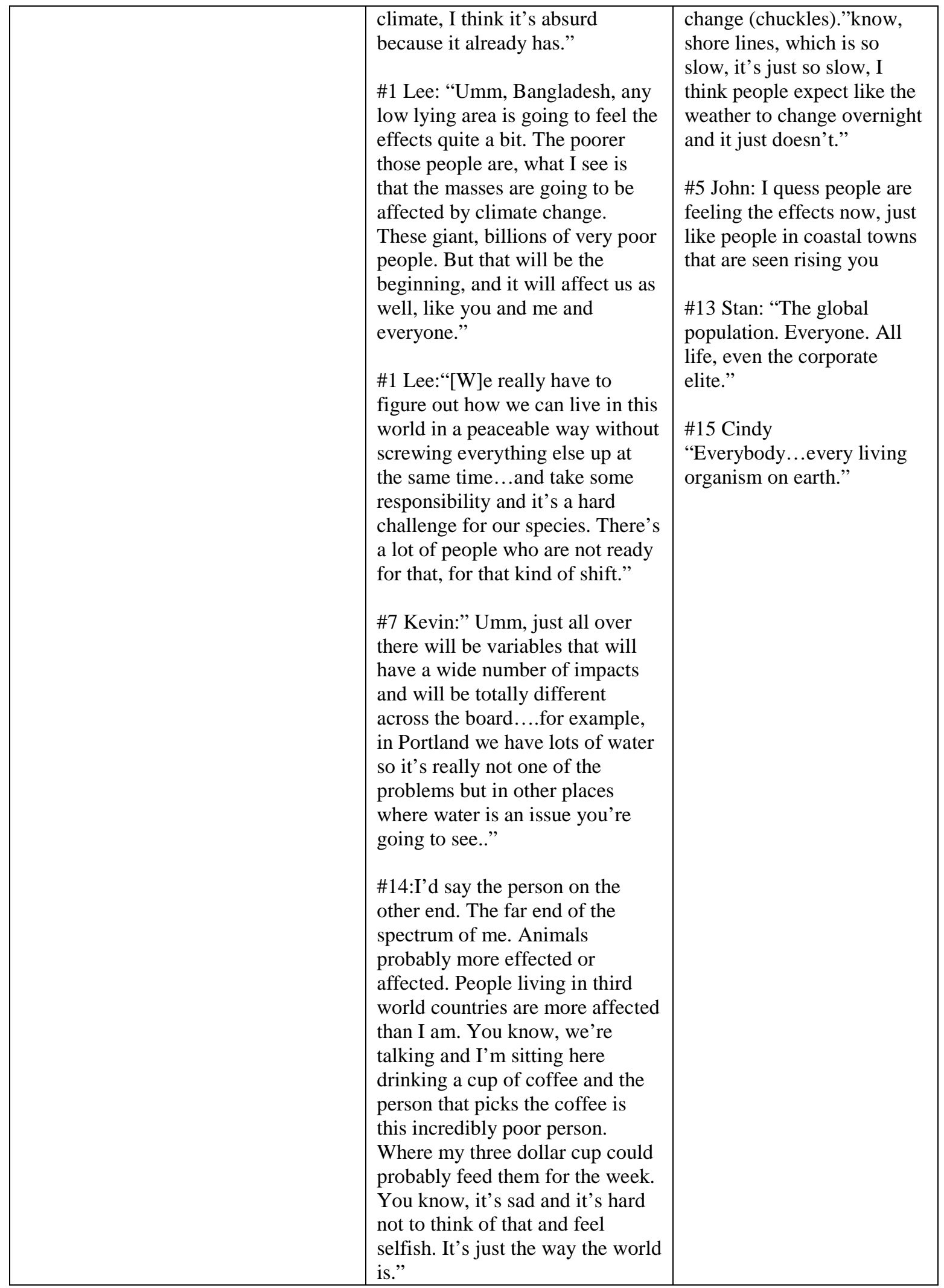




\begin{tabular}{|c|c|c|}
\hline & $\begin{array}{l}\text { \#15: Uh...the Ocean will } \\
\text { rise....hmmm the animals } \\
\text { willdife....could cause the } \\
\text { currents in the ocean to change } \\
\text { which could...result in another } \\
\text { ice age...uhh gosh, there, th...I } \\
\text { mean uhm, the possibilities are } \\
\text { endless. Could cause the polar } \\
\text { caps to melt... an...animal } \\
\text { extinction.” } \\
\text { \#17 Alan: "People in third world } \\
\text { countries the most, people that } \\
\text { are already at the bottom of the } \\
\text { ladder that are already having a } \\
\text { hard enough time getting } \\
\text { drinking water and food. Those } \\
\text { are the people that feel it first , I } \\
\text { think more than anybody. And } \\
\text { then I think it instead of trickling } \\
\text { down, it climbs up the ladder } \\
\text { over time and eventually we'll all } \\
\text { feel it much more. But I think the } \\
\text { more money you have as } \\
\text { individuals and families and } \\
\text { countries then the less it's going } \\
\text { to impact you right away.” }\end{array}$ & \\
\hline Environmental Behaviors & $\begin{array}{l}\text { \#1 Lee: "Recycle. I compost. I } \\
\text { eat vegetables that I grow. Umm. } \\
\text { I use public transit. Let's see, I } \\
\text { save my vegetable scraps and I } \\
\text { make stock with them and soups } \\
\text { and stuff. I like to make } \\
\text { sauerkraut and stuff like that so } \\
\text { fermentation-you're using kind of } \\
\text { old world techniques for } \\
\text { promoting your health.” } \\
\text { \#3 Eliza: "Recycle...and I also } \\
\text { don’t buy, uhm, most of the } \\
\text { things I buy are secondhand...I } \\
\text { recycle everything. I have my } \\
\text { own fork and knife I use at work } \\
\text { so I wash my fork and knives that } \\
\text { I use at work." } \\
\text { \#5 John: "I ride my bike } \\
\text { everyday which is one of the } \\
\text { reasons I moved here. We } \\
\text { compost, we recycle, even } \\
\text { though one of my roomates is not } \\
\text { recycling completely, which is }\end{array}$ & $\begin{array}{l}\text { \#8 Joan: “I have one but I } \\
\text { don't travel with it.” } \\
\text { (Nalgene bottle) } \\
\text { \#8 Joan: “One thing I do } \\
\text { that makes me feel sort of } \\
\text { guilty is leave a light on for } \\
\text { my dog. I don't want him to } \\
\text { be anxious in the dark....I } \\
\text { have tried in the past year or } \\
\text { so to avoid individually } \\
\text { packaged goods like energy } \\
\text { bars and things like that but } \\
\text { I'm not always successful.” } \\
\text { \#4 Alex: “Well, it's for } \\
\text { other reasons that affect } \\
\text { me know. I think } \\
\text { recycling is probably } \\
\text { more-like it's sanitary-it's } \\
\text { a sanitation label, I mean } \\
\text { sanitation issue, I think.” } \\
\text { \#9 Georgette: “Umm, }\end{array}$ \\
\hline
\end{tabular}




\begin{tabular}{|c|c|c|}
\hline & $\begin{array}{l}\text { kinda insane to me. I'm like, how } \\
\text { could you not recycle this?” } \\
\text { \#7 Kevin: "I try not to use, you } \\
\text { know, I take bags to the grocery } \\
\text { store, I use my own } \\
\text { container...bought the highest } \\
\text { efficient furnace possible. Try to } \\
\text { minimize energy use, umm, and } \\
\text { try not to travel so much.” } \\
\text { \#11 Jeff: “I don't know, like } \\
\text { climate change specifically. } \\
\text { But I try to live with a greater } \\
\text { awareness of being more } \\
\text { environmentally-responsible } \\
\text { in terms of like I said before; } \\
\text { recycling and trying to } \\
\text { conserve energy, and use less, } \\
\text { waste less.” } \\
\text { \#12 Daisy: “We recycle and we } \\
\text { only have one car. We have that } \\
\text { wind energy thin. Not the one } \\
\text { where you buy the wind energy } \\
\text { but where they offset...I mean } \\
\text { we try to walk and use public } \\
\text { transportation.” } \\
\text { \#13 Stan: Riding a bike, weaning } \\
\text { myself off of cars, trying to } \\
\text { support local agriculture, } \\
\text { recycling, that’s pretty much the } \\
\text { gist of it.” }\end{array}$ & $\begin{array}{l}\text { nope. I don't think every } \\
\text { day, but-and that's where } \\
\text { people can get lost } \\
\text { sometimes is because it's } \\
\text { not every day they, they } \\
\text { don't realize the effects of } \\
\text { everything." } \\
\text { \#13: "No. I would say the } \\
\text { main political reason that } \\
\text { I bike and all that is to } \\
\text { wean off of the fossil fuel } \\
\text { which I find is a political } \\
\text { problem. It fuels } \\
\text { American hegemony in } \\
\text { the world and I think that } \\
\text { they (cars) destroy cities.” }\end{array}$ \\
\hline Climate change and Cosmopolitanism & $\begin{array}{l}\text { \#1 Lee: "What the economy } \\
\text { every certain region has will } \\
\text { shift. I'm not thinking civilization } \\
\text { will collapse completely but } \\
\text { umm, I think that people are } \\
\text { really going to have to do a really } \\
\text { big re-think.." } \\
\text { Lee: "I'm not thinking that that } \\
\text { civilization will collapse } \\
\text { completely but umm, I think that } \\
\text { people are really going to have to } \\
\text { adapt and if things get bad } \\
\text { enough things could really } \\
\text { collapse, but umm, I think we are } \\
\text { going to have to do a really big } \\
\text { re-think on,,,its so fundamental } \\
\text { when you think about what }\end{array}$ & \\
\hline
\end{tabular}




\begin{tabular}{|c|c|}
\hline (⿸丆口 & 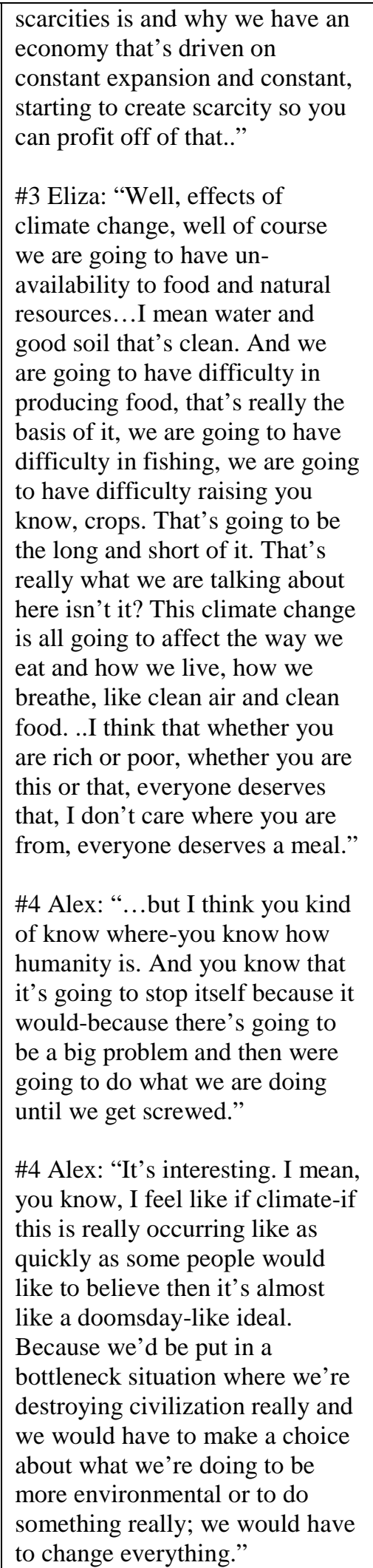 \\
\hline
\end{tabular}


\#10 Brock: "It looks like something I can't imagine because it means complete change. It looks like people coming together and mobilizing in thought and spirit and body. Or it looks like people scattering and cities falling. It looks like an ultimatum. I guess that is my final answer...It feels like instigation. It feels like it's going to happen whether we choose to address it or not. So we can try to address it together or I'll address it myself. That's when people start making bank runs and building panic rooms and things like that. People will address it themselves if they have to in private. It will be addressed.”

\#17 Alan: "I think you can go two ways. I feel like it can either be a really sad, devastating thing for lots of different parts of this world. And like I said, I think it's going to be the poorest people and nations first where you're going to see mass starvation and dealing with water supply and trying to have access to fresh water."

Alan: I think we are at the point now where we need to figure out how to live with it. And that means that I think we have to admit there are certain things that we're not going to be able to stop and we need to admit there are certain things that are going to happen and we need to figure out how, how we can change, what can we do now to start preparing for that. How can we, if there are cities that need to be moved, how do we start doing that? I think it can also be a bright picture if we can actually get our act together and figure out how to work better as a species, as a whole world.” 


\begin{tabular}{|l|l|l|}
\hline & \#10 Brock: “It looks like & \\
something that I can’t imagine & & \\
because it means complete & & \\
change. It looks like people & coming together and mobilizing & \\
in thought and spirit and body or & it would look like people & \\
& scattering and cities falling. It & \\
looks like an ultimatum.” & \\
\hline
\end{tabular}




\section{Appendix E: HSRRC Application- Approved March 28, 2011}

I. Project Title: Climate Change and the Lived Experience of Residents in Portland, Oregon

\section{Prospectus:}

The environment has emerged as one of the most important issues in modern society. While development and consumption patterns increase around the globe, so do calls for reform in both government policy and individual consumption. Consensus exists amongst scientists that climate change is indeed human induced, but the larger public remains more skeptical or dismissive of climate change.

The purpose of this research is to contribute to the developing field of knowledge regarding climate change and Communication. In addition, this research helps to satisfy the requirements of obtaining a Master of Science in Communication at Portland State University. Utilizing Max Van Manen’s phenomenological approach to human science research, this project seeks to discover the lived experience of Portland residents in relation to climate change through in-depth, one on one interviews. This research project adopts a hermeneutic phenomenological perspective as explained by Max Van Manen in Researching Lived Experience first published in 1990. Phenomenological research according to Van Manen is "the study of the lifeworld-the world as we immediately experience it pre-reflectively rather than as we conceptualize, categorize, or reflect on it (Van Manen, 1990, p. 9)

What do Portlanders know and believe about climate change? What are the sources of this information and how does the issue of climate change manifest itself in 
the everyday lived experience of Portland residents? These are some of the questions that will guide conversational interviews. The total interview will be 1 to 2 hours in length and the audio will be recorded and transcribed for later analysis.

\section{II.Exemption Category: Expedited}

\#6: “Collection of data from voice, video, digital, or image recordings made for research purposes.”

\#7: “ Research on individual or group characteristics or behavior (including but not limited to, research on perception, cognition, motivation, identity, language, communication, cultural beliefs or practices, and social behavior) or research employing survey, interview, oral history, focus group, program evaluation, human factors evaluation, or quality assurance methodologies.”

I will be conducting a minimum of 15 in depth conversations. These will be conversational one-on-one interviews in a location mutually agreed to by both the researcher and research participants. The audio will be recorded and transcribed for later analysis. This research will protect the confidentiality of the participants. They will be identified or referred to in the writing only by a first name of their choosing. Their identity will be kept private and not revealed to others.

\section{III.Subject Recruitment}

This research will utilize the non-probability method of convenience sampling. Initial recruitment will come from my own social network consisting of classmates, neighbors, friends and co-workers. After the initial interviews, I will utilize snowball 
sampling asking those interviewed for referrals of others who may be willing to participate in this study. The subject population of this research is Portland, Oregon residents. A minimum of 15 hour long interviews will be conducted. The population will not be restricted to one gender, ethnicity or age group. Instead, individuals will be selected if they meet the criteria living in Portland, Oregon after moving from another state within the last five years. This research is interested in the lived experience of newer Portland residents. Individuals will be excluded from the sample if they have prior knowledge of my research interests in climate change, are lifelong residents of Portland, or moved to Portland from elsewhere within the state of Oregon.

\section{$\underline{\text { IV.Informed Consent }}$}

Informed consent will be obtained from all research participants adapted from an example informed consent agreement from the text entitled Phenomenological Research Methods by Clark Moustakas (Moustakas, 1994, p.178). All participants of this research will be adult subjects or, in other words, all participants will be 18 years of age and older. Informed consent will be obtained from participants through the attached participant release agreement(Appendix A). The primary researcher, Stephen Flinn, will seek consent from research participants.

\section{$\underline{\text { V. First Person Scenario }}$}

I was approached by graduate student Stephen Flinn to participate in a study on the lived experience of new Portland residents in relation to climate change. I asked him what the research was for and he explained that he is working on his Master's thesis and that he was interested in finding out how climate change manifests itself in our everyday 
lives. I agreed to participate. We set up a mutually agreed upon time and place to meet and discuss and have a conversation. I was available a half hour later so we met at the library in the lobby on the third floor. We sat down and had small talk for a few minutes. He thanked me for agreeing to spend this time talking about this issue and then presented me with a participation agreement form. I read over the form, asked a few questions, he answered them and then I signed and dated the form. We talked for about an hour and a half. I forgot that the interview was even being taped. It felt just like we were having an in depth conversation centering around one subject that affects are lives. At the conclusion of our conversation, he thanked me and I thanked him as well. Last week, I received a thank you email from him indicating that he was completed with his project and that he appreciated my participation.

\section{$\underline{\text { VII.Potential Risks and Safeguards }}$}

The risks associated for subjects that participate in this research are minimal. The subjects participate in one-on-one conversations at mutually agreed upon locations and times. The risks associated with this research are comparable to the risks associated with having an in depth conversation with another person regarding a contemporary issue facing society. Participants will be asked to reflect on and describe their everyday lives in relation to climate change. Some participants may feel discomfort or guilt as a result of describing their everyday routine and how it does and does not impact climate change. The researcher will make every effort to safeguard against potential discomfort brought forth in the participants through their descriptions and self reflections of their lived experience. The researcher will help facilitate a comfortable environment where the 
participants feel free to express their opinions openly without fear of judgement. This begins with a mutually agreed upon time and place. The participant should not feel like they are being interviewed or judged based on the information provided but rather that they are engaged in a conversation with the researcher to help describe the everyday lived experience in Portland in relation to climate change.

\section{VII.Potential Benefits}

The benefits of this study is that it will help the researcher and the participants describe and uncover the ways that climate is experienced in our everyday lives. This research provides an opportunity for self discovery for both the researcher and the participants. Additionally, this will help add continuity and a local perspective to current scholarship regarding climate change and communication. The main purpose of phenomenological research is to describe the 'essence' or 'nature' of a particular phenomenon. The phenomenon is described with 'depth and richness'(Van Manen, 1990, pp.10-11). In the end, the goal of this research is not according to Van Manen a way to generate communication theories that can "explain and/or control the world" but rather a method that offers "the possibility of plausible insights that bring us in more direct contact with the world (Van Manen, 1990, p.9)." This research will "focus on descriptions of what people experience and how it is that they experience what they experience (Patton, 2002, p.107).” The main purpose of this phenomenological research is to "transform lived experience into a textual expression of its essence-in such a way that the effect of the text is at once a reflexive re-living and a reflective appropriation of 
something meaningful: a notion by which a reader is powerfully animated in his or her own lived experience (Van Manen, 1990, p. 36).”

\section{Records \& Distribution}

Participants confidentiality will be protected. A participants last name, address, or phone number will never be collected or made available as a result of this research. Identifiable information will not be collected by the researcher. Participants will choose a first name to identify their recorded interview and transcripts. The interviews will be captured by a digital audio recorder and then each interview will be transferred to a compact disc. The discs will be labelled by the participants chosen first name and the date of the interview. Each interview will be transferred to its own compact disc. The written transcription of the interviews will be labelled according to the participant's chosen first name and date as well. Any electronic data will be stored on the researcher's personal computer. A research file containing all audio compact discs and written transcripts, and field notes will be kept for a minimum of three years at the researcher's primary residence. At no time in the process will other individuals have access to the researcher's personal computer or research file. 
Appendix F

\section{Participant Informed Consent and Release Agreement}

I agree to participate in the research study of "What is the lived experience of Portland residents in relation to their environment?" I understand the purpose and nature of this study and I am participating voluntarily. I grant permission for the data to be used in the process of completing a Master of Science degree in Communication at Portland State University. I agree to this data being used in a Master's thesis and any other future publication.

I understand that participation in this study comes with minimal risks. I am aware that participants will describe and reflect upon their own life experiences which may in turn cause discomfort, embarrassment or guilt. I have been informed that identifiable information obtained about me in connection with this study will be kept confidential. I understand that a brief synopsis of each participant, including myself, will be used and will include the following information: participant chosen first name, occupation, age, neighborhood you reside in, number of years in Portland, prior state of residence, and any other information that will help the reader recall each participant. I grant permission for the above personal information to be used. I agree to meet on the following date__a a the following time_____ for approximately 1-2 hours. I also grant permission to tape-recording of the interview(s).

If I have concerns or problems about my participation in this study or my rights as a research subject, I am aware that I can contact the Human Subjects Research Review Committee, Office of Sponsored Projects, 600 Unitus Bldg., Portland State University, (503), 725-4288 or 1-877-480-4400. If I have questions about the study itself, I am aware that I can contact the researcher Stephen Flinn at swflinn@gmail.com or (503) 442-4634. A copy of this agreement was made available to me as a research participant.. 


\section{Appendix G- Interview Questions and Prompts}

\section{Part 1: City Questions}

1. How long have you lived in Portland?

2. Why did you choose to move to Portland?

3. What part of town do you live in?

-SE, NE, SW, NW, N

4. Describe your neighborhood.

-looks like, feel like, who lives there?

5. What are the benefits of living in your neighborhood?

6. What is your occupation?

7. Do you work near your home?

8. How do you move throughout the city? What is your main mode of transportation? -alternate transportation, ideal transportation, other?

9.What does it feel like to live in Portland?

-how do you feel energetically, culturally, physically

\section{Part 2: Portland Resident Questions}

1 Describe the average Portland resident. -occupation, income, health, fitness, diet, views

2..What does a Portland resident look like?

3.How do Portland residents interact? -store, sidewalk, street, in public places

4. Imagine and describe the ideal Portland resident.

5. How are Portland residents unique?

6. Do you feel cultural pressure to conform to any of these norms? If so how? -anecdotes, stories, concrete examples 


\section{Part 3: Climate and the Environment}

1. What significant challenges does the world face?

2. What significant challenges are faced by our nation?

3. What significant challenges face Portland residents?

4. Have you noticed unusual weather this past year?

5. What environmentally beneficial behaviors do you engage in?

-daily events(bike riding, recycling, eating local, eating organic, conserving water etc)

-long term events (gardening, social activism, etc)

6. How can you make your everyday routine more environmentally friendly?

7. What are the causes of climate change? What contributes to climate change?

8. When did you become aware of climate change?

9. How did you become aware of climate change?

10. Where do you get your information regarding climate change?

-Internet, television news, Al Gore, newspapers

11. Do you talk about climate change with friends or family? How often does this come up?

12.How do these conversations feel to you?

-how does this conversation feel

13. Who feels the effects of climate change?

14. What are the effects of climate change?

15. Does climate change influence your everyday behaviors? How?

16. Imagine Portland 20 years from now. Describe what you see.

-50 years, 100 years

17.What does climate change look like?

18. What does climate change feel like?

19. How does the issue of climate change make you feel? 